\title{
Neue Pflanzenfunde aus dem Tertiär der Rhön. - Teil 2: Pliozäne Fundstellen
}

\author{
Frank Gümbel ${ }^{1}$ \& Dieter Hans Mai $^{2}$
}

Mit 3 Abbildungen und 10 Tafeln

\section{Zusammenfassung}

Aus dem Jungtertiär der Rhön werden 127 Pflanzenarten aus 59 Familien nach Früchten und Samen beschrieben. Nur Leontodon rhoenensis nov. spec. (Asteraceae) ist eine neue Art. Sie entstammen den Füllsedimenten der Dolinen von Barchfeld, Kaltensundheim und Oberzella. Ihr oberpliozänes Alter ist durch tierische Fossilien (arvernensis-Schichten) und paläomagnetische Altersdatierungen festgelegt. Ihre Einordnung in die Florenkomplexe „Ceyssac-Kaltensundheim“ (2,8-2,56 Mio. J.) und „Berga-Reuver“ (2,65-2,47 Mio. J.) ist sicher.

Schlüsselwörter: Jungtertiär Rhön, arvernensis-Schichten, Oberpliozän, karpologische Fossilien.

\begin{abstract}
On the base of fossil fruits and seeds 127 plant species belonging to 59 families are described from the Upper Tertiary of the Rhön mountains, including Leontodon rhoenensis nov. spec. (Asteraceae). They have been derived from the filling of dolines near Barchfeld, Kaltensundheim and Oberzella. The age of the sediments is Upper Pliocene based on mammals (arvernensis$b e d s)$ and paleomagnetic dated. The assignment to the floral assemblages "Ceyssac-Kaltensundheim" (2.8 to 2.56 my.) and "Berga-Reuver" (2.65 to 2.47 my.) is quite sure.
\end{abstract}

Key words: Upper Tertiary Rhön mountains, arvernensis beds, Upper Pliocene, carpological fossils.

\section{Einleitung}

\section{Geologische und biostratigraphische Bemerkun- gen zu den Fundstellen und fossilen Pflanzen}

Die Fundstellen von fossilen Floren des Pliozäns liegen alle im Gebiet oder am Rande der Vorderen Rhön zwischen Meiningen-GerstungenHünfeld.

Geologisch gehört der Bereich zum südwestthüringischen Triasgebiet. Es treten weitläufig Sedimente von Buntsandstein und Muschelkalk an die Oberfläche. Die Rhön-Aufwölbung und eine Eruptionszone obermiozän-pliozäner Vulkanite (Kästner 1974) bedingen eine weitgehende Veränderung des Paläoreliefs und eine Umstellung der Entwässerungssysteme. Zugleich werden die obersten Schichten und Gesteine abgetragen und über sie nun linienhaft einschneidende Flüsse sedimentiert. Als jüngste tertiäre Ablagerungen sind im Vorland der Rhön
Flussablagerungen des Pliozäns bei Fulda (Bücking 1916) und zwischen Ostheim v. d. Rhön und Mellrichstadt, die z. T. Zähne von Mammut borsoni und Anancus arvernensis (Blanckenhorn 1902) geliefert haben, zu nennen. Die Ablagerungen sind in der Literatur als „borsoni-Schichten“" (Martini et al. 1994) oder ,arvernensis-Zeit“" (Rutte \& Wilczewski 1983) benannt und ins Oberpliozän eingeordnet worden. Das punktförmige Vorkommen solcher Reste in Flussschottern veranlasste Rutte (1987) von einem „Ostheimer Nebenfluss" des Main zu sprechen. Auch Florenreste in den Ablagerungen sollten die Altersdatierung beweisen. Neuerdings wird die in der Sandgrube Wollbach bei Bad Neustadt im südöstlichen Vorland der Rhön in einer Tonlinse entdeckte Flora, die durch die Dominanz von Blättern des Quercus pseudocastanea-Typus und die Anwesenheit von Alnus hoernesi Stur gekennzeichnet ist, in das Ober-Miozän gestellt (Kelber 1980).

\footnotetext{
1 Hauptstr. 8, D-36452 Neidhartshausen/Rhön, Germany.

2 Hamburger Str. 8, D-12623, Berlin, Germany, Institut für Paläontologie, Invalidenstr. 43, 10115 Berlin. Erhalten Februar 2003, angenommen Juli 2003
} 


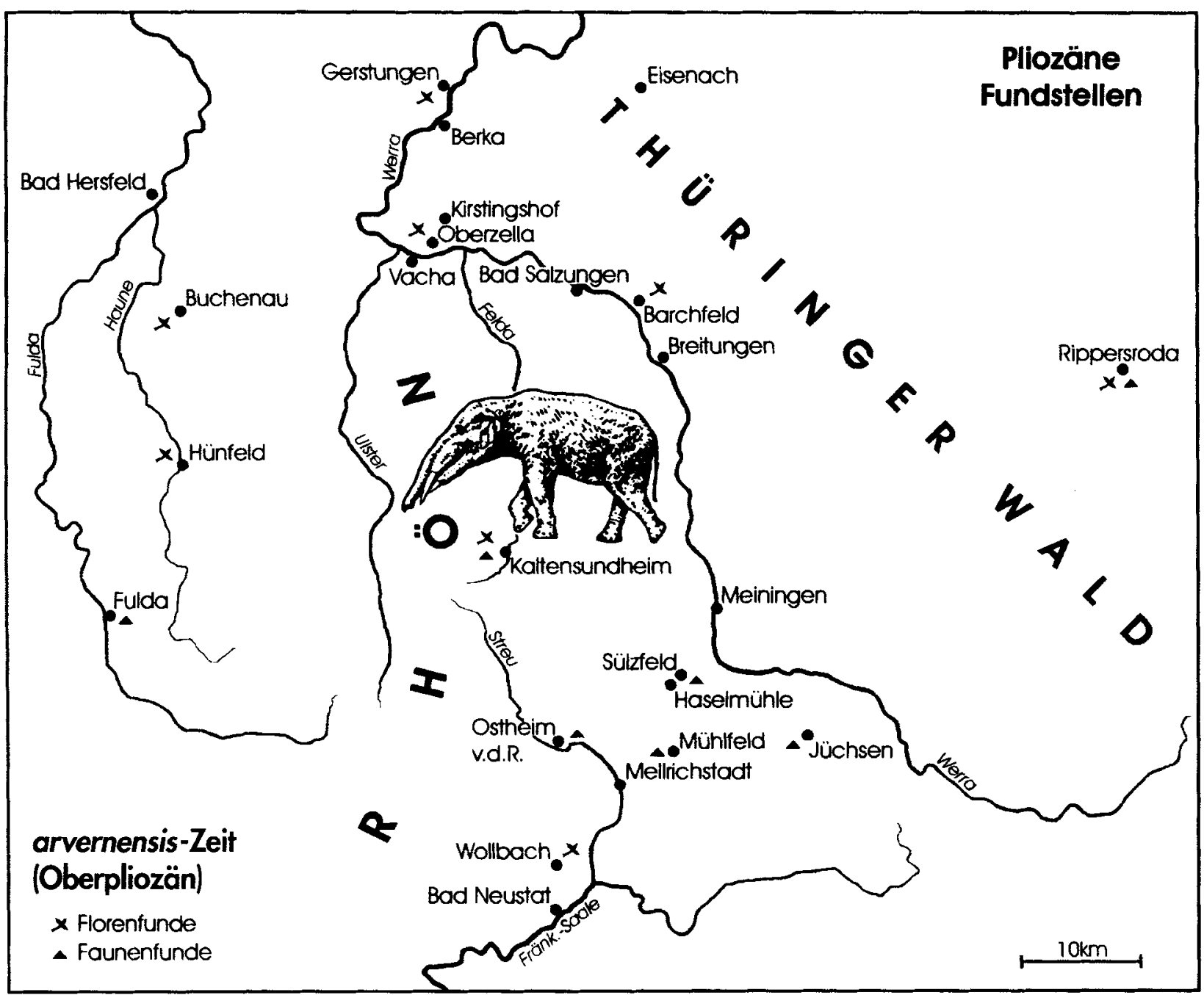

Abb. 1. Die pliozänen Fundstellen in der Rhön zur arvernensis-Zeit mit rekonstruiertem Mammut borsoni.

Die mächtigen arvernensis-Ablagerungen von Sülzfeld südwestlich von Meiningen haben in Sandlinsen über 40 Molaren der Mastodonten Mammut (Zygolophodon) borsoni und Mastodon (Anancus) arvernensis geliefert (Weber 1952: 22) und sind damit gut datiert.

Bis in das Oberpliozän lässt sich auch die Entwicklung des Werratales zurückverfolgen. Die ältesten fluviatilen Werraablagerungen sind als Zersatzkies anzusprechende Schotter, die unter limnischen Sedimenten des Oberpliozäns liegen (Oberzella, Gerstungen).

Im jüngsten Pliozän lag der Talboden der Werra 140 bzw. $124 \mathrm{~m}$ über seinem heutigen Niveau. Mindestens seit dieser Zeit hat die Werra südlich des Thüringer Waldes ihren Lauf von Ost nach West genommen. Der Schotterkörper in $124 \mathrm{~m}$ relativer Höhe wurde nach seiner Ablagerung östlich von Oberzella vom jüngsten Ausbruch eines vulkanischen Explosionsschlots durchschlagen (Ellenberg 1982).
Sicher als Reuver datiert sind die limnischen Tone und Torfe in der Senke Oberzella (Krutzsch \& Majewski 1965); bei den entsprechenden Vorkommen von Gerstungen und Breitungen spricht nichts gegen Reuver. Damit sind zugleich das Liegende und Hangende - der Zersatzkies und der Ältere Zersatzgrobschotter zeitlich fixiert.

Bei der Formung der Landschaft in der Vorderrhön kam es im Pliozän nicht nur zu fluviatiler Erosion und Sedimentation, sondern auch zu einer intensiven Salzauslaugung im Untergrund, die oberflächenformend in Erscheinung tritt. Diese Wechselwirkung zwischen normaler Talentwicklung einerseits und Subrosion andererseits führte zu flächig ausgebreiteten Akkumulationen pliozäner Sedimente in verschiedenen Höhenlagen. Hier sammelten sich überwiegend tonig-mergelige Ablagerungen an. Zwischengeschaltete Sandlinsen führen örtlich arvernensiszeitliche Fossilien, hauptsächlich Mastodontenzähne. Synsedimentä- 
Kaltensundheim 1974

(nach Wiegank 1981, S.183)

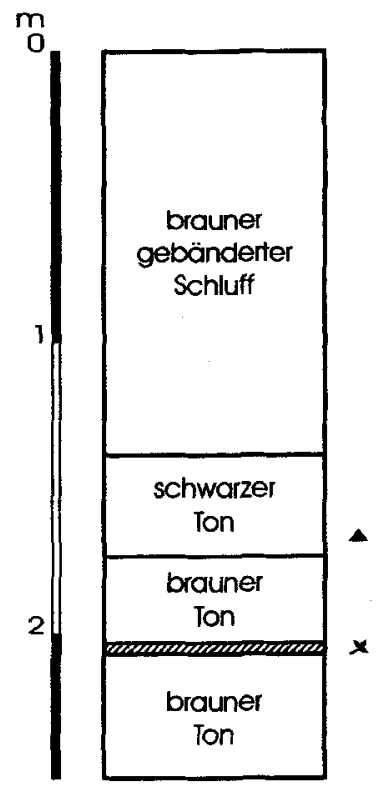

[x] Florenfunde
[4] Faunenfunde (Mormmut borsoni)
- Pollenanalyse
Oberzella 2001

Sandgrube Demmesgrund

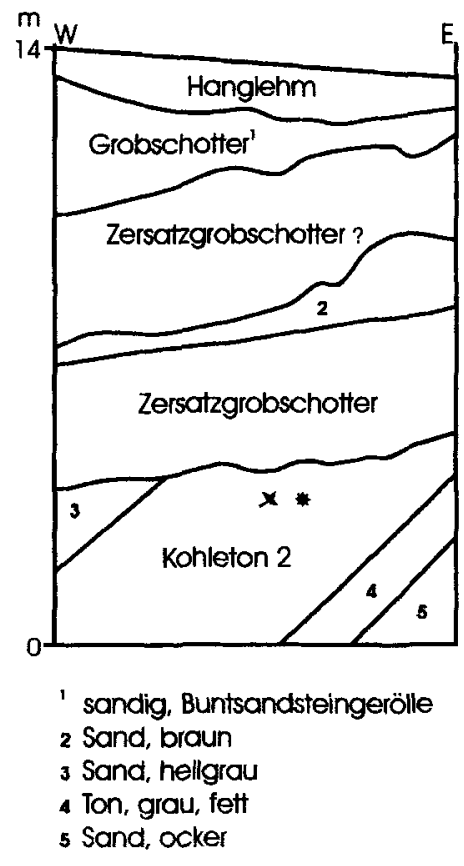

Barchfeld 2002

Sandgrube Dönnersberg

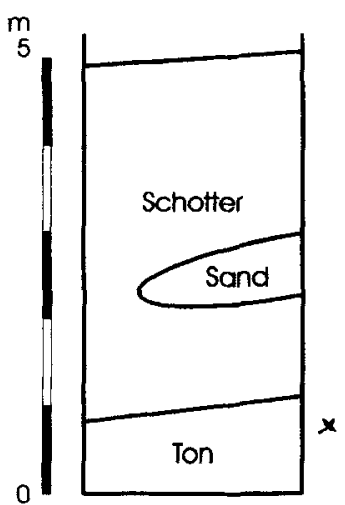

Abb. 2. Profile im Arbeitsgebiet Kaltensundheim (umgezeichnet nach Wiegank 1981), Oberzella (Original) und Barchfeld (umgezeichnet nach Weber 1955).

re Absenkungen des Untergrundes infolge der Auslaugung des Zechsteinsalinars führten zu hohen Mächtigkeiten und teilweise zu einer zyklischen Abfolge der Sedimente (Ellenberg 1968). In Vertiefungen wurden gebleichte Gerölle, Milchquarze und weiße Sande eingeschwemmt, im ruhigen Wasser kam es zum Tonabsatz, zur Verlandung und damit zur Entstehung schwacher Braunkohlenflöze. Meist ist deren Mächtigkeit unbedeutend. Bei Kirstingshof nordöstlich von Vacha wurde Anfang des 19. Jahrhunderts Braunkohle abgebaut, aber leider niemals paläontologisch untersucht (Weber 1952). In Buchenau bei Hünfeld westlich unseres Untersuchungsgebietes waren vier Flöze von Braunkohle mit 7-8 m Gesamtmächtigkeit eingeschaltet, die von Leschik (1952 a, b) untersucht wurden.

$\mathrm{Ob}$ diese Auslaugungsbecken im Oberpliozän alle gleichaltrig sind, bleibt bisher fraglich, wie überhaupt fraglich ist, ob die Mastodon arvernensis führenden Schotter und Sande überall dem gleichen Niveau angehören. Wesentlich bleibt, dass sie in die Zeit zwischen den Bewegungen zweier orogener Phasen, der rhodanischen und der walachischen, hineingehören (Weber 1955). Wir hoffen, die bisherigen Einstufungsversuche mit pflanzlichen Fossilien teilweise zu präzisieren, was durch unsere Neuaufsammlungen für folgende Fundpunkte möglich wird:
Barchfeld bei Bad Salzungen (MTBL. 3054 - Immelborn)

Das Tertiärvorkommen von Barchfeld östlich Bad Salzungen gehört in den Breitunger Zipfel des Werrabeckens.

Seit 1936 ist ein großer Anschnitt von pliozänen Sanden und Tonen sowie einer ca. $4 \mathrm{~m}$ mächtigen Lage von rötlich gefärbten Zersatzschottern am Dönnersberg bekannt (Weber 1952: 11). Der durch Auflassung lange Zeit verwachsene Aufschluss wurde erst mit dem Ausbau der Trasse zur neuen Bundesstraße B 19 erneut in Betrieb genommen. Die pliozänen Sedimente liegen hier mit einer starken Winkeldiskordanz auf stark verwitterten, roten und weißen Sandsteinschichten des Unteren Buntsandsteins. Die Folge besteht vorwiegend aus Sand und teilweise weißem Ton von über $1 \mathrm{~m}$ Mächtigkeit, in den ein lignitreiches, humoses, bräunlich-graues Tonband von etwa 0,3 bis $0,5 \mathrm{~m}$ Mächtigkeit eingelagert ist. Aus diesem Tonband wurde im Sommer 2002 eine Frucht- und Samenflora ausgewaschen, die alle Zweifel über eine tertiäre Altersstellung beseitigt.

Die Beckenfüllung von oberpliozänem Ton wurde im Altpleistozän zugeschottert. Bodenbewegungen, vermutlich infolge neuauflebender Subrosion, haben die Lagerung aller Schichtfolgen gestört (Weber 1952, 1955). 
Die von uns gefundene Flora zeigt folgende Zusammensetzung:

\author{
Actinidia faveolata \\ Caldesia cilindrica \\ Carex carpophora \\ Carex klarae \\ Carpinus betulus \\ Chenopodium spec. \\ Decodon globosus \\ Fagus deucalionis \\ Hypericum foveolatum \\ Lycopus europaeus \\ Magnolia cor
}

\author{
Meliosma cf miessleri \\ Mentha pliocenica \\ Microdiptera menzelii \\ Morus ucrainica \\ Picea rotunde-squamosa \\ Pilea bashkirica \\ Pinaceae indet. \\ Potentilla heptaphylla \\ Potentilla supina \\ Ranunculus gailensis \\ Ranunculus sceleratus
}

\author{
Sambucus pulcella \\ Selaginella borysthenica \\ Sparganium neglectum \\ Taxodium dubium \\ Teucrium pripiatense \\ Thalictrum minimum \\ Trema lunatica \\ Typha aspera \\ Viola neogenica \\ Vitis cf. sylvestris
}

Mit ihren 32 Arten (bisher) liegt diese Flora an der Untergrenze einer biostratigraphischen Vergleichbarkeit. Ihr oberpliozänes Alter scheint aber sicher zu sein. Jedoch ist sie nicht gleichartig und gleichaltrig mit den artenreichen Floren von Oberzella und Kaltensundheim (s. S. 214-216). Das Vorkommen wichtiger „miozäner" Arten (z. B. Meliosma cf. miessleri, Trema lusatica) nähert sie der Flora von Gerstungen, bei der diese Tendenz ebenfalls deutlich in Erscheinung tritt (Mai \& Walther 1988: 211-212).

\section{Kaltensundheim (MTBL. 3115 - Tann)}

Durch die Auslaugung von Sulfatgesteinen der Salinarrötfolge (Untere Trias) sind fossil in einem Flachmuldental bei Kaltensundheim/Rhön Erdfälle im Muschelkalk entstanden. Sie wurden durch rasche Zufuhr feinklastischen Materials im limnischen Milieu vollständig aufgefüllt. Die Füllsedimente sind gebänderte Tone und Schluffe, welche einen unregelmäßigen Wechsel dunkler und hellerer Lagen bilden, deren Mächtigkeit von $\mathrm{mm}$ - bis zu mehreren cm-Stärke schwankt. Die ungestörte Schichtung der Füllsedimente fällt im aufgeschlossenen Bereich mit ca. $35^{\circ}$ zum Zentrum des Erdfalles ein. Sie ist eine subaquatische Böschungsschichtung (Böhme 1992).
Die aus grauschwarzen mergeligen Tonen und Schluffen bestehenden Sedimente enthalten unter anderem Skelettreste einer Wirbeltierfauna (z. B. Mammut borsoni), die eine Datierung der Füllsedimente ins Oberpliozän gestatten.

Beim Bau einer Wasserleitung wurde in der Nähe der Lotte-Mühle diese kleine Doline im Unteren Muschelkalk angeschnitten, aus der 1958 das fast vollständige Skelett vom Mammut (Zygolophodon) borsoni ausgegraben wurde (Schaarschmidt 1958). Mit diesem Fund, der jetzt im Naturkunde-Museum in Meiningen deponiert ist, rückte das Vorkommen in den Blickpunkt paläontologischen Interesses. Als die dunklen Tone (Faulschlämme) der Doline auch beim Neubau eines Rinderstalls 1974 wiederum angeschnitten wurden, gelangen G. Böhme, H.-D. Kahlke und E. Pietrzeniuk pflanzliche Funde in Schlämmrückständen paläozoologischer Proben. Die Fauna enthält Mammut (Zygolophodon) borsoni, den primitiven Hirsch Metacervoceros und einen Hasen Hypolagus, sowie Fische und anure Amphibien (Böhme 1963, 1992, 2002). Neben einer „plio-pleistozänen Übergangsflora“ kennt man eine Wasser- und Sumpfflora mit teils tertiären, teils heutigen Arten von Früchten und Samen (revidiert und nach Mai \& Walther 1988: 212):

Acanthopanax uralensis
Acer striatum
Acorellus distachyoformis
Actinidia faveolata
cf. Argusia complicata
Baldellia ranunculoides
Betula cholmechensis
Boehmeria lithuanica
Carex acutiformis
Carex caespitosa
Carex elongatoides
Carex flavaeformis

Acanthopanax uralensis

Acer striatum

Acorellus distachyoformis

Actinidia faveolata

cf. Argusia complicata

Betula cholmechensis

Boehmeria lithuanica

Carex caespitosa

Carex elongatoides

carex flavaeformis
Carex nigra

Carex riparia

Carpinus miocenica

Carpolithus lloydiaeformis

Cirsium palustre

Comarum palustre

Corylus avellana

Cyperus fuscus

Eleocharis praemaximowiczii

Euphorbia stricta

Hippuris vulgaris

Hypericum faveolatum
Hypericum tertiaerum

Ilex aquifolium

Lemna gibba

Lemna trisulca

Lycopus antiquus

Lycopus europaeus

Myrica goretskyi

Myriophyllum praespicatum

Myriophyllum spicatum

Phellodendron elegans

Physalis alkekengii

Picea abies 
Picea rotunde-squamosa

Polygonum pliocenicum

Potamogeton felixii

Potamogeton filiformoides

Potamogeton neptunii

Potamogeton palaeorutilus

Potamogeton panormitanoides

Potamogeton polymorphus

Potamogeton tanaiticus

Potentilla erecta

Potentilla pliocenica

Prunella vulgaris

Prunus spinosa
Ranunculus aquatilis
Ranunculus gailensis
Ranunculus tanaiticus
Rubus idaeus
Rubus spec.
Rumex acetosella
Rumex hydrolapathum
Salix spec.
Schoenoplectus lacustris
Scirpus sylvaticus
Silene cf. conica

Prunus spinosa

Ranunculus aquatilis

Ranunculus tanaiticus

Rubus idaeus

Rubus spec.

Rumex acetosella

Rumex hydrolapathum

Salix spec.

Schoenoplectus lact
Scirpus sylvaticus

Silene cf. conica
Sparganium neglectum
Stellaria holostea
Swida bessarabica
Taxodium dubium
Thalictrum simplex
Thesium nikitinii
Typha pseudoovata
Urtica dioica
Viola bergaensis
Viola palustris

den Florenkomplex Ceyssac (Mein-Zone 16: 2,7-2,6 Mio. J.) eingeordnet. Diese genaue biostratigraphische Datierung der Füllsedimente der Doline von Kaltensundheim gestattet eine Datierung der Anlage des Flachmuldentales und die Bestimmung des Zeitraumes für die Reliefentwicklung der Rhön seit der Beendigung des Basaltvulkanismus. Mio. J.). Die von Ukraintseva (Kahlke \& Ukraintseva 1986) untersuchte Mikroflora wird als „plio-pleistozäne Übergangsflora“ interpretiert. In der von Mai \& Walther (1988) bearbeiteten Makroflora überwiegen Wasser- und Sumpfpflanzengesellschaften mit heutigen Arten oder z. T. längerlebigen tertiären Arten. Waldgesellschaften sind durch Reste von Taxodium, Betula cholmechensis, Carpinus miocenica, Picea rotunde-squamosa, Picea abies, Prunus spinosa, Corylus avellana, Acanthopanax uralensis, Actinidia faveolata und Ilex aquifolium repräsentiert. Osteuropäische Einflüsse sind mit Acorellus distachyoformis, Acanthopanax uralensis, Myrica goretskyi, Swida bessarabica und Taxodium rossicum gegeben. Die Flora ist insgesamt nicht so reich an Arten wie die der anderen Lokalitäten. Es handelt sich bei dem Vorkommen um eine der infrapliozänen Oszillationsphasen, in denen der Reichtum von Exoten zugunsten heutiger Arten stark zurücktritt. Es ist aber eine pliozäne Flora. Positive Paläomagnetik deutet auf die Gauss-Normal-Epoche (= 2,5-3,4 Mio. J.) hin (Wiegank 1982). Diese Datierung lässt sich mit Hilfe der Flora dahingehend präzisieren, als diese Flora eben nicht genau mit den exotenreicheren Waldfloren der Wetterau (vgl. Mai 1973, S. 112ff.) oder des „Reuverien“ im Niederrheingebiet (C. \& E. M. Reid 1915) übereinstimmt. Wir haben in Kaltensundheim aller Wahrscheinlichkeit nach makrofloristisch die erste echte intraoberpliozäne Verarmungs- und Abkühlungsphase untersucht, denn mit 70 Arten ist diese Lokalflora durchaus nicht arten- wohl aber exotenarm. Auch sie gehört in das "Oberpliozän“" und wurde von Mai \& Walther (1988: 221) in
Oberzella an der Werra (MTBL. 2990 - Vacha)

Die Auslaugungssenke Oberzella bildet heute eine große morphologische Depression mit einer Breite von $3 \mathrm{~km}$ in W-E-Erstreckung und etwa $5 \mathrm{~km}$ in N-S-Richtung nordöstlich von Vacha. Diese Auslaugungssenke wird charakterisiert durch ihre Füllung mit pliozänen und altpleistozänen Sedimenten sowie durch eine Schlotbrekzie auf dem Eierberg. Durch die Explosion des Vulkanschlots im Oberpliozän wurde die Auslaugung des Zechsteinsalinars initiiert. In einem sich bildenden wassergefüllten Becken werden Tone und Kohle abgelagert. Bei Kirstingshof nordöstlich von Vacha sind die Flöze bis 1,60 m mächtig. Sie wurden Anfang des 19. Jahrhunderts abgebaut.

Östlich von Oberzella wurde der pliozäne Zersatzkies (Kieselablagerungen der Werra) von einem vulkanischen Eruptionsschlot durchschlagen. Die Basis dieser Flussschotter hat primär $124 \mathrm{~m}$ über der heutigen Werraaue gelegen. Einzelne Gerölle dieser Kiese sind in der Schlotbrekzie eingeschlossen. Die Abtragungsprodukte der Schlotbrekzie überlagern wiederum den Zersatzkies, und werden selbst von den Tonen des Oberpliozäns überlagert (Ellenberg 1982). Dem Vorkommen dieser Schlotbrekzie galt schon seit Hirsch (1937) und Weber (1952) eine besondere Aufmerksamkeit für die Altersdatierung des Vorkommens von Oberzella. Dabei stufte Hirsch (1937) das Becken als „oberchattisch“ ein. Aber schon Weber (1952) zeigte, daß die Ablagerun- 


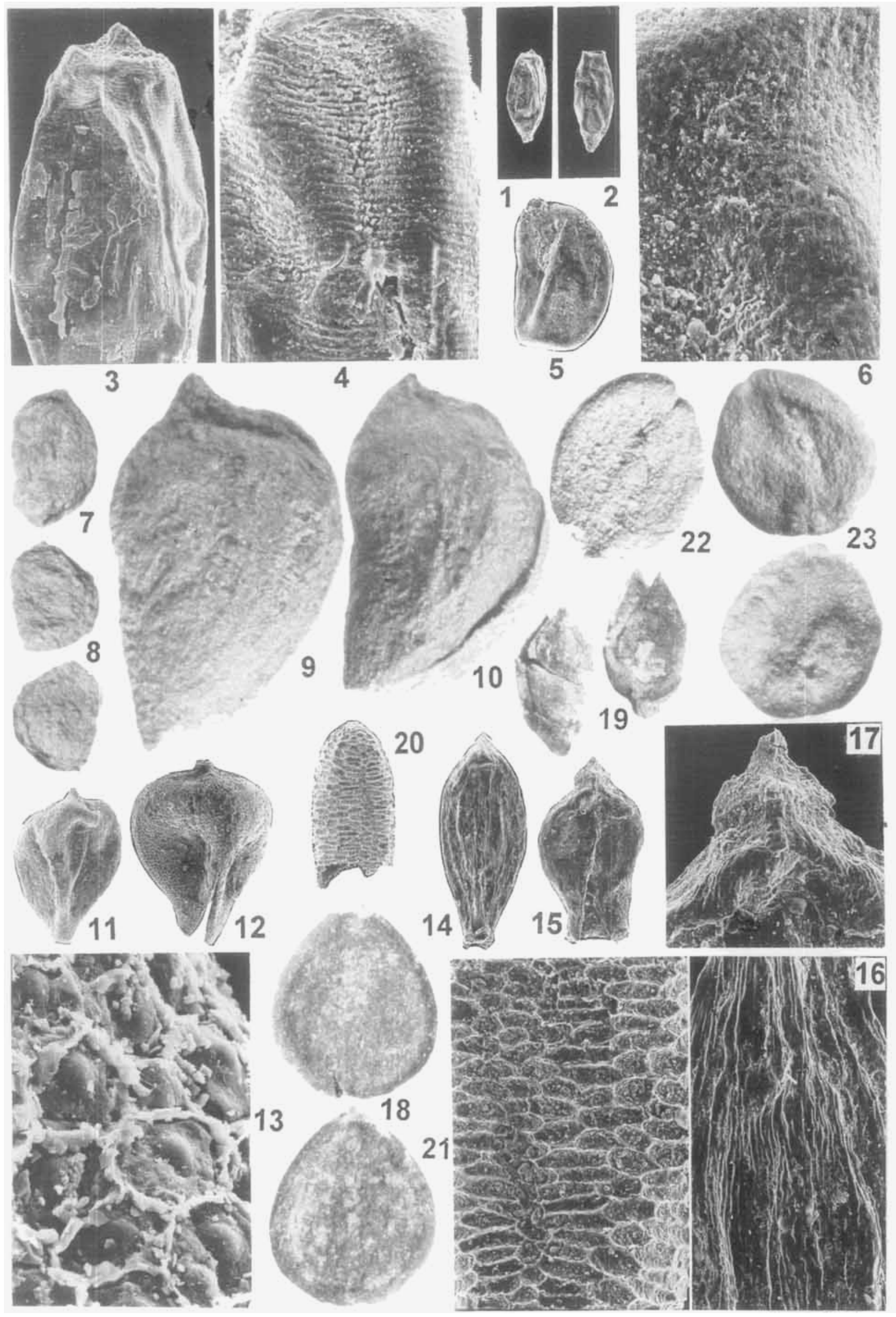


gen (Sande, graue und bunte Tone, Schotter und Braunkohle) mit dem Oberpliozän von Gerstungen übereinstimmen. Er vertritt eine oberpliozäne Entstehung des Auslaugungsbeckens von Oberzella. Tierische Leitfossilien des Arvernensis-Pliozäns fehlen jedoch bisher.

Aus einem Schurf am Tonberg wurden 1963 von Ellenberg Tone und Kohlen entnommen, die wegen starker Verwitterung nur zwei sehr durable Makroreste lieferten, die biostratigraphisch nicht auswertbar waren:

\section{Alisma ex gr. plantago-aquatica \\ Salvinia miocenica}

Das Vorkommen kann jedoch als pollenanalytisch recht gut charakterisiertes und mit „Reuver“ vergleichbares Oberpliozän gelten (Krutzsch \& Majewski 1965). Während ältere jungtertiäre Elemente fehlen oder sehr selten sind, kommen im Gegensatz zum Tegelen Nyssa (bis 9\%), Taxodiaceen (Sequoia-Typ und Taxodium-Typ, bis $28 \%$ ), Sciadopitys (bis $23 \%$ ) und Tsuga (bis $34 \%$ ) vor. Außerdem sind Symplocos, Platycarya-Typ, Liqui- dambar- und Castanea-Typ in einzelnen Proben bis zu $1 \%$ vertreten. Ein Alnus-Gipfel ist an der Basis der Hauptkohlenbank ausgebildet.

Nahe des Austrichs der pliozänen Sedimente der Auslaugungssenke entstanden in den 90er Jahren mehrere Kiesgruben, die vor allem die altpleistozänen nahezu $50 \mathrm{~m}$ mächtigen Kiese und Sande als Abbauprodukt zum Ziel hatten. In einer unweit des Ortes Oberzella gelegenen Grube wurden in den Jahren 1998 und 2000 Tone mit pflanzlichen Fossilien entdeckt (F. Gümbel) und abgesammelt. Humose, sandige Tonlinsen von jeweils 0,6 bis $0,8 \mathrm{~m}$ Mächtigkeit lagen unterhalb der deutlichen Diskordanz, den die rötlich gefärbten „Älteren Zersatzschotter“ zu der Dolinenfüllung aus gelblichem Sand (Pliozän) bildeten. Ihr Abstand zu dieser Diskordanz, die wir als Oberkante der Dolinenfüllung ansehen, betrug jeweils $3 \mathrm{~m}$ und $6 \mathrm{~m}$. Ihr Fossilinhalt war nahezu gleich und ergab eine bemerkenswerte Flora aus 103 Arten von Früchten und Samen. Die wenigen Blattreste aus der Tonlinse 2 sind noch nicht bestimmt worden.

\author{
Acer berganum \\ Acer campestrianum \\ Acorus palaeocalamus \\ Actinidia faveolata \\ Alisma spec. ex gr. plantago \\ Alnus lusatica \\ Alnus tanaitica \\ Alnus spec. \\ Ampelopsis macrosperma \\ Apium nodiflorum \\ Aralia szaferi \\ Baldellia ranunculoides \\ Betula cholmechensis \\ Betula digitata \\ Bidens tripartita
}

Caldesia cylindrica
Carex elongatoides
Carex flagellata
Carex hostianoides
Carex nigra
Carex ornithopoda
Carex pseudocyperus
Carex riparia
Ceratophyllum pannonicum
Ceratophyllum protanaiticum
Cercidiphyllum helveticum
Cicuta virosa
Collinsonia europaea
Corylopsis urselensis
Corylus avellana

\author{
Decodon globosus \\ Diervilla tertiaria \\ Dulichium arundinaceum \\ Eleocharis praemaximowiczii \\ Epipremnites reniculus \\ Euphorbia platyphyllos \\ Ficus tambovica \\ Frangula alnus \\ Glechoma hederacea \\ Humulus scabrellus \\ Hypericum androsaemum \\ Hypericum tertiaerum \\ Ilex aquifolium \\ Itea europaea \\ Lactuca protomuralis
}

\footnotetext{
Tafel 1. Flora von Kaltensundheim. 1-4. Typha pseudoovata Dorofeev - MfN Ka 9720 u. 9733. 1,2. Einzelne Tegmen von Samen; SEM $\times$ 25. 3. Apikalteil eines Samens mit Keimdeckelchen; SEM $\times 125$. 4. Maschenschicht der Testa; SEM $\times 250$. 5-6. Lemna gibba L. fossilis - MfN Ka 9747. 5. Samen in Umriß; SEM $\times$ 35. 6. Oberflächenstruktur der Testa; SEM $\times 400$. 7-8. Potamogeton panormitanoides Dorofeev - MfN Ka 9720 u. 9728. 7. Steinkern ohne Keimklappe; $\times 20$. 8. Weiterer Steinkern mit gekielter Keimklappe von beiden Seiten; $\times$ 20. 9-10. Potamogeton felixii Dorofeev - MfN Ka 9723 u. 9726 (Orig. Mai \& Walther 1988, Tafel X, 3-4); Steinkerne verschiedener Form und Größe; $\times 20$. 11-13. Carex flavaeformis Łańcucka-Srodoniowa - MfN 9719 u. 9725. 11-12. Früchte verschiedener Größe; SEM $\times 25$. 13. Zellmuster der Oberfläche von Frucht Fig. 12; SEM $\times 1500$. 14-17. Eleocharis praemaximowiczii Dorofeev - MfN Ka 9731 u. 9732. 14-15. Früchte verschiedener Form und Größe; SEM $\times 25$. 16. Zellmuster der Oberfläche von Fig. 14; SEM $\times 125.17$. Spitze der Frucht von Fig. 15 mit Stylokarp; SEM $\times$ 125. 18. Carpinus miocenica Negru - MfN Ka 9747. Nüßchen von beiden Seiten; $\times 12.19$. Myrica goretskyi Dorofeev - MfN Ka 9732. Steinfrucht von beiden Seiten, an der Spitze dehisziert; $\times 12$. 20-21. Hypericum foveolatum Dorofeev - MfN Ka 9720. 20. Samen mit zerstörter Basis; SEM $\times 125$. 21. Oberfläche der Testa von $20 ;$ SEM $\times$ 125. 22-23. Swida bessarabica Negru - MfN Ka 9747. Steinkerne mit umlaufender Furche von der inneren Begrenzung der Fächer; $\times 10$.
} 


Leontodon rhoenensis
Liriodendron geminata
Lobelia pliocenica
Ludwigia chandlerae
Lycopus europaeus
Magnolia cor
Magnolia ultima
Mentha longifolia
Microdiptera menzelii
Naumburgia subthyrsiflora
Nuphar canaliculata
Oenanthe aquatica
Origanum vulgare
Peucedanum moebii
Picea abies
Pilea cantalensis
Pinus spec.
Polygonum pliocenicum
Polygonum wolfii
Populus spec.

Leontodon rhoenensis

Liriodendron geminata

Lobelia pliocenica

Ludwigia chandlerae

Lycopus europaeus

Magnolia cor

Magnolia ultima

Mentha longifolia

Microdiptera menzelii

Naumburgia subthyrsiflora

Nuphar canaliculata

Oenanthe aquatica

Origanum vulgare

Picea abies

Pilea cantalensis

Pinus spec.

Polygonum wolfii

Diese Flora ist biostratigraphisch sehr gut einzuordnen. Auffällig ist ihre Ähnlichkeit mit der Flora von Berga bei Sangerhausen, so dass damit die Zuordnung zum Florenkomplex Reuver (Mai \& Walther 1988, Mai 1995) erfolgen kann. Die absoluten Altersdatierungen für diesen Florenkomplex liegen zwischen 2,4 und 3,2 Mio. J. Damit ist
Potamogeton aculeatus

Potamogeton borysthenicus

Potamogeton palaeorutilus

Potamogeton polymorphus

Potamogeton spp.

Proserpinaca reticulata

Prunus schlechtendalii

Prunus tenerirugosa

Pterocarya limburgensis

Pyracantha angusticarpa

Pyrus microsperma

Ranunculus aquatilis

Ranunculus gailensis

Ranunculus reidii

Ranunculus trachycarpoides

Rubus spec.

Rumex hydrolapathum

Salix spec.

Salvinia miocenica
Sambucus pulchella

Scirpus (Schoenoplectus)

isolepioides

Scirpus sylvaticus

Sium latifolium

Solanum dulcamara

Sparganium neglectum

Stratiotes aloides

Symplocos casparyi

Thalictrum pliocenicum

Trapa heerii

Trichosanthes fragilis

Tsuga section Tsuga

Typha aspera

Urtica dioica

Viola neogenica

Vitis cf. sylvestris

Weigela szaferi

Zelkova ungeri

die Flora von Oberzella wohl die jüngste Flora innerhalb der thüringisch-fränkischen ,arvernensisZeit", obgleich sie mit $36 \%$ heutiger Arten unterhalb der Anzahl in der fossilen Flora von Kaltensundheim liegt. Doch diese Erscheinung ist typisch für den Floren- und Klimawechsel im Oberpliozän Mittel- und Westeuropas (Mai 1995).

\section{Systematische Beschreibung der Neufunde}

Vorbemerkung: Die Beschreibung einer großen Zahl von typischen und häufigen Arten aus den pliozänen Lokalfloren Thüringens ist durch Mai \& Walther (1988) sehr ausführlich erfolgt. Um den Text unserer Abhandlung über die pliozänen Floren der Rhön kurz zu halten, wird auf eine Wiederholung dieser Beschreibungen verzichtet, und es werden nur einige Bemerkungen über Synonymie, Neuigkeiten von Morphologie und Anatomie sowie über das fossile Vorkommen gegeben. Damit treten auch die wirklichen Neufunde für das Pliozän in Thüringen deutlich hervor.

Die Abkürzungen bei den Aufbewahrungsorten des Materials bedeuten: $\mathrm{Ba}=$ Barchfeld, $\mathrm{Ob}=$ Oberzella in der Privatsammlung von F. Gümbel, Neidhartshausen, Ka = Kaltensundheim, MfN = Museum für Naturkunde der Humboldt-Universität zu Berlin mit den jeweiligen Sammlungsnummern; Slg. = Sammlung.

Tafel 2. Flora von Barchfeld. 1. Selaginella borysthenica Dorofeev \& Weliczkiewicz - MfN 2003/141. Megaspore von zwei Seiten: $\times$ 40. 2. Typha aspera Dorofeev - MN 2003/128. Tegmen eines Samens ohne Keimdeckelchen; $\times$ 40. 3-4. Picea rotunde-squamosa (Ludwig) Mai \& Walther - MfN 2003/153. Nadelbruchstücke von dorsal und ventral mit stechenden Spitzen; $\times$ 12. 5-7. Taxodium dubium (Sternberg) Heer - MfN 2003/158. 5. Sprossteil mit Blattbasis von beiden Seiten; $\times$ 12. 6. Weitere Blattbasis von beiden Seiten; $\times 12$. 7. Blattunterseite mit zerstreuten Stomata; $\times 12.8-9$. Carex carpophora Mai \& Walther - MfN 2003/115. Früchte jeweils von zwei Seiten: $\times$ 20. 10-11. Carex klarae Mai - MfN 2003/138. Früchte jeweils von beiden Seiten; $\times$ 20. 12-13. Magnolia cor Ludwig - MfN 2003/150. Samen verschiedener Größe von beiden Seiten; $\times$ 6,5. 14 Sparganium neglectum Beeby fossilis - MfN 2003/155. Steinkern; $\times 20.15$. Caldesia cylindrica (E. M. Reid) Dorofeev - MfN 2003/154. Frucht von beiden Seiten: $\times$ 30. 16. Thalictrum minimum (Szafer) Martinetto - MfN 2003/140. Nüsschen von beiden Seiten; $\times$ 20. 17 Ranuncults gailensis E. M. Reid - MfN 2003/123. Nüsschen von beiden Seiten; $\times 25$. 18-20. Ranunculus sceleratus L. fossilis - MfN 2003/116. 18-19. Zwei verschiedene Nüsschen mit strukturlosem Mittelteil; $\times$ 25. 20. Spalthälften eines Nüsschen von außen und innen: $\times$ 25. 21. Fagus spec. cf. deucalionis Unger - MfN 2003/151. Nuss mit Flügelkanten im apikalen Teil von drei Seiten; $\times 6.5$. 22. Trema lusatica Mai - MfN 2003/139. Steinkern von zwei Seiten; stark verdrückt; $\times$ 20. 23. Morus ucrainica Dorofeev - MfN 2003/132. Steinkern von beiden Seiten mit Funikulus-Fortsatz; $\times$ 20. 24-28. Chenopodium spec. - MfN 2003/119. 24-25. Samenbruchstücke mit glatter, glänzender Testa; $\times 25.26-28$. Eingerollte, durchscheinende Tegmen von Samen: $\times 25$. 


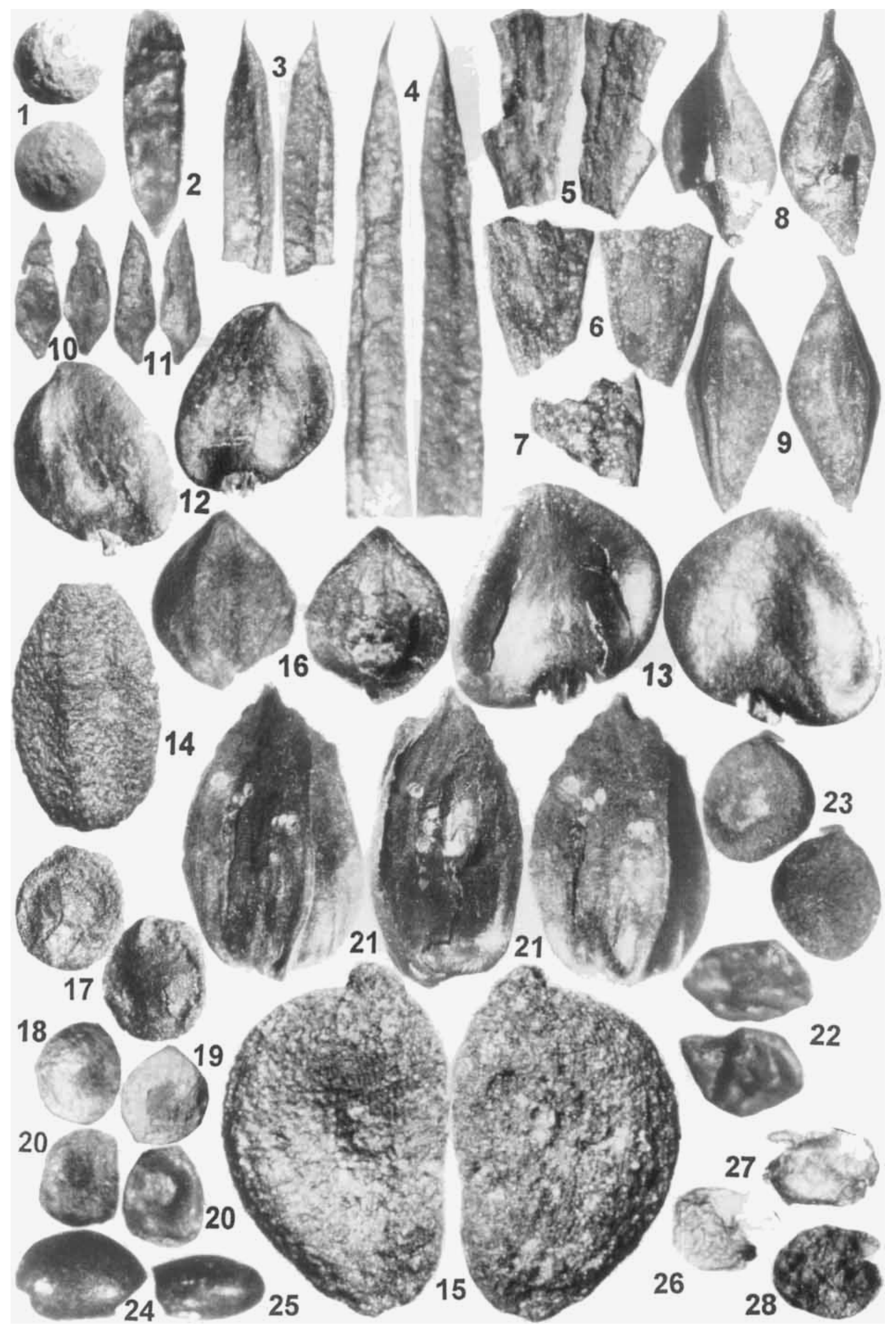




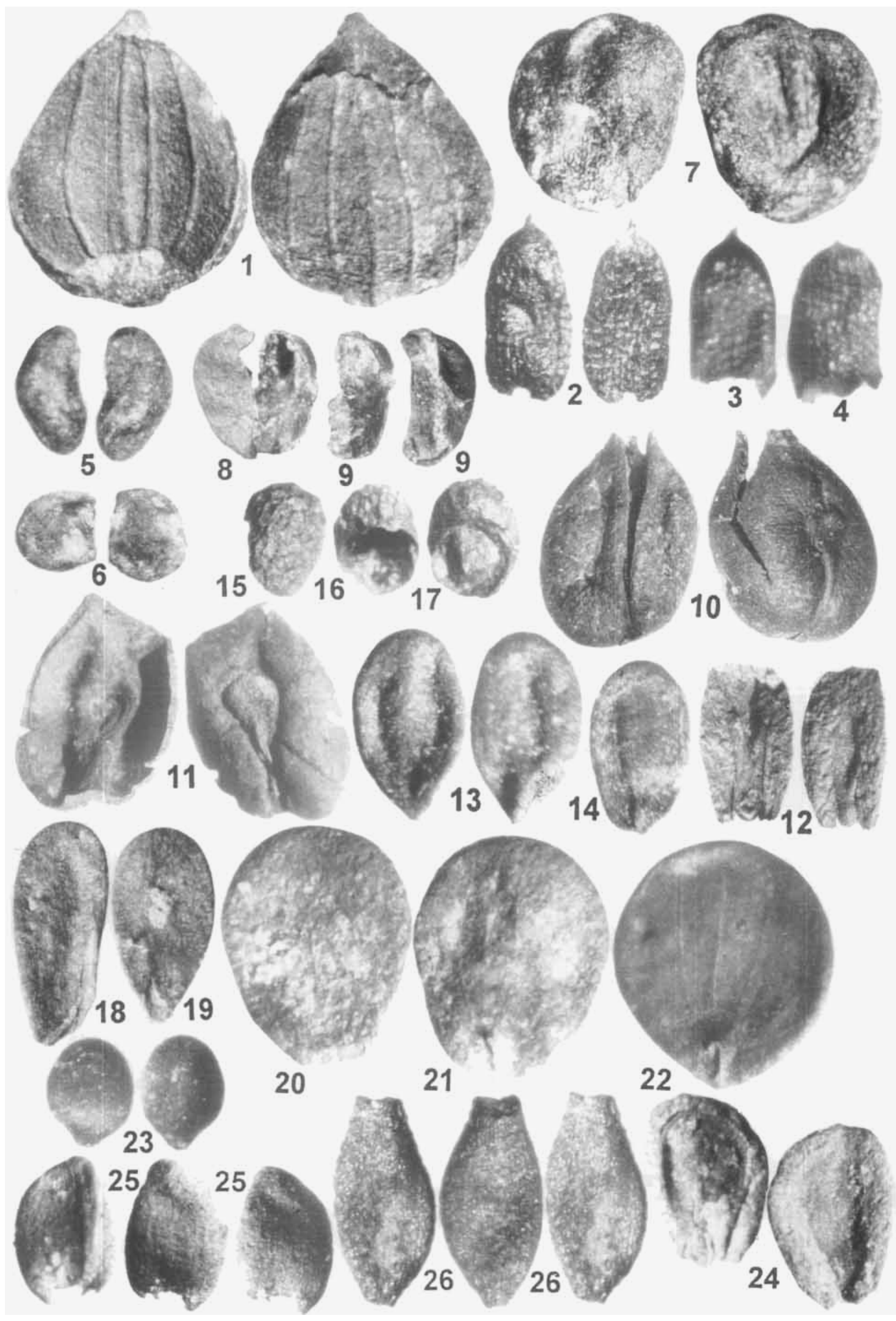




\section{Selaginellaceae}

\section{Selaginella borysthenica Dorofeev \& Weliczkie- wicz}

Taf. 2, Fig. 1

1971 Selaginella borysthenica Dorofeev \& Weliczkiewicz Dokl. Akad. Nauk. SSSR 200 (5): 1175, Abb. 1, f. 1-11 Dvorec (Oberpliozän).

Material: Barchfeld MfN 2003/141.

Beschreibung: Megaspore 0,4 $\mathrm{mm}$ im Durchmesser, kugelförmig, trilet, aber Marke auf einem abgeflachten Teil. Markenstrahlen über die ganze Länge, selten abgerissen, schwach sichtbar. Skulptur der Oberfläche fast glatt, gelegentlich mit Warzen von unterschiedlicher Größe und Aussehen besetzt.

Bemerkungen: Die sehr unterschiedlich groBen und verschieden skulpturierten Megasporen wurden von Dorofeev (1986b, Dorofeev \& Weliczkiewicz. 1971) mit verschiedenen heutigen europäischen Arten verglichen. Exemplare mit wenig Skulptur der Oberfläche, wie sie uns aus Barchfeld vorliegen, kommen Selaginella denticulata (L.) Link sehr nahe, deren Megasporen durch niedrige Markenstrahlen und eine fast völlig ohne Warzen besetzte Oberfläche auffielen. Das immergrüne krautige Gewächs tritt im Westmeditcrrangebiet, Portugal, Madeira und auf allen Kanaren-Inseln auf und ist hier typisch für die Mauer- und Felsspalten-Gesellschaften (Asplenictea trichomanis) und Gesellschaften nasser Felsstandorte (Adiantetea capilli-veneris). Wenig ähnlich sind die Megasporen der mehr subarktisch-boreal-montan verbreiteten Arten $S$. helvetica (L.) Link und S. selaginoides (L.) Link, die ebenfalls als Vergleichsarten genannt wurden. Ähnlich sind auch die pliozänen Arten S. tertiaria Dorofcev (1960)a) und S. baskirica Dorofeev (1962).
Vorkommen: Oberpliozän von Dvorec am Dnjepr (Dorofeev \& Weliczkicwicz 1971, Weliczkiewicz 1990).

\section{Pinaceae}

\section{Picea rotunde-squamosa (Ludwig) Mai \& Wal- ther}

Taf. 2, Figs 3-4

1861 Pinus Abies rotunde-squamosa Ludwig, Palacontographica 8 (6): $169-170$, t. LXV, f. $1-9$ - Dernbach (Oberpliozän).

1938 Picea echinata Müller-Stoll, Bot. Zbl., Beih. B 58: 396-398, t. IX, f. 8, 9; t. XL, f. 2-4, text-f. 4c - Dernbach (Oberpliozän).

1988 Picea rotunde-squamosa Mai \& Walther, Quartärpaläontol. 7: 63. t. Il, f. 12-20 - Berga u. Kaltensundheim (Oberpliozän).

Material: Barchfeld MfN 2003/153 (Ba009); Kaltensundheim MfN Ka 9734 (Orig. Mai \& Walther 1988, t. II. f. 19, 20).

Beschreibung und Bemerkungen: Mai \& Walther 1988, p. 63.

Vorkommen: Häufig im Pliozän (Müller-Stoll 1938, Szafer 1947, Bůžek et al. 1985, Mai \& Walther 1988, Mai \& Wähnert 2000), aber auch schon im Obermiozän am Nicderrhein (van der Burgh 1987) und der Niederlausitz (Mai 2000c).

\section{Hydrocharitaceae}

\section{Stratiotes aloides Linné fossilis}

Taf. 5, Fig. 5

1907a Stratiotes cf. aloides L. - C. \& E. M. Reid: The fossil flora of Tegelen: 21, pl. 3, fig. 86, text-fig. - Tegelen (Oberstes Pliozän).

Material: Oberzella MfN 2002/43.

Tafel 3. Flora von Barchfeld. 1. Carpinus betulus L. fossilis - MfN 2003/126. Nüsschen von beiden Seiten: $\times 12.2-4$ Hypericum foveolatum Dorofeev - MfN 2003/135. 2 Samen von beiden Seiten; $\times$ 40. 3-4. Weitere Samen; $\times 40$. 5. Potentilla cf. heptaphylla L. fossilis - MfN 2003/129. Nüsschen von beiden Seiten; $\times$ 30. 6. Potentilla supina L. fossilis - MfN $2003 / 148$. Nüsschen von beiden Seiten: $\times$ 30. 7. Microdiptera menzelii $(E$. M. Reid) Mai - MfN 2003/149. Samen von ventral und dorsal; × 25. 8-9. Meliosma ef. miessleri Mai -- MfN 2003/152. 8. Steinkern, in zwei Klappen dehiszierend: $\times$ 8. 9. Klappen des Stcinkerns von Fig. 7; $\times 8.10-11$. Vitis cf. sylvestris Gmelin fossilis - MfN 2003/134. 10. Samen von dorsal und ventral: $\times$ 10. 11. Samenbruchstücke von innen und außen mit Chalazaknoten: $\times 10$. 12. Lycopus europaeus L. fossilis - MfN $2003 / 121$ Nüsschen von zwei Seiten: $\times$ 25. 13-14. Mentha pliocenica Dorofeev - MfN 2003/120. Nüsschen verschiedener Form und Größe; $\times$ 40. 15-17. Teucrium pripiatense (Dorofeev) Weliczkiewicz \& Zastawniak - MfN 2003/122. 15. Nüsschen von der Seite; $\times 25$. 16. Nüsschen von ventral mit kreisrunder Vertiefung, ohne Deckel; $\times 25$. 17. Nüsschen von ventral mit Deckel und Ansatzstelle; $\times 25$. Flora von Oberzella. 18-19. Glechoma hederacea L. fossilis - MfN 2003/041. 18. Nüsschen von der Seite mit basaler Ansatzstelle; $\times$ 25. 19. Nüsschen von ventral: $\times 25.20-22$. Collinsonia europaea Mai - MfN $2003 / 044$. Nüsschen verschiedener Form mit Leitbündelnetz; $\times 2$ 25. 23. Origanum vulgare L. fossilis $-\mathrm{MfN} 2003 / 106$. Nüsschen von beiden Seiten; $\times$ 25. 24. Lycopus europaeus L. fossilis - MfN 2003/037. Nüsschen mit deutlichem Randsaum von beiden Seiten; $\times$ 25. 25. Ludwigia chandlerae Knobloch - MfN 2003/098. Samen von verschiedenen Seiten; $\times$ 50. 26. Lobelia pliocenica (Dorofeev) Mai - MfN 2002/062. Samen von verschiedenen Seiten und verschiedener Bcleuchtung: $\times 50$. 


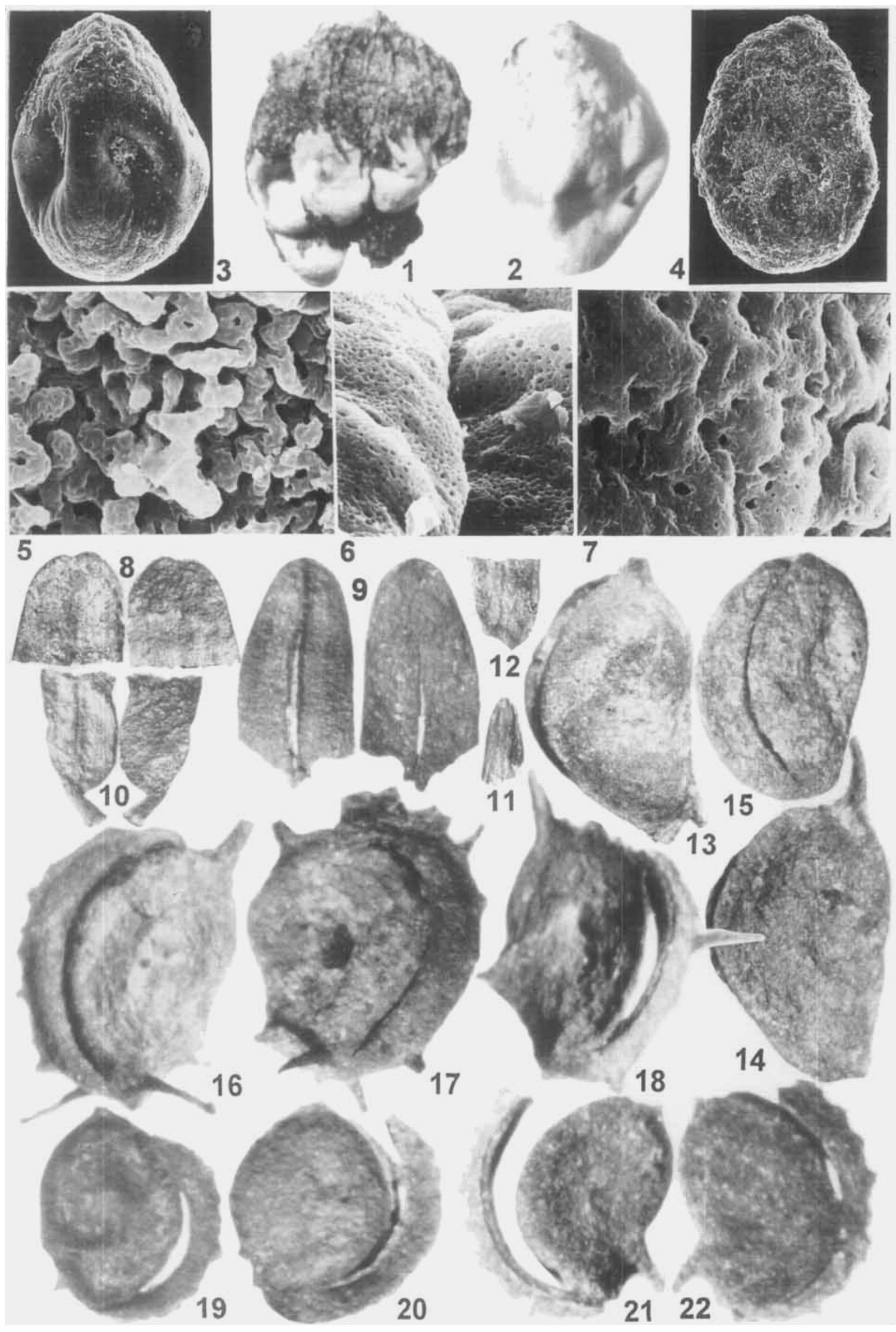




\section{Version 1}

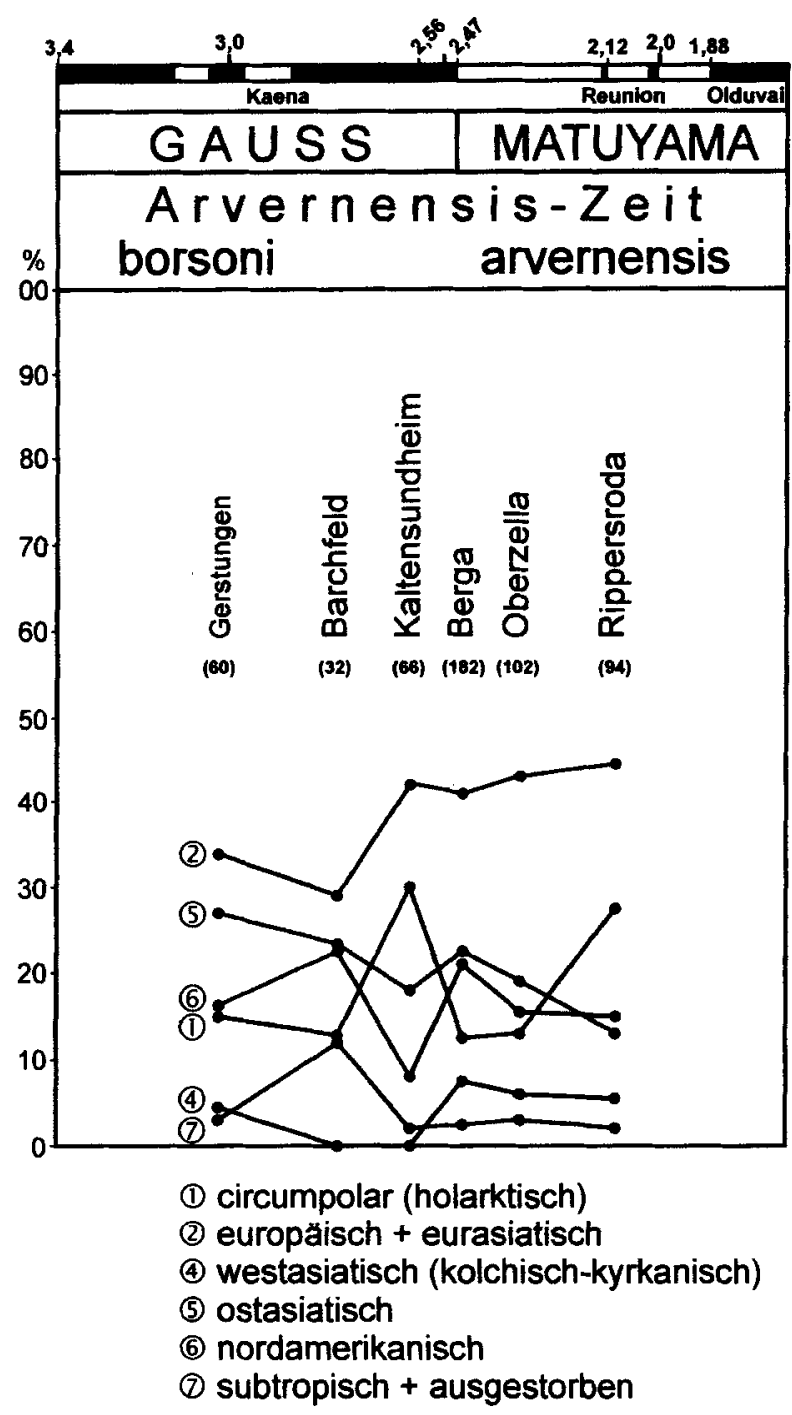

Version II

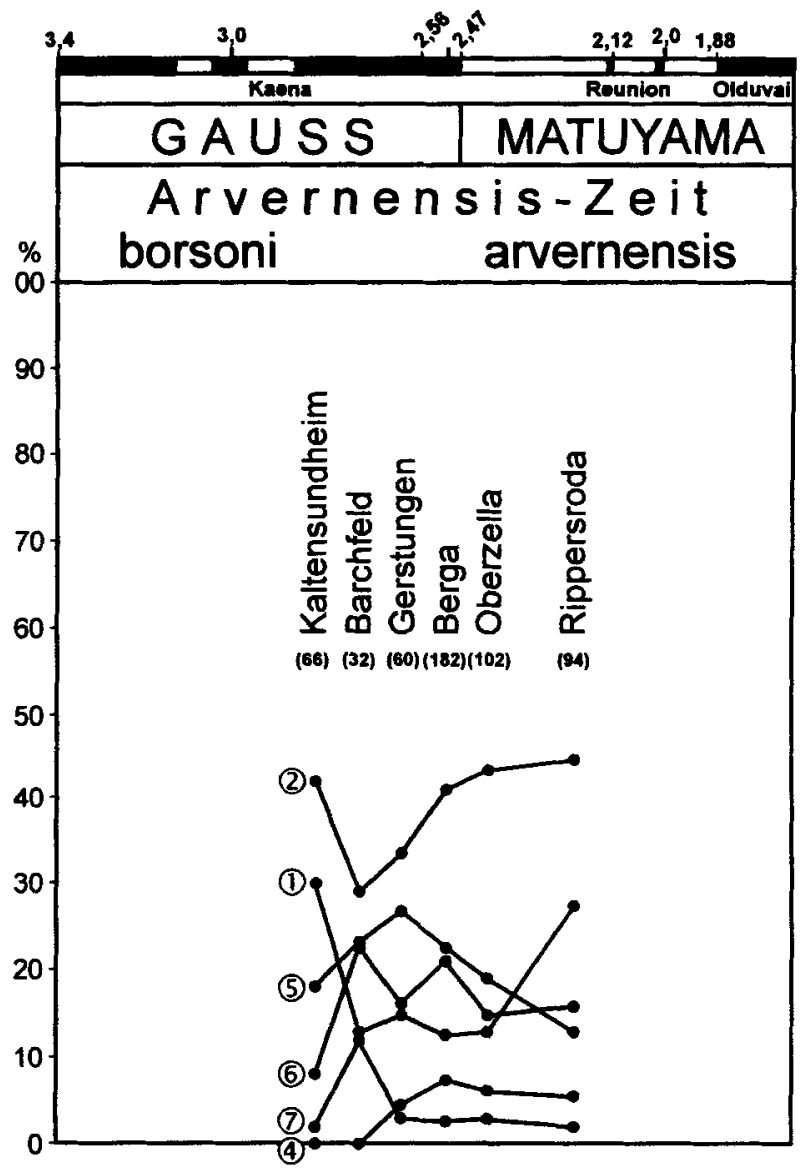

Abb. 3. Veränderungen der pflanzengeographischen Elemente in den oberpliozänen Floren der Vorderrhön. Version I und II. Legende: 1, circumpolar, 2+3, europäisch + eurasiatisch, 4, westasiatisch (kolchisch-hyrkanisch), 5, ostasiatisch, 6, nordamerikanisch, 7, subtropisch + ausgestorben. Zahlen in ( ) - Anzahl der ausgewerteten Arten. Zeitliche Eckdaten: 3,4 Mio. J.-Kaena Event (Beginn Oberpliozän); 2,56 Mio. J. Aussterbedatum von M. borsoni in Montopoli; 2,47 Mio. J.--Umpolung Gauss-Matuyama; 1,88 Mio. J.-Olduvai Event.

Beschreibung: Samen linealisch, schwach gekrümmt, mit abgestumpften Enden, basal mit rundlichem Chalazaknoten, Kiel gut differenziert, mit Raphe im Innern. Oberfläche kleinpunktat und außerdem schwach längsgestreift, ohne Knötchen. Zellen länglich mit verdickten, gewellten Wänden und kleinen Poren. Innere Wand der Testa glänzend, aus schmalen, stark gestreckten, schief gezogenen Zellen. Länge $7,5 \mathrm{~mm}$, größte Breite $2,4 \mathrm{~mm}$.

Tafel 4. Flora von Oberzella. 1-7. Salvinia miocenica Dorofeev - MfN 2002/049. 1. Megasporangium mit Teilen einer Umhüllung (apikal); $\times$ 30. 2. Megaspore; $\times$ 65. 3-4. Weitere Megasporen in Seitenansicht; SEM $\times$ 65. 5-7. Details von der Oberfläche des Spermoderms von 3; SEM $\times$ 2000. 8-10. Tsuga section Tsuga Engelmann fossilis - MfN 2003/090. 8-9. Apikalteile von Nadelblättern von der Unter- und Oberseite; $\times 12$. 10. Basalteil eines Nadelblattes mit Stielchen von der Unter- und Oberseite; $\times$ 12. 11-12. Picea abies Karsten fossilis - MfN 2003/091. 11. Apikalteil eines Nadelblattes mit stumpfer Spitze; $\times$ 12. 12. Basis einer Nadel mit schräger Ansatzszelle; $\times 12$. 13-14. Potamogeton felixii Dorofeev - MfN 2003/113. Steinkerne verschiedener Form und Größe; $\times$ 20. 15. Potamogeton palaeorutilus Dorofeev - MfN $2003 / 047$. Steinkern mit breiter Keimklappe; $\times 20$. 16-18. Potamogeton aculeatus Dorofeev - MfN 2003/036. Verschieden geformte Steinkerne mit deutlicher Bestachelung; $\times$ 20. 19-20. Potamogeton polymorphus Dorofeev - MfN 2003/048. Steinkerne verschiedener Form und Größe; $\times$ 20. 21-22. Potamogeton borysthenicus Dorofeev - MfN 2003/002. Steinkern von beiden Seiten mit verdrehter Keimklappe (22); $\times 20$. 


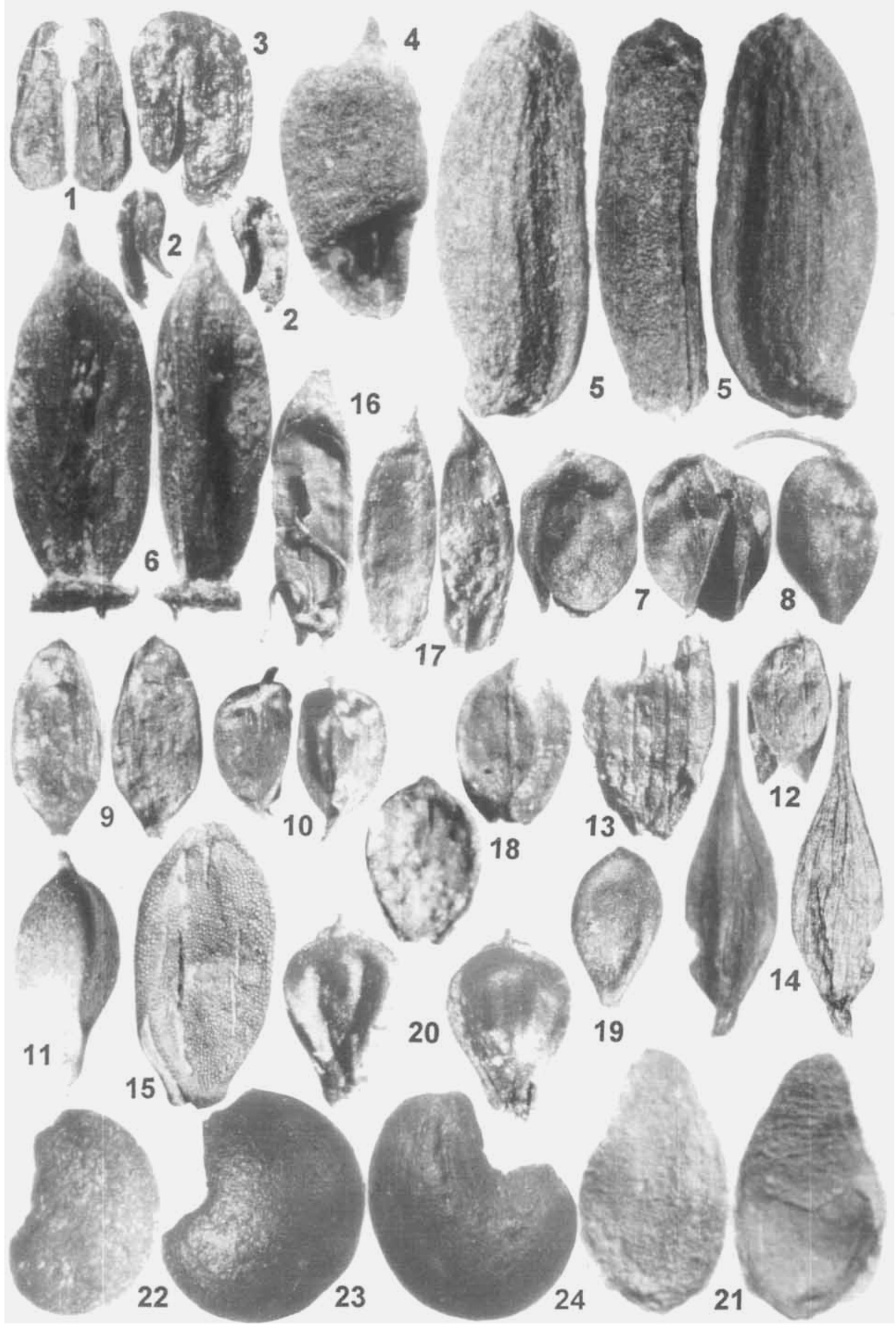


B emerkungen: Stratiotes-Samen ohne knotige Verdickungen auf der Außenfläche der Testa lassen sich nur zu $S$. aloides L. stellen. Dieser heute noch in Eurasien lebenden Art sind einige weitere Stratiotes-Arten samenmorphologisch verwandt: S. intermedius (Hartz) Chandler 1923, S. brevispermus Weliczk. und S. goretskyi Weliczk. (Weliczkiewicz 1982). Sie unterscheiden sich so geringfügig, dass sie als Formen einer polymorphen Wasserpflanzenart aufgefasst werden können.

Vorkommen: Oberpliozän (selten). Pleistozän vom Ural (Baschkirien) bis Westeuropa, teilweise häufig.

\section{Potamogetonaceae}

\section{Potamogeton aculeatus Dorofeev \\ Taf. 4, Figs 16-18 \\ 1986a Potamogeton aculeatus Dorofeev, Iskop. Potamogeton: 90-91, Fig. 46, 3-9 - Daumantaj/Litauen (Mittleres Pliozän) \\ Material: Oberzella MfN 2003/036 (Ob 036).}

Beschreibung: Endokarpien oval und halbkreisförmig, gerollt auf der Dorsalseite, dünn-, seltener dickwandig, $2,3-2,6-1,6-2,1 \mathrm{~mm}$. Dorsalkiel konvex, fast gerade oder leicht gebogen, mit großem oder kleinem Dorn. Stielchen kurz, dreieckig, seltener dünn und schmal. Griffelrest schwach kanneliert, kurz, auf der Verlängerung der Dorsallinie. Keimklappe zusammengedrückt, mit niedrigem Kamm, aber mit zahlreichen kleinen, dünnen, kurzen oder selten langen Dornen. Seite mit großer Vertiefung, bisweilen fast mit Foramen, am Rande nahe der Keimklappe mit kleinen Dornen oder Warzen in der Anzahl 3-5, an der Basis der Seiten ein langer, flacher, gewöhnlich umgelegter Dorn.

Bemerkungen: Dorofeev (1986a) vergleicht die Endokarpien mit denen der heutigen $P$. trichoi- des Cham. \& Schlecht, hebt aber den außergewöhnlichen Bau der stacheligen Fossilien hervor. Er nennt die fossile Art eine sehr eigenständige Art.

Vorkommen: Obermiozän bis Mittelpliozän von Osteuropa. In der Ukraine vielleicht auch im Pleistozän (Dorofeev 1986a).

\section{Potamogeton borysthenicus Dorofeev}

Taf. 4, Figs 21-22

1971 Potamogeton borysthenicus Dorofeev, Dokl. Akad. Nauk SSSR 200: 918, t. 1, f. 22, 23 - Cholmech/Dnjepr (Oberpliozän).

Material: Oberzella MfN 2003/002.

Beschreibung und Bemerkungen: Mai \& Walther 1988, p. 76. Bei Potamogeton ultimus Dorofeev (1986a, Weliczkiewicz 1990) handelt es sich um ein Synonym.

Vorkommen: Pliozän von der Atlantikküste bis an Dnjepr und Don.

\section{Potamogeton felixii Dorofeev}

Taf. 1, Figs 9-10; Taf. 4, Figs 13-14

1986a Potamogeton felixii Dorofeev; Iskop. Potamogeton: 38, Fig. 15, 1-2 - Dvorec (Oberpliozän).

Material: Kaltensundheim MfN Ka 9723, 9726 (Orig. Mai \& Walther 1988, t. X, f. 3-4); Oberzella MfN 2003/113.

Beschreibung: Endokarpien schief-oval, abgeflacht, dickwandig, aber von mittlerer Größe; 2,0-2,6 mm lang, 2,0-2,2 mm breit. Ventralseite merkbar konvex, gerundet, mit einem konischen, langen oder kürzeren Stielchen an der Basis. Dorsale Keimklappe zusammengedrückt, gekielt, mit undeutlich gekräuseltem, niedrigem Kamm. Schulter kurz bis fehlend. Griffelrest mehr oder weniger lang und dicklich, zugespitzt, zentral gelegen und aufrecht. Seitenflächen konvex, mit kleiner tiefer, kommaförmiger Depression und Basalwarze.

Tafel 5. Flora von Oberzella. 1-2. Baldellia ranunculoides (L.) Parlatore fossilis - MfN 2003/033. 1. Nüsschen von beiden Seiten; $\times$ 20. 2. Samen von beiden Seiten; $\times$ 20. 3. Sagittaria sagittifolia L. fossilis - MfN 2003/055. Zweischenkliger Samen; $\times$ 20. 4. Caldesia cylindrica (E. M. Reid) Dorofeev - MfN 2003/003. Frucht mit abgeworfener basaler Keimklappe; $\times 20.5$. Stratiotes aloides L. fossilis - MfN 2002/043. Samen in drei verschiedenen Ansichten; $\times 12$. 6. Carex flagellata C. \& E. M. Reid - MfN 2002/059. Nüsschen von zwei Seiten; $\times 20.7$.8. Carex hostianoides Mai - MfN 2003/102. 7. Nüsschen von zwei Seiten; $\times 20.8$. Weitere Nüsschen mit langem Griffelrest; $\times 20.9$. Carex elongatoides Lańcucka-Środoniowa - MfN $2003 / 056$. Nüsschen von beiden Seiten; $\times$ 20. 10. Carex ornithopoda Willdenow fossilis - MfN 2003/093. Nüsschen von zwei Seiten; $\times$ 20. 11. Carex ornithopoda Willdenow - Rezent BHU. Nüsschen; $\times 20$. 12-14. Carex pseudocyperus L. fossilis - MfN $2003 /$ 039. 12. Nüsschen von einer Seite; $\times 20$. 13. Utriculus-Bruchstück mit eingeschlossenem Nüsschen; $\times 20.14$. Utriculus mit langem Griffelrest und eingeschlossenem Nüsschen; $\times 20$. 15. Carex riparia Curtis fossilis - MfN 2003/052. Nüsschen von der Seite; Griffel abgebrochen; $\times$ 20. 16-17. Dulichium arundinaceum (L.) Britton fossilis - MfN 2003/070. 16. Nüsschen mit Basalborsten; $\times 20$. 17. Nüsschen von beiden Seiten mit deutlichem Griffelrest; $\times 20$. 18. Scirpus sylvaticus L. fossilis - MfN 2003/104. Nüsschen von beiden Seiten; $\times$ 40. 19. Schoenoplectus isolepidoides Mai \& Walther - MfN 2003/103. Nüsschen; $\times$ 20. 20. Eleocharis praemaximowiczii Dorofeev - MfN 2003/097. Nüsschen von beiden Seiten ohne Perianthborsten; $\times 40$. 21. Acorus palaeocalamus Dorofeev - MfN 2003/092. Samen von beiden Seiten mit geknitterter Testaschicht; $\times 20.22-24$. Epipremnites reniculus (Ludwig) Mai - MfN 2002/045. Samen verschiedener Form und Größe; $\times 15$. 
Bemerkungen: Diese Art ist der Vertreter einer eigenen Gruppe, die dem ostasiatischen Potamogeton fryeri A. Benn. nahesteht (Dorofeev 1986a). Die Gruppe ist auch der P. maackianus-Gruppe nahestehend und umfasst nur wenige Arten im europäischen Pliozän und Obermiozän: Potamogeton felixii Dorofeev, $P$. tataricus Dorofeev \& Weliczkiewicz, P. lipetskianus Dorofeev und $P$. ilovaicus Dorofeev (Dorofeev 1986a), welche sich wenig voneinander unterscheiden.

Ein Teil des als Potamogeton neptunii Mai \& Walther (1988) bestimmten Materials aus Kaltensundheim gehört nach den neueren Bestimmungen sicherlich zu $P$. felixii Dorofeev (z. B. Mai \& Walther 1988, Taf. X, Figs 3-4). Jedenfalls gehören sie nach der kleinen Schulter nicht in die Untergattung Coleogeton Reichenb.

Vorkommen: Pliozän von Dvorec/Belorussland (Dorofeev 1986a, Weliczkiewicz 1990), Cholmech (Weliczkiewicz \& Lesiak 1999), Thüringen (Mai \& Walther 1988).

\section{Potamogeton palaeorutilus Dorofeev}

\section{Taf. 4, Fig. 15}

1986a Potamogeton palaeorutilus Dorofeev. Iskop. Potamogeton: 103-104, Fig. 33.1-9 - Ranino/Tambov (Oberpliozän).

Material: Kaltensundheim MfN Ka 9734 (Orig. P. tonaiticus in Mai \& Walther 1988, t. X. fig. 14): Oberzella MfN 2003/047 (Ob047)

Beschreibung: Endokarpien elliptisch, fast halbkreisförmig oder schief-eiförmig, gestreckt, gewöhnlich dick, 1,5-1,9-0,9-1,4 mm. Dorsalseite symmetrisch gebogen, bei einigen Exemplaren Biegung auf die obere Hälfte verschoben. Stielchen kurz, dick, seltener spitz. Griffel kurz, dick oder dünn, zentral oder nach dorsal verschoben. Keimklappe stumpf, seltener zusammengepresst, aber ohne Kamm. Schulter schmal, bisweilen mit Schlitz, aber meistens fehlend. Seite gewölbt.

Bemerkungen: Dorofeev (1986a) vergleicht mit den Endokarpien der heutigen europäischen Arten $P$. rutilus Wolfg., aber auch $P$. friesii Rupr. und $P$. pusillus L., stellt aber in Form und Größe erhebliche Unterschiede fest. Auch ein Teil der Endokarpien aus Kaltensundheim (z. B. Mai \& Walther 1988, Taf. X, Fig. 14) gehört zu dieser Art, nicht aber in die $P$. lucens-Gruppe, wozu $P$. tanaiticus Dorofeev (1966) gehören würde.

Vorkommen: Oberpliozän im Gebiet Tambov (Dorofeev 1986a) und Cholmech/Belorussland (Weliczkiewicz \& Lesiak 1999).

\section{Potamogeton panormitanoides Dorofeev}

Taf. 1, Figs 7-8

1986a Potamogeton panormitanoides Dorofeev, Iskop. Potamogeton: 107, Fig. 54, 2-8 - Tambovsk. obl., Neznanovskie Vyselki (Altpleistozän).

Material: Kaltensundheim MfN Ka 9720, 9728 (2 Expl.).

Beschreibung: Endokarpien sehr klein, 1,2-1,7 mm lang und 1,0-1,2 $\mathrm{mm}$ breit, schief verkehrt-eiförmig, über die Seiten schwach konvex, in der Mitte mit punktförmiger, zentraler Vertiefung. Ventraler Rand stark konvex im oberen Teil, fast gerade oder sigmoid gerundet. Keimklappe glatt, das zugespitzte Ende fast den Apex des Endokarps erreichend, sehr kurze Schulter. Griffelrest kurz, unbedeutend. Stielchen kurz, dreieckig-länglich, selten erhalten. Basal bisweilen mit zwei kurzen Wärzchen. Oberfläche glatt, glänzend.

Bemerkungen: Ein Endokarp aus der Potamogeton pusillus-Gruppe. Von allen Arten, die in diese große Gruppe um $P$. pusillus L. zu stellen sind, ist $P$. panormitanus Biv.-Bern. (LadogaSee, oft als $P$. pusillus L.) die Art mit den ähnlichsten Endokarpien. Aber auch $P$. friesii Rupr. zeigt vergleichbare Merkmale des Steinkerns: Gekrümmte Achse, Vorkommen einer kurzen Schulter, paarige Warzen an der Basis der Seiten.

Vorkommen: Pliozän von Mizerna/Südpolen und Cholmech/Belorussland. Mittelpleistozän von Belorussland und der Tambov-Region (Dorofeev 1986a, Weliczkiewicz \& Lesiak 1999).

\section{Cyperaceae}

\section{Carex hostianoides Mai}

Taf. 5, Figs 7-8

1989 Carex hostianoides Mai, Natur u. Landschaft Cottbus 11: 34. t III, f. 13, Abb. 12a - Wischgrund (Obermiozän).

Material: Oberzella MfN 2003/102 (3 Expl.).

Beschreibung: Früchte rundlich-dreikantig, aufgeblasen, mit deutlich sichtbarer Mittelkante, im Umriss breit eiförmig. Griffelrest kurz, dicklich, gerade bis gebogen, abrupt abgestutzt. Basis breit bis schmal, mit Ansätzen zu Diskusbildungen. Wände dünn. Oberfläche zellig-grubig, dunkel. Länge 2-1,8 mm; Breite um 1,5 mm.

B emerkungen: Eine mit $C$. hostiana DC. verwandte fossile Art. Die heutige Art ist fast in ganz Europa mit Ausnahme des Nordostens und Südens verbreitet. Sie ist häufig auf nassen, moorigen Riedwiesen, Flachmooren oder Heiden. 
Vorkommen: Mittel- und Obermiozän in der Niederlausitz (Mai 2000c). Erstfund im Pliozän.

\section{Carex klarae Mai}

Taf. 2, Figs 10-11

2000c Carex klarae Mai, Palaeontographica B, 256: 35-36, t. 15 , f. $1-4$ - Kausche, Gr. Klara (Obermiozän).

Materia ]: Barchfeld MfN 2003/138.

Beschreibung: Oval-abgeflachte Früchte, im Umriß elliptisch-lineal, schmal, mehr als 2 mal so lang wie breit, terminal und basal verschmälert. Basis sehr wenig abgesetzt. Griffelrest dicklich, mittelgroß, zugespitzt. Oberfläche zellig-wabig. Früchte sehr zartwandig. Länge (ohne Griffel) 1,9-1,6 mm, Breite 0,6-0,4 mm. Schläuche unbekannt.

Bemerkungen: Eine sehr schmalfrüchtige Art mit mittellangem Griffelrest. Von allen fossilen europäischen Carices ist sie in erster Linie durch die Fruchtgestalt und Struktur der Oberfläche unterschieden. Wesentlich enger als zur pliozänen $C$. paucifloroides Weliczkiewicz (1979) ist die Verwandtschaft der Art zur nordamerikanischen $\mathrm{Ca}$ rex muskingumensis Schweinf., die jedoch größere Früchte mit längerem Griffel besitzt.

Vorkommen: Obermiozän in der Niederlausitz und im Oberpliozän in Südpolen (Mizerna), vielleicht Oberpliozän/Altpleistozän Osteuropas (Mai 2000c).

\section{Carex ornithopoda Willdenow fossilis}

Taf. 5, Fig. 10

1967 Carex ornithopoda Willd. - Nilsson \& Hjelmqvist, Nutlet structure of Carex species: 463, Fig. 2 F - Rezent.

Material: Oberzella MfN 2003/093.

Beschreibung: Früchte dreikantig, mehr oder weniger deutlich gestielt. Stielchen gekrümmt, $0,9-1 \mathrm{~mm}$ lang und ca. $0,2 \mathrm{~mm}$ dick. Griffelrest sehr kurz. Seiten breit oval bis ovat, glatt. Länge 1,7-2 mm.

Bemerkungen: Früchte mit Stiel sind bei den europäischen Carices selten, und nur zwei Arten besitzen ein gekrümmtes Stielchen: $C$ digitata $\mathrm{L}$. und $C$. ornithopoda Willd (Taf. 5, Fig. 11). Beide Arten sind in Mitteleuropa Besiedler von wärmeliebenden Laubwäldern. Die letztere ist kalkhold.

Vorkommen: Bisher nur im Pliozän der Vorderrhön.

\section{Eleocharis praemaximowiczii Dorofeev}

Taf. 1, Figs 14-17; Taf. 5, Fig. 20

1986b Eleocharis praemaximowiczii Dorofeev, Problemy Paleobot.: 60, t. II, f. 17-25 - Dvorec (Oberpliozän).
Material: Kaltensundheim MfN Ka 9731-32, Ka 9720: Oberzella MfN 2003/097.

Beschreibung: Früchtchen zusammengedrückt ei- oder keulenförmig, bikonvex, rundlich, dreikantig. Spitze mit kleinem Stylokarp, von einem kleinen Teil des Apikalbezirkes sehr deutlich hervortretend, zentral mit warzenartigem Griffelspitzchen. Nahe der Basis Früchtchen zusammengezogen und auf der ganzen Breite abgestutzt, mit dünnen, kurz abgebrochenen Borsten oder ohne solche. Oberfläche glatt, stark glänzend. Länge $0,7-1,1 \mathrm{~mm}$; Breite $0,5-0,6 \mathrm{~mm}$.

Bemerkungen: Die Früchtchen dieser Art unterscheiden sich von der pliozänen Eleocharis microstylosa Mai 1963 (Mai, Majewski \& Unger 1963) durch stärkere Verbreiterung im oberen Teil und ein etwas größeres und breiteres Stylokarp. Sie sind im ganzen größer.

Die Früchtchen der europäischen Arten $E$. ovata (Roth.) Roem. \& Schult. und E. carniolica K. Koch sind deutlich bikonvex und nicht dreiflächig, immer auch etwas kleiner. Vollkommen gleich gebaute Früchtchen gibt es unter den heutigen Arten auch in Amerika und Ostasien nicht (Dorofeev in Weliczkiewicz 1990). Am meisten ähnlich sind nach Dorofeev (1986b: 60) die Früchtchen von E. maximowiczii Zinserl.; diese sind jedoch etwas größer und mit deutlicheren Flächenbegrenzungen. Ähnlich sind auch die Früchtchen der E. parvula (Roem. \& Schult.) Link von Fundorten im Fernen Osten.

E. maximowiczii Zinserl. gedeiht in küstennahen Sümpfen im Fernen Osten nahe dem Japanischen Meer (z. B. Posjeta-Bucht unweit Wladiwostok).

Vorkommen: Früchtchen dieses Typs sind weit verbreitet im Pliozän und im Don-Dnjepr-Altpleistozän der osteuropäischen Niederung (Weliczkiewicz 1982). Oberpliozän von Dvorec (Dorofeev 1986b, Weliczkiewicz 1990); vielleicht auch Pliozän von Oberitalien (Martinetto mdl.)

\section{Araceae}

\section{Acorus palaeocalamus Dorofeev}

Taf. 5, Fig. 21

1973 Acorus palaeocalamus Dorofeev, Dokl. Akad. Nauk Beloruss. 17 (7): 657, Fig. 1: 5-9 - Cholmech/Gomel (Oberpliozän).

Material: Oberzella MfN 2003/092 (5 Expl.).

Beschreibung: Samen ursprünglich bikonvex, abgeflacht, länglich oval bis rundlich, sehr unter- 
schiedlich in Form und Größe, mit gestreckter oder gekrümmter Achse, 2,3-3,4 mm lang und 1,2-3,2 $\mathrm{mm}$ breit, einzeln oder in paarigen $\mathrm{Ag}$ gregaten. Apex gerundet, zusammengezogen oder zugespitzt, mit einer breiten Mikropyle, die oft auf eine Seite etwas verschoben ist. Basis verjüngt bis zugerundet, bisweilen in ein kurzes Stielchen verschmälert. Oberfläche ungleichmäBig gerunzelt, geknittert oder grubig punktiert. Schale ungleichmäßig dick, oft etwas gefaltet, deutlich mehrschichtig. Fachnahe Schicht sehr dünn, aus rundlichen, stark verdickten Sklereiden, bisweilen obliteriert; mittlere Schicht aus mehreren Zellreihen von großen, radial angeordneten Zellen mit wenig verdickten Wänden; äuBere Schicht aus meist zerknitterten, parenchymatischen Zellen. Diese Schicht leicht sackartig ablösbar.

Bemerkungen: Bisher sind im Thüringer Pliozän nur die Samen, aber keine Früchte gefunden worden. Sie sind durch ihre sehr variable Form und die zellige Oberfläche auffallend. Die Samen des heutigen Acorus calamus L. sind länger und dünnwandiger als die der fossilen Art. Kalmus ist eine krautige Sumpfpfanze in der Verlandungszone von Gewässern und heimisch ursprünglich nur in Ostasien.

In Europa ist die Pflanze ein Neophyt seit dem 16. Jahrhundert und auch in Nordamerika und dem tropischen Asien nur eingewandert oder eingeschleppt. Sie fruchtet außerhalb ihres heimischen Areals meist nicht, sondern vermehrt sich vegetativ zu großen Beständen.

Nach Kac et al. (1965) fossile Samen im Mittelpleistozän vom $\mathrm{Ob} /$ Westsibirien gefunden und als Acorus procalamus benannt. Sprossteile sind als Acorus brachystachys Heer im Obermiozän von Polen bekannt (Kownas 1955).

Vorkommen: Bisher nur im Oberpliozän von Belorussland (Dorofeev 1973).

\section{Epipremnites reniculus (Ludwig) Mai}

Taf. 5, Figs 22-24

1857 Cytisus reniculus Ludwig. Palaontographica 5: 101, t. 20, f. 21 - Dorheim (Pliozän).

1989 Epipremnites reniculus Mai, Natur und Landschaft Bez. Cottbus NLBC 11: 40, Taf. VIII, Figs 21-22 - Klettwitz (Obermiozän. XIII).

Material: Oberzella MfN 2002/045.

Beschreibung und Bemerkungen: Mai \& Walther 1988, p. 94. Nach Dorofeev (1963) ist die Herkunft von Araceen-Monsteroideen sicher, unklar jedoch die Gattungszugehörigkeit (Epi- premnum, Raphidophora oder eine andere Gattung dieser Unterfamilie). Gregor \& Bogner (1984) reihen diese Art unter der „Crassum"-Gruppe bei Scindapsites ein.

Vorkommen: Untermiozän bis Pliozän in Europa; in Westsibirien im Oberoligozän selten (Dorofeev 1963).

\section{Sparganiaceae}

\section{Sparganium neglectum Beeby fossilis}

\section{Taf. 2, Fig. 14}

1909 Sparganium ramosum Huds. fossilis Hartz, Danm. Geol. Unders., II, 20: 191, t. 9, f. 15 - Tislund bei Brørup (Eem-Interglazial).

Material: Barchfeld MfN 2003/155(Ba 012); Kaltensundheim MfN Ka 9732 (Orig. zu Mai \& Walther 1988, t. XIV, f. 10); Oberzella MfN 2003/024 (Ob 024).

Beschreibung: Mai \& Walther 1988, p. 95.

Bemerkungen: Art aus der Reihe Neglecta Juz., aber fossil kleinere Steinkerne als bei der rezenten $S p$. neglectum Beeby, welche in der neuen Literatur (Hempel in Rothmaler 1976: 742) als Unterart zu Sp. erectum L. gezählt wird. Morphologisch stehen auch die Steinkerne von Sp. bessarabicum Negru (1979) und Sp. microcarpum (Neum.) Celak. fossilis (Mai 2000c) sehr nahe. Im jetzigen Umfange (vgl. Knobloch \& Mai 1975) eine Sammelart von größerer stratigraphischer Reichweite.

Vorkommen: Untermiozän bis Obermiozän der Lausitz (Mai 1999a, 2000c); Obermiozän von Moldavien, Ukraine (Negru 1979, 1986), Slowakei, Mähren (Knobloch 1976) und Niederschlesien (Sadowska \& Szynkiewicz 1998). Pliozän von Osteuropa bis zum Niederrhein. Meist häufig auch in Interglazialen und Interstadialen (Knobloch \& Mai 1975).

\section{Typhaceae}

\section{Typha aspera Dorofeev}

Taf. 2, Fig. 2

1971 Typha aspera Dorofeev, Dokl. Akad. Nauk SSSR 200 (4): 918, Abb. 1, Figs 2-6 - Cholmech/Gomel (Oberpliozän).

Material: Barchfeld MfN 2003/128; Oberzella MfN 2003/111.

Beschreibung: Samen (Tegmen) länglich-lagenoid, wenig verbreitert zur Basis und fast parallelrandig, gerade oder nur leicht gekrümmt, über 3 mal länger als breit; $1-1,3 \mathrm{mal} 0,3-0,4 \mathrm{~mm}$. Ohne besonders abgesetzten Hals. Deckelchen 
klein mit kurzem Griffelrest. Basis keilförmig, bisweilen stumpf, mit dicklichem Stielchen. Testa von mäßiger Dicke, mit mittlerer Schicht (Maschenschicht) aus kleinen, rechteckigen Zellen, deren stärker verdickte tangentiale Wände in geraden Längsreihen angeordnet sind.

Bemerkungen: Samen aus der PoltavicaGruppe (Dorofeev 1982a). Mit gewissen Beziehungen zur rezenten $T$. gracilis Jord., diese aber kleinsamiger.

Vorkommen: Mittelmiozän der Lausitz (Mai 2000c); Obermiozän der Ukraine (Negru 1979). Pliozän von Weißrussland (Dorofeev 1971).

\section{Typha pseudoovata Dorofeev}

Taf. 1, Figs $1-4$

1982a Typha pseudoovata Dorof.; Dorofeev, Paleokarpol. issled. Kajnozoja: 23, Pl. 2, figs 38-45; Holotypus: Pl. 2, fig. 39 - Cholmech/Gomel (Oberpliozän).

1988 Typha hercynia Mai \& Walther, Quartärpal. 7: 96, Abb. 23d-f; Taf. XIV, Figs 21, 22, 30, 31 - Nordhausen (Oberpliozän).

Material: Kaltensundheim MfN Ka 9720 u. 9732, 9733, 9747.

Beschreibung: Samen ellipsoidal, größte Breite in der Mitte, mehr als dreimal so lang wie breit, 0,6-0,8-0,2-0,4 mm. Ohne Hals, Spitze des Samens mindestens zweimal schmäler als die allergrößte Breite des Samens. Keimdeckelchen nicht eingesenkt. Griffelrest kurz. Basis spitz, mit kurzem Stielchen. Maschenschicht der Testa aus großen, quergestellten, rhombischen bis hexagonalen Zellen mit dünnen, wenig hohen Wänden, die flache, quergestellte Maschen-Skulptur bewirken (SEM-Aufnahmen Taf. 1, Fig. 4).

Bemerkungen: Durch kleines Keimdeckelchen, Zellstruktur und eine allgemein ovale Form deutlich von rezenten europäischen Arten unterschieden. Nach der breiten Mitte und der quergestellten Maschenstruktur in die Gruppe um T. ovata Dorofeev (1982a) zu stellen. Von den rezenten Arten ist $T$. capensis Rohrb. und $T$. minima Funk ähnlich.

Vorkommen: Pliozän von Thüringen und Westmecklenburg (Bülow \& Mai 1992); Pliozän von Weißrussland (Dorofeev 1971, 1982a).

\section{Magnoliaceae}

\section{Magnolia ultima Kirchheimer}

Taf. 6, Figs $1-2$

1949 Magnolia ultima Kirchheimer, Kenntn. Pliozänfl. Soufflenheim: $216-218$, t. 1, f. 4 - Soufflenheim/Elsaß (Oberpliozän).

Material: Oberzella MfN 2002/050 (Ob 010, 017).
Beschreibung: Samen wesentlich breiter als lang, nierenförmig, 7,5-6 mm lang, aber 8,5 bis $9,0 \mathrm{~mm}$ breit, mit großer, runder Chalazagrube, die bis $3,5 \mathrm{~mm}$ im Durchmesser misst, mit Kondylus. Mikropyle häufig auf einem winzigen Spitzchen. Sklerotesta 0,7 mm dick.

Bemerkungen: Kirchheimer (1949: 216-217) stellt alle bisher unter Magnolia kobus DC. beschriebenen Reste aus dem europäischen Pliozän hierher. Das ist nicht richtig, da die meisten dieser Reste mit Magnolia cor Ludwig (1857) zu vereinigen sind. Nur solche extrem breiten Samen mit sehr großer Heteropyle und deutlichem, dickem Kondylus dürfen als $M$. ultima Kirchhheimer bezeichnet werden, die wie der Holotypus aus Soufflenheim (Kirchheimer 1949, t. 1, f. 4) aussehen. Im Heteropylenbau und in der Umrißkontur ist $M$. kobus DC. nahestehend (Mai 1975). Diese Art dringt bis in die nördlichsten Arealteile der Gattung nach Hokkaido vor, hat aber eine größere Verbreitung und Bedeutung in den südlicheren Sommerlaubwald-Gebieten von Nordhondo bis Shikoku/Japan, Hupeh und Kweitchou in China.

Vorkommen: Untermiozän bis Oberpliozän, vielleicht auch Altpleistozän (Kirchheimer 1957).

\section{Nymphaeaceae}

\section{Nuphar canaliculata C. \& E. M. Reid}

\section{Taf. 6, Figs 5-7}

1915 Nuphar canaliculatum C. \& E. M. Reid, Plioc. Floras Dutch-Prussian border: 86, t. VII, f. 1 - Reuver (Oberpliozän).

Materia1: Oberzella MfN 2003/057 (Ob 057).

Beschreibung: Samen eiförmig bis rundlich, $3-3,5 \mathrm{~mm}$ lang und $2,8-3,0 \mathrm{~mm}$ breit; derbhäutiges Spermoderm flachgedrückt und mit unregelmäßigen Falten versehen. Basis breit gerundet, Mittelteil zum Apex verjüngt, Spitze abgeflacht und mit rundlichem bis fast dreieckigem Loch, das durch einen Deckel verschlossen wird. Deckel mit elliptischem Hilum und warzenartigem Rest der Mikropyle, beide benachbart. Raphe am Rand des Keimlochs beginnend und besonders im oberen Teil als schwache Längskante sichtbar. Sklereiden in der Testa verdickt, mit kanalartiger Rinne, oberflächlich als größere polygonale Elemente sichtbar.

Bemerkungen: Die Samen der Art wurden nach C. \& E. M. Reid (1915) noch einmal genauer von Kirchheimer (1957) untersucht. Verbessert wurde die Schreibweise canaliculata durch 


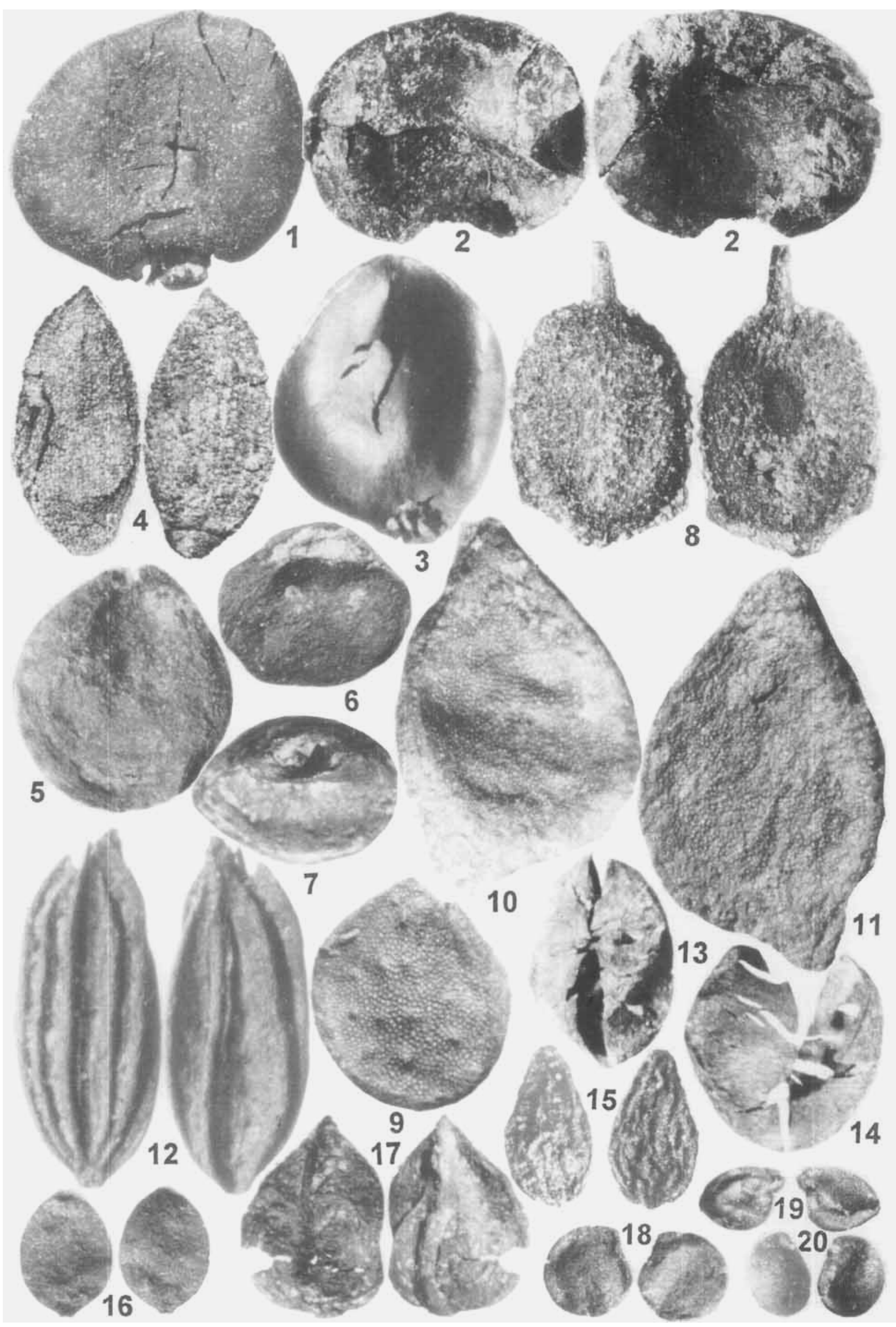


Dorofeev (1974), der auch einen Lectotypus der Art auswählte. Unsere Oberzellaer Exemplare stimmen mit dem Material vom Locus typicus am Niederrhein überein. Auf Grund der Spermoderm-Struktur lassen sich keine anderen Zuordnungen als zu dieser pliozänen Art finden. Diese Spermoderm-Struktur ist mehr variabel, als es nach Dorofeev (1974) den Anschein hat, so dass viele der Arten des osteuropäischen Pliozäns wahrscheinlich alle zu N. canaliculata C. \& E. M. Reid gehören. Die nächstverwandte Art ist N. lutea (L.) Sm. (Europa, Vorderasien, Sibirien).

Vorkommen: Untermiozän der Oberlausitz (Mai 1999b); Mittel- bis Obermiozän im Rheinland (Schultz 1962). Pliozän in ganz Europa (Reid \& Reid 1915, Szafer 1947, Palamarev 1970, Dorofeev 1974).

\section{Ceratophyllaceae}

\section{Ceratophyllum pannonicum Dorofeev}

Taf. 6, Fig. 8

1974 Ceratophyllum pannonicum Dorofeev, Iskop. cvetkov. rastenija 1: $86-87$, t. 116, f. 5-6 - Malaja Began'/Ukr. (Obermiozän).

Material: Oberzella MfN 2002/044 (Ob 004).

Beschreibung: Früchte mit 1 langen, dornartigen, bleibenden Griffelrest und je $4-5$ mehr oder weniger deutlichen Stacheln an beiden Seiten, von denen die untersten am kräftigsten ausgebildet sind, zwischen diesen Stacheln Reste eines häutigen Saumes. Frucht mit warziger Oberfläche, dünnerem Perikarp, 3,5 mm lang (ohne Griffelrest), 2,5 mm breit.

Bemerkungen: Es bestehen Beziehungen zu Ceratophyllum platyacanthum Chamisso und $C$. tanaiticum Sapjegin, ohne dass jedoch die Bestachelung so unregelmäßig und kräftig ausgebildet ist wie bei diesen Arten. Artgleich mit unseren Fossilien dürfte Ceratophyllum balcanicum Palamarev (1982) aus dem bulgarischen Pliozän sein.
Vorkommen: Obermiozän der Ukraine (Dorofeev 1974) und Pliozän Bulgariens (Palamarev 1982); Mittelmiozän in der Lausitz (Mai 2001).

\section{Ranunculaceae}

\section{Ranunculus gailensis E. M. Reid}

Taf. 2, Fig. 17

1920 Ranunculus gailensis E. M. Reid, Graines du Pont-deGail: 65-66, t. III, f. 2 - Pont-de-Gail (Unterpliozän).

1948 Ranunculus sceleratoides Nikitin, Dokl. Akad. Nauk SSSR 61: 1104 (nomen nudum) - Kireevskoe/Westsibirien (Miozän).

1951 Ranunculus sceleratoides Nikitin in Dorofeev, Bot. žurn. Akad. Nauk Ukrain. SSR 8: 35, t. 19 - Odessa (Obermiozän).

Material: Barchfeld MfN 2003/123; Oberzella MfN 2002/061 (Ob 021).

Beschreibung: Früchte fast kreisförmig im Umriß, schief, stark zusammengedrückt, mit breitem, abgeflachtem Saum um den größten Umfang. Seitenflächen mit 6-8 Querrunzeln. Durchmesser 0,9-1 $\mathrm{mm}$.

Bemerkungen: Eine Art, die Ranunculus sceleratus L. nahesteht, sich jedoch durch größere Früchte mit breitem Saum und eine stärker betonte Querrunzelung auszeichnet. Sie wurde in der russischen Literatur seit Nikitin (1948) immer als Ranunculus sceleratoides Nikitin bezeichnet (vgl. Dorofeev 1951; 1974). Eine Zuordnung zum Subgen. Batrachium D.C., wie von E.M. Reid (1920) vorgenommen, ist falsch. Das zeigte das Studium des Typus-Exemplares im British Museum N.H. in London, B. M. V 25581 (vidi am 6. 04. 1993) ganz eindeutig.

Vorkommen: Oligozän Sibiriens (Dorofeev 1974) und Obermiozän Osteuropas und der Lausitz (Mai 2001). Pliozän vom Ural bis Mitteleuropa (Mai \& Walther 1988); Altpleistozän in Weißrussland (Weliczkiewicz 1990).

Tafel 6. Flora von Oberzella. 1-2. Magnolia ultima Kirchheimer - MfN 2002/050. 1. Samen mit Basalkondylus. $\times 6,5.2$. Weiterer Samen von beiden Seiten; $\times 6,5$. 3. Magnolia cor Ludwig - MfN 2003/023. Samen mit großem Heteropylarkondylus; $\times$ 6,5. 4. Liriodendron geminata Kirchheimer - MfN 2003/067. Samen von beiden Seiten; $\times 12$. 5-7. Nuphar canaliculata C. \& E. M. Reid - MfN 2003/057. 5. Samen von der Seite; $\times$ 12. 6-7. Samen von apikal mit Deckelchen von Hilum und Mikropyle; $\times 12$. 8. Ceratophyllum pannonicum Dorofeev - MfN 2002/044. Frucht mit Griffelsäule und Dornansätzen von zwei Seiten; $\times$ 12. 9. Ranunculus reidii Szafer - MfN 2003/051. Frucht von der Seite mit Warzenstruktur; $\times 25.10-11$. Ranunculus trachycarpoides Dorofeev - MfN 2003/058. Verschieden große Früchte von der Seite; $\times 25$. 12. Thalictrum pliocenicum Dorofeev - MfN 2003/085. Nüsschen von beiden Seiten mit Längsrippen; $\times 25$. 13-14. Corylopsis urselensis Mädler - MfN 2003/001. Dehiszierendes Endokarp in zwei verschiedenen Stadien; × 6,5. 15. Pilea cantalensis (E. M. Reid) Dorofeev - MfN 2003/142. Nüsschen von beiden Seiten; $\times 25$. 16. Urtica dioica L. fossilis - MfN 2003/046. Nüsschen von beiden Seiten; $\times$ 25. 17. Zelkova ungeri Kováts - MfN 2003/088. Steinkern von dorsal und ventral; $\times 12$. 18-20. Ficus tambovica Dorofeev - MfN 2003/069. 18. Steinkern von beiden Seiten; $\times 25$. 19. Weiterer Steinkern von beiden Seiten, etwas verdrückt; $\times 25$. 20. Sehr schmaler Steinkern von beiden Seiten; $\times 25$. 


\section{Thalictrum minimum (Szafer) Martinetto}

Taf. 2, Fig. 16

1947 Carpinus minima Szafer. Rozpr. Wydz. Matcm.-przyrod. PAU 72, B 2: 66-68, pl. 5, figs 20-24 - Krościenko (Pliozän).

1988 Carpolithus minimus (Szafer) Mai \& Walther. Quartärpaläont. 7: 209, pl. 40, figs 14-17 - Berga (Oberpliozän).

2001 Thalictrum minimum Martinetto, Palaeontographica, B, 259: 157, t. 5, f. 4-5 - Stura (Mittleres Pliozän).

Material: Barchfeld MfN 2003/140.

Beschreibung: Nüsschen oval bis eiförmig, einfächrig, zweiklappig dehisziert. Basis gerundet, bisweilen mit Resten eines Stiels, apikal verschmälert, abgestutzt, mit polsterartiger Griffelbasis. Über die Oberfläche drei flache Rippen auf jeder Seite, die von der Basis ausgehend divergieren und sich apikal unterhalb des Griffelpolsters abrupt verlieren. Oberfläche großpunktat, bisweilen mit häutigen Fetzen eines Epikarps (oder einer Hülle). Wände relativ dünn, deutlich zweischichtig. Fach groß, innen glatt, ohne deutliche Reste eines Samens, aber von einem einzelnen Samen wohl völlig ausgefüllt. Länge 1,7-2,7 mm, Breite 1,2-2,0 mm.

Bemerkungen: Diese von Szafer (1947) völlig unzutreffend mit Carpinus polyneura Franch. verglichenen Nüsschen, deren Bestimmung Mai \& Walther (1988) und Mai \& Wähnert (2001) nicht gelungen ist, erfuhr neuerlich durch Martinetto (2001) eine Deutung als Thalictrum mit Beziehungen zu einer bislang unbestimmten heutigen Art aus Sichuan/China.

Vorkommen: Unter- bis Obermiozän in der Lausitz. Pliozän von Südpolen (Mai \& Wähnert 2001; Szafer 1947, 1954) und Unterpliozän bis Altpleistozän in Oberitalien (Martinetto 2001).

\section{Thalictrum pliocenicum Dorofeev}

Taf. 6, Fig. 12

1986b Thalictrum pliocenicum Dorofeev, Problem. Paleobotaniki: 64, t. V, f. 14-19 - Dvorec (Oberpliozän).

Material: Oberzella MfN 2003/085.

Beschreibung: Früchte ellipsoidal, länglich, bisweilen in der oberen Hälfte verbreitert, etwas gekrümmt, selten völlig gerade, apikal zugespitzt. Basis verengt und fließend in den Stiel übergehend oder abgestutzt, mit 8 bis 11 scharfen Rippen, zwischen denen sich breite Zwischenräume befinden, davon 3 mittlere Rippen auf jeder Seite niedriger als die anderen. Über den Grad der Rippen laufen die Leitbündel, eingesenkt in das Gewebe der Rippen. Bei einigen Früchten sind auch sehr dünne, unverdrückte Nebenrippen vor- handen. Perikarp insgesamt dünnwandig. Länge der Früchte 1,7-2,4 mm, Breite 0,6-1 mm.

Bemerkungen: Bei der Mehrzahl heutiger Arten, vor allem der europäischen, sind die Früchte deutlich dickwandiger. Nur wenige Arten aus Ostasien besitzen nach Dorofeev (1986b) dünnwandige und länglich-ellipsoidale Früchte, z. B. Th. squarrosum Steph. (Mandschurei). Entfernt ähnlich ist auch Th. kireevskianum Dorofeev (1963) aus dem Miozän Westsibiriens, welche weniger und etwas dickere Rippen besitzt.

Vorkommmen: Bisher nur im oberen Pliozän von Dvorec/Belorussland (Dorofeev 1986b).

\section{Hamamelidaceae}

\section{Corylopsis cf. urselensis Mädler}

Taf. 6, Figs 13-14

1939 Corylopsis urselensis Mädler, Abh. senckenb. naturforsch. Gesellsch. 446: 103; t. 8, f. 26-28 - Frankfurt a.M. (Mittleres Pliozän).

Material: Oberzella MfN 2003/001.

Beschreibung: Kapselrest einer Frucht. Endokarp dieser Frucht vom Exokarp ablösbar, oval-schief, $7 \mathrm{~mm}$ lang und ca. $3 \mathrm{~mm}$ breit, zweiklappig dehisziert, holzig-hornig, quergestreift, von mitlerer Wanddicke. Bisher ohne Samen.

Bemerkungen: Ein sehr ähnlich gebautes und ähnlich großes Endokarp hat Mädler (1939, Taf. 8, Fig. 26) bei der Typuskollektion von Corylopsis urselensis Mädler neben den typischen ungleichschenkligen Samen abgebildet. Ähnliche Endokarpien zeigt auch Dorofeev (1974, Taf. 122. Fig. 2) bei Corylopsis uralensis Dorofeev, so dass wir an einer Herkunft unseres Fossils von der Gattung Corylopsis Siebold \& Zuccarini nicht zweifeln. Sicherheit der Bestimmung würden die Samen geben.

Vorkommen: Miozän der Lausitz (Mai 2001). Pliozän des Maingebietes (Mädler 1939), Oberrheintal (Geissert 1972), Karpatenvorland (Szafer 1947, 1954) und Thüringen (Mai \& Walther 1988).

\section{Ulmaceae}

\section{Trema lusatica Mai}

Taf. 2, Fig. 22

1964 Trema lusatica Mai, Pal. Abh. Berlin, B 2: 22, Taf. IV, Figs 21-23 - Wiesa (Untermiozän).

Material: Barchfeld MfN 2003/139, 1 Expl. 
Beschreibung: Die dünnwandigen Steinkerne besitzen eiförmige Gestalt, häufig sind sie etwas verdrückt. Längs des größten Umfanges läuft eine abgerundete Kante, entlang der die Dehiszenz erfolgt. Von diesen Kanten gehen kürzere Wülste aus, die über die Seiten laufen, so dass die ganze Oberfläche buckelig erscheint. Durch kleine Querrunzeln wird fast ein Maschenwerk erreicht. Die Eintrittsstelle des die Plazenta innervierenden Leitbündels ist als kleiner, heller Fleck subapikal an der seitlichen Kante festzustellen. Die Dehiszenz beginnt an der gegenüberliegenden Kante unweit der Spitze. Sie läuft nicht über den gesamten Umfang, so dass nur ein langer Schlitz, nicht aber zwei Klappen entstehen. Samen im Innern nicht isoliert.

Länge 2,0 mm; Breite $1,9 \mathrm{~mm}$.

Bemerkungen: Die vergleichbare Gattung Trema Lour. ist mit etwa 30 Arten pantropisch vertreten. Fruchtmorphologisch zeigen die Arten große Einheitlichkeit, so dass für einen artlichen Vergleich mit unseren Fossilien keine Möglichkeit besteht.

Vorkommen: Unter- bis Mittelmiozän in der Lausitz (Mai 2001) und der Oberpfalz (Gregor 1975); Obermiozän von Hambach/Indener Schichten (MfN Berlin). Nun erster Fund im europäischen Pliozän.

\section{Moraceae}

\section{Ficus tambovica Dorofeev}

Taf. 6, Figs 18-20

1988 Ficus tambovica Dorofeev, Mioc. fl. Tambovsk. obl.: 100-101, t. XIX, f. 1-9, fig.-text. 17 - Berezovka/Tambov (Miozän).

Material: Oberzella MfN 2003/069.

Beschreibung: Endokarpien rundlich schiefeiförmig und nierenförmig, bikonvex, klein, nur 0,50-0,75 mm Durchmesser. Spitze (Stylarhöcker) oberhalb der subapikalen Plazenta schief und zur Ventralkante abgeschrägt. Basis gerundet und in die gewölbte Dorsalseite überleitend; einfächrig, in zwei gleiche Klappen dehiszierend. Wand dünn, zweischichtig, außen mit kleinen, dünnwandigen Sklerenchymzellen, innen Zellen länglich und stärker verdickt. Oberfläche fein punktat.

Bemerkungen: Diese Endokarpien sind merklich kleiner und dünnwandiger als die der bisher beschriebenen Arten Ficus potentilloides Mai (1964), F. europaea Negru (1972) und F. kolakovskyi Dorofeev (1982b). Sie wurden von Do- rofeev (1988) klar abgegrenzt und mit ostasiatischen Arten verglichen. Sehr nahe stehen Ficus tashirio Maxim. (Taiwan), F. gibbosa Bl. (Yünnan) und $F$. erecta Thunb. (Japan). Das Vorkommen einer exotischen Ficus-Art im Oberpliozän Thüringens ist sehr bemerkenswert.

Vork ommen: Miozän von Tambov (Dorofeev 1988).

\section{Urticaceae}

\section{Urtica dioica Linné fossilis}

Taf. 6, Fig. 16

1907a Urtica dioica L. fossilis C. \& E. M. Reid, Fl. of Tegelen: 20, t. 2, f. 75 - Tegelen (Oberstes Piozän).

Material: Oberzella MIN 2003/046.

Beschreibung und Bemerkungen: Mai \& Walther 1988, p. 118.

Vorkommen: Obermiozän in Belorussland (Dorofeev 1960a) und Polen (Raniecka-Bobrowska 1959). Pliozän in ganz Europa. Besonders häufig im Pleistozän.

\section{Fagaceae}

\section{Fagus spec. cf. deucalionis Unger}

Taf. 2, Fig. 21

1847 Fagus deucalionis Unger, Chloris protogaea: 101-103, Taf. 27, Figs $1-4$ (non Figs $5-6=$ fol.) - Počerna (Mitteloligozän).

1887 Fagus pliocenica Geyler \& Kinkelin, Abh. senckenberg. naturforsch. Gesellsch. 15: 23, Taf. 2, Figs 9-10-Niederrad (Pliozän).

Material: Barchfeld MfN 2003/151 (Ba 004).

Beschreibung: Früchte (Nüsse) dreieckig-eiförmig, relativ kurz und breit, besonders im oberen Teil flügelkantig, metallisch glänzend, schwarz, $8 \mathrm{~mm}$ lang und $5 \mathrm{~mm}$ breit.

Bemerkungen: Da bisher keine Kupulen gefunden wurden, ist die artliche Zuordnung der Nüsse nahezu unmöglich. Sie werden wegen ihrer geringen Größe und eiförmigen Form mit Vorbehalt zu Fagus deucalionis Unger (1847) gestellt.

Es ist auch sehr schwierig, die Kupulen und Früchte der nahe verwandten Arten $F$. decurrens C. \& E. M. Reid (1915) und F. deucalionis Unger (1847) zu differenzieren (zu dieser Problematik vgl. auch Denk 2002).

Vorkommen: Oberoligozän bis Pliozän in Europa, zeitweise häufig, im Osten bis ? Westsibirien (Dorofeev 1982b). 


\section{Betulaceae}

\section{Alnus lusatica Mai}

Taf. 7, Figs 1-7

1987 Alnus lusatica Mai, Feddes Repert. Berlin 98: 111-112. Taf. VI, Figs 4-10; Abb. 1a-c - Schlabendorf-Süd (Untermiozän).

Materia1: Oberzella MfN 2002/046 (Ob 006, 035).

Beschreibung: Fruchtkätzchen (Strobili) länglich-elliptisch, stets mehr als doppelt so lang wie breit. Schuppen sehr locker stehend, mit tief gelapptem Vorderrand, innerste Vorblätter gut entwickelt, meist über große Strecken frei, alle Vorblätter in der Regel länger als das dreieckige, ledrige Deckblatt. Strobili bis $18 \mathrm{~mm}$ breit. Breite der Schuppen bis $4,5 \mathrm{~mm}$. Früchte (Nüsschen) länglich-rhombisch bis eiförmig, zugespitzt, mit 2 Griffelnarben, schmal und dünn geflügelt, basal mit breitem Hilum. Früchte $1,5-3.3 \mathrm{~mm}$ lang; $1,3-2,8 \mathrm{~mm}$ breit, $\mathrm{z}$. T. aus Strobili isoliert.

Bemerkungen: Nach der Länge der Strobili und den tief geteilten, relativ kurzen Schuppen eine Art aus dem Subgen. Clethropsis Spach, zu der die Arten $A$. nitida Endl. (Himalaja, Kashmir) und $A$. nepalensis D. Don (Sikkim, Nepal, Assam, Burma, Yünnan, Kweichow) gehören. Am nächsten steht davon $A$. nitida, auch was die Größe der Schuppen und Früchte anbelangt.

Vorkommen: Oberoligozän bis Pliozän in West- und Mitteleuropa, teilweise häufig (Mai 1987).

\section{Corylaceae}

\section{Carpinus miocenica Negru}

Taf. 1, Fig. 18

1969 Carpinus miocenica Negru, Bot. Žurn., 54: 763-765. Taf. 1. figs 9-15, Taf. 2, figs 1-4 - Bursuk (Mittelmiozän).

Material: Kaltensundheim MfN Ka 9747.
Beschreibung: Nüsschen kleiner als die von Carpinus betulus L., auffällig eiförmig bis rundlich dreieckig, 3,5-4,5 $\mathrm{mm}$ lang, 3-3,5 $\mathrm{mm}$ breit, mit Basiswinkel von mehr als $150^{\circ}$. Apex ohne Griffelrest. Rippen 3-6 auf jeder Seite, aber nur schwach entwickelt. Perikarp dünn, aus kleinen Zellen, die nur im Mittelteil größer werden.

Bemerkungen: Involukren dieser Art, die sehr typisch sind, wurden am Fundort Kaltensundheim nicht nachgewiesen. Aber die Nüsschen weichen von C. betulus L. ab und vereinigen Merkmale von C. caroliniana Walt. und C. laxiflora Bl.

Vorkommen: Mittel- bis Obermiozän, vielleicht bis Pannon (Berger 1953, Mai 2001); nun auch Pliozän.

\section{Myricaceae}

\section{Myrica goretskyi Dorofeev}

Taf. 1, Fig. 19

1967a Myrica goretskyi Dorofeev, Nizhn. Pleistocen lednik. rajon. Russk. ravniny: 108 , Tabl. 3, Figs $20-25-$ Sivkovo/Belorussl. (Unterpliozän).

Material: Kaltensundheim MfN Ka 9732, 1 Expl.

Beschreibung: Endokarp eiförmig bis fast ellipsoidal, bikonvex, zweiklappig, klein, nur 1,3 $\mathrm{mm}$ lang und $1,2 \mathrm{~mm}$ breit. Basis verschmälert, mit kurzem Stielchen. Apex zugespitzt bis zugerundet, mit kurzem Griffelansatz. Seiten zusammengedrückt, mit Kante, in der Mitte eine Schwiele mit Ansatz des Flügels, undeutlich. Wände von mäßiger Dicke, aus bis zur Unkenntlichkeit verdickten Zellen, aus der einige rundliche Sklereiden hervortreten.

Bemerkungen: Eine Art mit den Merkmalen der Sektion Myrica, die nahe mit der europäischen Myrica gale L. verwandt ist. Zur Gale-Gruppe rechnet Dorofeev (1994) 7 Arten, die in Asien von der oberen Kreide bis ins Pleistozän vorkommen.

Tafel 7. Flora von Oberzella. 1-7. Alnus lusatica Mai - MfN 2002/046. 1. Fruchtkätzchen von beiden Seiten; $\times 5.2$. Apikales Ende eines Fruchtkätzchen; $\times 5$. 3. Schuppen von innen und außen; $\times 10.4$. Weitere Fruchtschuppe mit gut entwickelten Vorblättern im Inneren; $\times 10.5$-7. Nüsschen verschiedener Form und Größe aus dem Fruchtkätzchen Fig. 2; $\times 12.8$. Alnus tanaitica Dorofeev - MfN 2003/065. Zerbrochenes Nüsschen mit Griffelrest; $\times 12$. 9-10. Betula cholmechensis Dorofeev MfN 2003/066. Schlankes Nüsschen ohne Flügelreste von beiden Seiten: $\times 12$. 10. Breiteres Nüsschen; $\times 12.11$. Betula digitata C. \& E. M. Reid - MfN 2003/040. Nüsschen ohne Flügelreste; $\times 20$. 12-13. Humulus scabrellus Dorofeev - MfN 2003/089. 12. Frucht mit deutlichem Plazentapfropf an der Seite: $\times 20$. 13. Weitere Frucht von fast kugeliger Gestalt; $\times 20$. 14-16. Pterocarya limburgensis C. \& E. M. Reid - MfN 2002/048. 14. Endokarp (Nuss) mit breit ausladenden Flügelrippen; $\times 6.5$. 15-16. Spalthälften von Nüssen von der Seite: $\times$ 6.5. 17-18. Polvgonum wolfii (Kinkelin) Mädler - MfN 2002/054. 17. Nüisschen mit basalen Perigonresten; $\times 20$. 18. Weiteres Nüsschen von länglicher Gestalt; $\times 20$. 19. Polygonum pliocenicum Dorofeev - MfN 2002/052. Nüsschen mit basalem Perigonrest; $\times 2$ 25. 20. Rumex hydrolapathum Hudson fossilis - MfN 2003/ 108. Nüsschen mit Resten des Perigons und der seitlichen Schwielen; $\times 2$ 25. 21. Hypericum tertiaerum Nikitin - MfN $2003 / 034$ Samen von zwei Seiten: $\times$ 40. 22-23. Hypericum androsaemum L. fossilis - MfN 2003/050. Samen in zwei Ansichten; $\times 40$. 24. Trichosanthes fragilis E. M. Reid - MfN 2002/042. Samen von beiden Seiten; $\times 6,5$. 


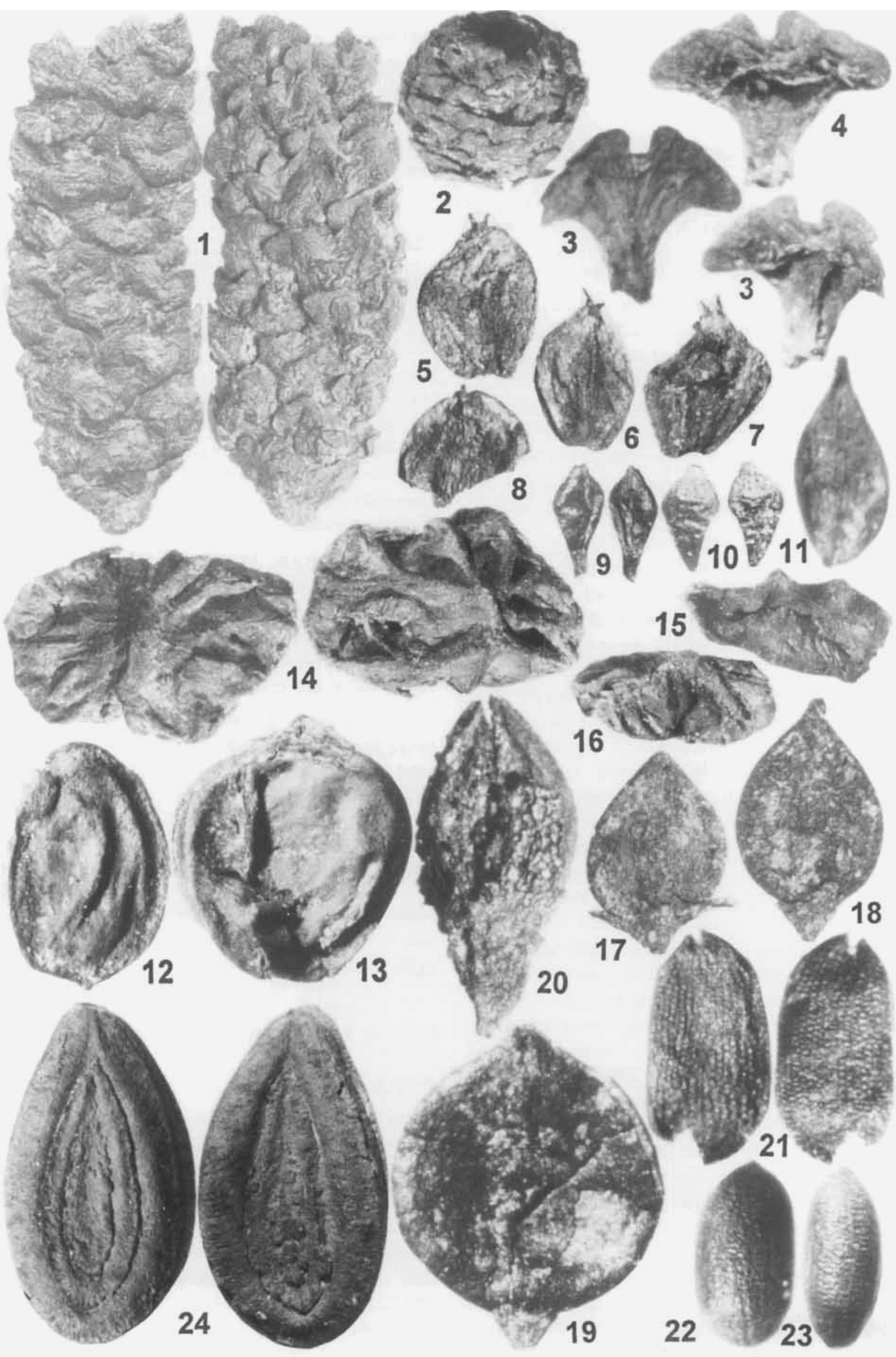


Vorkommen: Obermiozän bis Pliozän in Weißrussland; Mittelpliozän der Kinel'-Suite (Dorofeev 1967a, 1994).

\section{Juglandaceae}

\section{Pterocarya limburgensis C. \& E. M. Reid}

Taf. 7, Figs 14-16

1915 Pterocarya limburgensis C. \& E. M. Reid. Plioc. Fl. Dutch-Prussian border: 73 , t. 4, f. 15-21 - Reuver (Oberpliozän)

Material: Oberzella MfN 2002/048 (Ob 008).

Beschreibung: Endokarpien (Nüsse) im oberen Teil am breitesten, nach unten verschmälert, an der Spitze abgestutzt und mit einem sehr kleinen Griffelspitzchen, seitlich zusammengedrückt, mit gewöhnlich stumpfen, bisweilen anastomosierenden, flügeligen Rippen. Sekundäre Septen einfach, vor dem Fach aufgewölbt, aber nicht als Hörner oder Lappen entwickelt, im apikalen Teil mit großen bis sehr großen Lakunen. Durchmesser $6,5-8 \mathrm{~mm}$.

Bemerkungen: Nach C. \& E. M. Reid (1915) mit Pt. hupehensis Scan (Mixed Mesophytic Forests in China) am besten vergleichbar. Nach Il'jinskaja (1953: 76) ist Pt. limburgensis ,zweifellos analog zu Pt. pterocarpa (Michx.) Kunth (= Pt. fraxinifolia (Lam.) Spach)". Auch nach Kirchheimer (1957: 510-511) ist der von Reid erwähnte Vergleich mit Pt. hupehensis irrtümlich, da die größere Breite der fossilen Früchte (welcher?) im unteren Drittel des Endokarps läge. Czeczott et al. (1961) vereinigen miozäne Früchte sogar mit Pt. stenoptera C. DC. Bis $\mathrm{zu}$ einem gewissen Grade haben alle Autoren recht. Pt. limburgensis C. \& E. M. Reid bezeichnet ursprünglich apikal sehr breite Früchte. In den Populationen stecken aber auch schmälere, eiförmige Früchte vom Aussehen der Pt. fraxinifolia und solche mit Merkmalen der Pt. stenopte$r a$. Wahrscheinlich hat sich aus dem tertiären europäischen Formenkreis besonders Pt. fraxinifolia (Lam.) Spach ab Obermiozän abgespalten, während die Verwandtschaftsbeziehungen zu den ostasiatischen Arten lockerer waren und die Merkmale dieser Formen durch Aussterben des Pt. limburgensis-Formenkreises in Europa allmählich verloren gingen. Jedenfalls tendierte die Population im mittleren und oberen Miozän sehr stark zu Pt. hupehensis und Pt. stenoptera, auch im Bau des vorgewölbten sekundären Septums und der geringfügig erhobenen Griffelspitze. Im Pliozän tritt Pt. limburgensis sehr stark gegenüber der Pt. fraxinifolia zurück.
Im Tegelen ist sie (entgegen der bei C. \& E. M. Reid 1915: 73 geäußerten Meinung) kaum noch vorhanden.

Vork om men: Untermiozän bis Obermiozän in Mittel- und Osteuropa (Mai 2001); in Westeuropa besonders Pliozän (C. \& E. M. Reid 1915, Kilpper 1959, Geissert 1972); selten Altpleistozän (Baas 1932).

\section{Chenopodiaceae}

\section{Chenopodium spec.}

Taf. 2, Figs 24-28

Material: Barchfeld MfN 2003/119.

Beschreibung: Samen von linsenförmiger Gestalt, nicht größer als $1,5 \mathrm{~mm}$, mit Bruchstücken der schwarzglänzenden Testa. Im Innern mit eingerolltem, durchscheinendem, häutigem Tegmen, über dessen seitlichen Rand als Fortsatz die Radikula ein wenig hinausragend. Chalaza oft als kreisrunder, dunkler Fleck unterhalb des Radikula.

Bemerkungen: Die Arten von Chenopodium L. lassen sich nach der Beschaffenheit der Testaoberfläche gut voneinander unterscheiden, weniger wichtig sind Form und Größe. Die TestaBruchstücke unseres Materials lassen $C h$. album L. fossilis vermuten.

Vorkommen: Chenopodium tritt fossil erstmalig im oberen Mittelmiozän auf (Gregor 1984), wird im Pliozän und besonders Pleistozän sehr artenreich (10-12 Arten; Mai \& Walther 1988).

\section{Polygonaceae}

\section{Rumex hydrolapathum Hudson fossilis}

Taf. 7, Fig. 20

1907b Rumex hydrolapathum Huds. fossilis C. \& E. M. Reid, J. Linn. Soc. 38: 219, t. 14, f. 128 - Castle Eden (Altpleistozän).

Marterial: Kaltensundheim MfN Ka 9746; Oberzella MfN 2003/108

Beschreibung: Mai \& Walther 1988, p. 145.

Bemerkungen: In Oberzella ließen sich auch Reste der Perigonblättchen mit der großen, länglichen Schwiele nachweisen. Sie sind sehr charakteristisch für die angeführte Art.

Vorkommen: Ab Oberpliozän am Dnjepr (Weliczkiewicz 1975), in Thüringen (Mai \& Walther 1988) und Altpleistozän am Main (Baas 1932). In Interglazialen von Großbritannien (C. \& E. M. Reid 1907b) bis in die Ukraine (Woronesh; Nikitin 1957). 


\section{Hypericaceae}

\section{Hypericum foveolatum Dorofeev}

Taf. 1, Figs 20-21; Taf. 3, Figs 2-4

1986b Hypericum foveolatum Dorofeev, Problemy Paleobot.: 66, Taf. VIII, Figs 26-39 - Dvorec (Oberpliozän).

Material: Barchfeld MfN 2003/135; Kaltensundheim MfN Ka 9720.

Beschreibung: Samen zylindrisch, leicht bis kräftig gebogen, mit gerundeter Basis und Spitze, gekrönt mit einem kleinen, warzenartigen Buckel, der Chalaza und Mikropyle trägt. Oberfläche grubig. Grübchen mittelgroß, sechseckig, quer zur Samenachse gekrümmt, bis fast isodiametral oder schmal und hoch, in nicht sehr deutlichen Längsreihen angeordnet. Samen $0,65-1,05 \mathrm{~mm}$ lang und $0,25-0,35 \mathrm{~mm}$ breit.

Bemerkungen: Nach Dorofeev (1986b) besitzen eine Reihe von europäischen, ostasiatischen und nordamerikanischen Arten ähnlich skulpturierte Samen. Besonders ähnliche große Grübchen hat die Oberfläche der Samen von $H$. yezoense Maxim. und $H$. elegans Steph. aus dem Fernen Osten.

Vorkommen: Bisher nur Oberpliozän von Weißrussland (Dorofeev 1986b; Weliczkiewicz 1990).

\section{Hypericum tertiaerum Nikitin}

Taf. 7, Fig. 21

1957 Hypericum tertiaerum Nikitin, Plioc. i četvert. fl. Voronež. obl.: $169-170$, t. 6 , f. 50,51 ; textf. $25 / 2,3-$ Krivobor'je/Don (Oberpliozän).

Material: Kaltensundheim MfN Ka 9732; Oberzella MfN 2003/034.

Beschreibung: Mai \& Walther 1988, p: 147.

Bemerkungen: Samen aus dem Pliozän Thüringens von derartiger Bauform wurden von Mai \& Walther 1988: 147 als zwei unterschiedliche Arten ( $H$. perforatum L. fossilis und $H$. tertiaerum Nikitin) aufgefasst. Die Samen aus Gerstungen, Kaltensundheim und Kranichfeld lassen sich aber voneinander nicht abgrenzen und gehören mit der nunmehr vorliegenden Population aus Oberzella (33 Exemplare) zu $\mathrm{Hy}$ pericum tertiaerum Nikitin. Diese Art ist der $H$. elodes L.-Gruppe (atlantisches Europa) nahestehend.

Vorkommen: Pliozän von Osteuropa häufig, Reuver und Tegelen von Holland, Mizerna in den Vorkarpaten. In Deutschland ab Untermiozän (Mai 2000a).

\section{Salicaceae}

\section{Salix spec.}

ohne Abbildung

1997 Salix spec. Mai, Palaeontographica, B 244: 51, Taf. 8, Fig. 15 - Niederheide NSL 35/65 (Oberoligozän).

Material: Oberzella MfN 2002/051 (Ob 011).

Beschreibung: Tütenförmige, bräunliche, durchscheinende Blattknospen mit einer einzigen geschlossenen Schuppe, abgerundet, bis $5 \mathrm{~mm}$ lang, basal abgestutzt bis abgeschnitten.

Bemerkungen: Ähnliche nur bis zur Gattung bestimmbare Knospenschuppen wurden in der Literatur nur selten behandelt (vgl. Mai, Majewski \& Unger 1963 aus dem Pliozän von Rippersroda/Thür.).

Vorkommmen: Oberoligozän bis Pleistozän.

\section{Symplocaceae}

\section{Symplocos Casparyi Ludwig}

Taf. 8, Fig. 3

1857 Symplocos casparyi Ludwig, Palaeontographica 5: 99, t. 20, f. 6a-f - Docheim (Pliozän).

1867 Carpolithus lignitarum Quenstedt, Handb. Petrefaktenkde., 2. Aufl.: 914, t. 86, f. 35, 41 - Salzhausen (Mittelmiozän).

1920 Symplocos jugata E. M. Reid, Graines du Pont-de-Gail: 73-74, t. 4, f. 7 - Pont-de-Gail (Unterpliozän).

1950 Symplocos lignitarum Kirchheimer, Palaeontographica, B 90: 14-15, t. 1, f. 4, t. 2, f. 15 - Salzhausen (Mittelmiozän).

Materia 1: Oberzella MfN 2002/060 (Ob 020).

Beschreibung: Steinkerne eiförmig bis gestreckt, gewöhnlich walzenförmig, $5 \mathrm{~mm}$ lang, 4,2 $\mathrm{mm}$ breit, mit 6-10 mehr oder weniger entwickelten, nicht selten verbundenen Längsrippen, in der Anlage gewöhnlich 3-fächrig. Fächer nicht selten etwas ungleich entwickelt, die an der flachen Spitze befindliche Grube seicht, rundlich bis dreieckig, häufig breiter als die Hälfte des Steinkerns. Endokarp mit Kristallidioblasten. Exokarp fleischig, sehr dick.

Bemerkungen: Häufig gebrauchte jüngere Synonyme sind S. lignitarum (Quenst.). Kirchheimer (1950) und S. jugata E. M. Reid (1920). Vergleichbare Arten der heutigen Flora nach dem Bau der Steinkerne sind S. yunnanensis Brand (Südchina, Thailand) und $S$. touranensis Guill. (Südvietnam $)=$ S. macrophylla Wall.

Vorkommen: Unteroligozän (Mai \& Walther 1978) bis tieferes Pliozän (Reid 1920, Zagwijn 1959); nun auch Oberpliozän (Oberzella). 


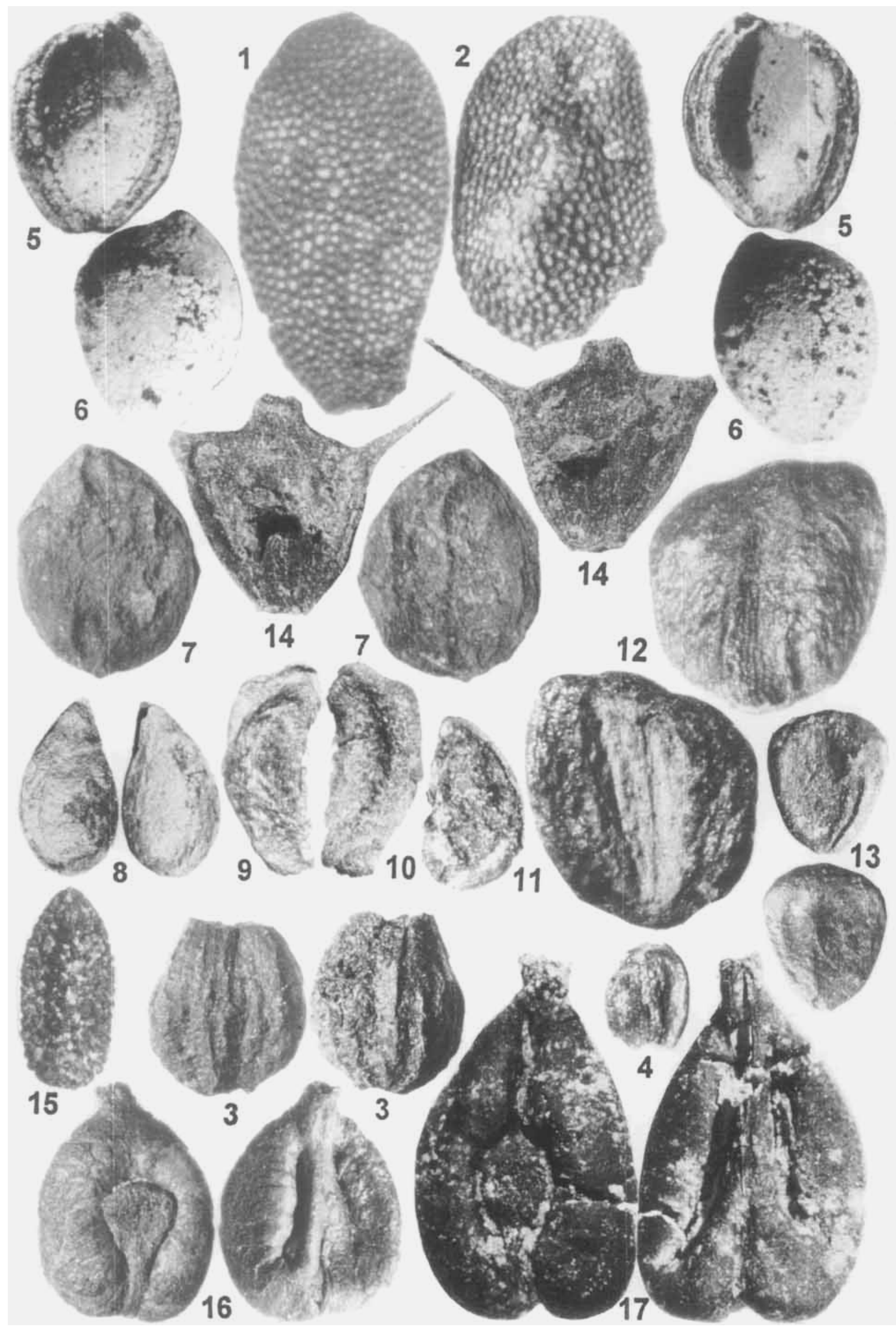




\section{Iteaceae}

\section{Itea europaea Mai}

Taf. 8, Fig. 4

1985 Itea europaea Mai, Gleditschia 13 (1985) 1: 84-85, Taf VI, Fig. 1 - Berzdorf (Untermiozän).

Material: Oberzella MfN 2003/105, 1 Expl.

Beschreibung: Samen zusammengedrückt, schief-eiförmig bis länglich, mit deutlicher Raphekante. Oberfläche der Testa deutlich gefeldert, mit beiderseitig mindestens 12-15 Längsreihen großer, polygonaler, perlschnurartig hervortretender Zellen, etwas glänzend, am schräg angeordneten Hilum dehiszierend. Samen 1,5 mm lang und $1,0 \mathrm{~mm}$ breit.

Bemerkungen: Nach der Beschaffenheit der Samen ist die fossile Art Europas mit der heutigen nordamerikanischen $I$. virginica L. am besten vergleichbar. Diese Art ist sehr typisch für die immergrünen Pocosion-Moorgehölze.

Vorkommen: Miozän bis Pliozän in Europa, von der Balkanhalbinsel bis an den Niederrhein (Mai \& Palamarev 1997).

\section{Rosaceae}

\section{Potentilla cf. heptaphylla Linné fossilis}

Taf. 3, Fig. 5

1977a Potentilla spec. 2 Dorofeev, Fauna i flora Simbugino: 68, tabl. XI, f. 22-25 - Simbugino/Baschkirien (Oberpliozän).

Material: Barchfeld MfN 2003/129.

Beschreibung: Nüsschen $0,9-1,3 \mathrm{~mm}$ lang und $0,7-0,8 \mathrm{~mm}$ breit, länglich-nierenförmig, bikonvex, mit einem tuberkulaten Griffelansatz nahe unter dem Apex. Dorsalseite uniform konvex, gerundet. Oberfläche glatt, ohne Zeichnung. Wände mäßig dick aus kleinen Zellen.

Bemerkungen: Die Nüsschen sind im ganzen $P$. pliocenica E. M. Reid (1921) ähnlich, aber viel schmäler und etwas mehr gestreckt, ohne Vor- sprung der Ventralseite. Sehr ähnlich sind die Nüsschen von $P$. heptaphylla L., aber auch $P$. alba L., $P$. humifusa Willd. und $P$. virgata Lehm. Eine endgültige Bestimmung war bisher nicht möglich.

Vorkommen: Oberpliozän von Baschkirien (Dorofeev 1977a) und Belorussland.

\section{Rubus spec.}

ohne Abbildung

Material: Oberzella MfN 2003/096, 1 Bruchst

Beschreibung: Steinkerne abgeflacht mit halbkreisförmig gewölbtem Rücken, Ventralseite fast gerade oder schwach gebogen. Oberfläche netzig-grubig, mit Netzrippen. Nur ein Bruchstück von $1,5 \mathrm{~mm}$ Länge.

Bemerkungen: Wahrscheinlich eine Art des Subgen. Ideobatus Focke, die sich nach dem vorliegenden Bruchstück nicht bestimmen lässt.

\section{Malaceae}

\section{Pyracantha angusticarpa (E. M. Reid) Mai}

Taf. 8, Figs 9-11

1923 Crataegus angusticarpa Reid, Graines du Pont-de Gail: 325, Taf. X, Fig. 18 - Pont-de-Gail (Unterpliozän).

2000a Pyracantha angusticarpa Mai, Palaeontographica, B 253: 5, Taf. 2, Figs 1-4 - Spremberg $37 / 60$ u. $11 E / 58$ (Untermiozän).

Materia 1: Oberzella MfN 2003/109, 2 Expl.

Beschreibung: Steinkerne schmal apfelsinenscheibenförmig, länglich, zu fünft in der Frucht, in der Mitte am breitesten. Ventralkante mehr oder weniger gerade. Seitenfläche glatt. Dorsalseite gebogen, mit geriefter, rauher Oberfläche. Hypostyl nur die Gipfelregion bedeckend, deutlich abgesetzt, auf der Ventralseite herabziehend, selten auch fast fehlend. Wände dünn. Länge $3,0-4,5 \mathrm{~mm}$, Breite $1,5-2,5 \mathrm{~mm}$.

Bemerkungen: Die Steinkerne sind im Gegensatz zu anderen bekannten Arten schmallänglich, mit 3,5 mm etwas größer, und zeigen

Tafel 8. Flora von Oberzella. 1-2. Actinidia faveolata C. \& E. M. Reid - MfN 2003/074. 1. Großer Samen; $\times 20.2$. Weiterer Samen mit seitlichem schrägem Hilum; $\times 20$. 3. Symplocos casparyi Ludwig - MfN 2002/060. Steinkern von zwei Seiten; $\times 6$ 6.5. 4. Itea europaea Mai - MfN 2003/105. Samen von der Seite; $\times 25$. 5-6. Prunus schlechtendalii Mai - MfN 2003/005. 5 . Ansicht des Faches bei einem dehiszierten Steinkern; $\times 10.6$. Oberfläche des Endokarps von Fig. $5 ; \times 10.7$. Prunus tenerirugosa Mai - MfN 2003/086. Steinkern von zwei Seiten; $\times$ 10. 8. Pyrus microsperma Mai - MfN 2003/110. Samen von beiden Seiten; $\times$ 10. 9-11. Pyracantha angusticarpa (E. M. Reid) Mai - MfN 2003/109. 9. Dehiszierter Steinkern mit Samen im Fach; $\times$ 10. 10. Rückseite des Steinkerns von Fig. $9 ; \times 10.11$. Weiterer Steinkern von elliptischer Form; $\times 10.12$. Microdiptera menzelii (E. M. Reid) Mai - MfN 2002/063. Samen von ventral und dorsal; $\times 25$. 13. Decodon globosus (E. M. Reid) Nikitin - MfN 2002/040. Samen von ventral (mit Keimklappe) und dorsal; $\times 20$. 14. Trapa heerii Fritsch - MfN 2002/041. Frucht mit Hörnern von beiden Seiten; $\times$ 5. 15. Sambucus pulchella C. \& E. M. Reid - MfN 2002/056. Samen; $\times 15$. 16. Ampelopsis macrosperma Dorofeev - MfN 2002/047. Samen von ventral und dorsal; $\times 10$. 17. Vitis cf. sylvestris Gmelin fossilis MfN - 2002/055. Samen von ventral und dorsal; $\times 10$. 
ein sehr kleines, nur in der Apikalregion vorhandenes Hypostyl. Von der Größe und Form her paßt zum Vergleich am besten $P$. rogersiana (Jacks.) Bean aus Südwestchina.

Vork ommen: Untermiozän von Goitsche, Bitterfeld (Mai \& Walther 1991) und Lausitz (Mai 2000a); Obermiozän des Rheinlandes (Van der Burgh 1987) und Unterpliozän des Cantal (E. M. Reid 1923).

\section{Pyrus microsperma Mai}

Taf. 8, Fig. 8

1991 Pyrus microsperma Mai in Mai \& Walther. Abh. Staatl. Mus. Mineral. Geol. Dresden 38: 96--97. Taf. 11. Fig. 12 - Borna-Ost (Oberoligozän).

Material: Oberzella MfN 2003/110. 3 Expl.

Beschreibung: Samen schief-verkehrt-eiförmig bis schief oval, abgeflacht, klein, an einem Ende zugespitzt, am anderen Ende mehr gerundet, mit saumartiger Kante, besonders an der ventralen Seite. Hilum als ovale Vertiefung seitlich am spitzen Ende. Raphe als deutliche ventrale Kante mit dünnem Leitbündel. Dehiszenz in zwei gleiche Klappen vom Hilum beginnend und längs der Raphe fortschreitend. Testa derb, etwa $0,2 \mathrm{~mm}$ dick, oberflächlich feinpunktat durch rundliche, vieleckige Zellen, die sich in Längsreihen anordnen, matt. Innen im Fach mit quergestellten, sich etwas kreuzenden Faserzellen, die eine Querstreifung und matten Glanz ergeben. Länge der Samen 2,5-4,5 mm, Breite 1,5-2,3 mm (im Mittel 4-2 mm).

Bemerkungen: Ein kleiner Pyrus-Samen, der sich durch Form, Oberflächenzellstruktur, Hilumund Raphemerkmale sowie Fachstreifung als zu Pyrus gehörig erweist. Bisher konnten von etwa 65 rezenten nur 5 häufiger kultivierte Arten zum Vergleich beschafft werden, die sich alle durch größere Samen auszeichneten. Die im Obermiozän und Pliozän nachgewiesene Pyrus communis L. fossilis hat ähnliche, aber größere Samen (Mädler 1939, Szafer 1947).

Vorkommen: Oberoligozän von Nordwestsachsen (Mai \& Walther 1991). Mittelmiozän und Obermiozän (Mai 2001). Im Pliozän bisher Neufund.

\section{Amygdalaceae}

\section{Prunus schlechtendalii Mai}

Taf. 8, Figs 5-6

1984 Prunus schlechtendalii Mai, Feddes Repert. 95: 317. Taf. 48. Figs 1-2 - Goitsche (Untermiozän).

Material: Oberzella MfN 2003/005.
Beschreibung: Steine fast kugelig bis rundlich-eiförmig, stumpf, klein, nur 3-6 $\mathrm{mm}$ lang und $2,5-4 \mathrm{~mm}$ breit, ohne Ventralwulst oder hervortretende Naht. Schalenhälften nicht besonders dickwandig, nur bis $0,5 \mathrm{~mm}$ stark. Leitbündelkanal etwa in der Mitte auf das Fach treffend.

Bemerkungen: Eine Art aus dem Subgen. Padus (Moench) Focke mit kleinen Steinen. Prunus alabamensis Mohr (atl. Nordamerika von Ontario bis Florida) hat ähnlich geformte, glatte, kleine Steine. Auch P. virginiana L. (westl. Nordamerika) hat glatte Steine mit fast fehlendem Ventralwulst.

Vorkommen: Untermiozän von Bitterfeld und der Oberlausitz (Mai 1984), in der Niederlausitz bis ins Obermiozän an einigen Fundorten (Mai 2001). Im Pliozän bisher Neufund.

\section{Prunus tenerirugosa Mai}

\section{Taf. 8, Fig. 7}

1984 Prunus tenerirugosa Mai, Feddes Repert. 95: 320, Taf. 50, Figs 6-9 - Sessenheim (Oberpliozän).

Material: Oberzella MfN 2003/086.

Be schreibung: Steine subglobular, abgeflacht, ohne deutliches Stielchen, nur mit kurzem dickem Fuß; 4,0 mm lang und 3,5 mm breit. Leitbündelkanal im oberen Drittel das Fach erreichend. Oberfläche der Steine mit niedrigen, flachen Rippen und Runzeln, die basal als deutliche Längsrippen, apikal nur noch als stumpfe Buckel ausgebildet sind. Ansatzstelle rundlich, ventrale Naht wulstig.

Bemerkungen: Vergleich mit Sect. Phyllomahaleb (Koehne) Rehd., ähnlich $P$. maximowiczii Rupr. (Japan, Sachalin, Korea, Mandschurei und Amurgebiet); mit dem Namen der heutigen Art nicht zu bezeichnen, da Unterschiede in geringerer Anzahl basaler Längsrippen sowie deren Höhe und Verlauf vorhanden sind. Viel kleinere Steine besitzt $P$. maackii Rupr. (Korea, Mandschurei, Ferner Osten).

Vorkommen: Möglicherweise schon im Mittelmiozän von Schlesien (Szafer 1961 als „Pr. maximowiczii fossilis"). Im Pliozän Brunssum und Reuver/Limburg (C. \& E. M. Reid 1915), Elsass (Mai 1984), Weißwasser-Nochten/Oberlausitz (Mai \& Wähnert 2000), Tegelen/Holland (C. \& E. M. Reid 1910).

\section{Microdiptera menzelii (E. M. Reid) Mai}

Taf. 3, Fig. 7; Taf. 8, Fig. 12

1927 Diclidocarya menzelii Reid, J. Botany 65: 3 , t. 580, f. 1-7 - Kausche (Obermiozän). 
1972 Mneme menzelii Eyde, Brittonia 24: 114.

1987 Microdiptera menzelii Mai, Feddes Repert. Berlin 98: 113, Taf. VII, Figs 11-12 - Kausche (Obermiozän).

1988 Microdiptera sibirica Mai in Mai \& Walther, Quartärpaläontol. 7: 166, Taf. XXXI, Figs 8-11 - Berga (Pliozän).

Material: Barchfeld MfN 2003/149; Oberzella MfN 2002/063 (Ob 018).

Beschreibung: Samen trapezoidal bis breiteiförmig, flachgewölbt, mit einem länglichen Deckelchen (Keimklappe) in der unteren Hälfte der Ventralseite und mit zwei tiefen oder seichten Furchen beiderseits der Raphe auf der Dorsalseite. Testa gestreift, dick, seitlich stark verdickt oder kantig. Samen 1,2-1,7 mm lang und $1,2-2,0 \mathrm{~mm}$ breit.

Bemerkungen: Das Fossilmaterial aus dem Thüringer Pliozän (Berga, Gerstungen) wurde vor der Untersuchung der Kauscher Population (Locus typicus, Obermiozän) zur westsibirischen Art M. sibirica (Nikitin 1929) Mai (1988) gestellt. Es sollte sich von der länger bekannten Microdiptera menzelii (E. M. Reid) Mai besonders durch die beiden tiefen Rinnen längs der Raphe, die meist trapezoidale Form mit größter Breite oberhalb der Keimklappe unterscheiden. Diese Merkmale variieren aber in der Typuspopulation und auch bei dem Fossilmaterial aus Oberzella so stark, dass diese Trennung nicht aufrecht gehalten wird. Auch die Barchfelder Fossilien mit mehr oder weniger kantigen und flügelartigen Seiten lassen sich nicht zu M. sibirica (Nikitin) Mai \& Walther 1988 stellen, sondern nur zu $M$. menzelii (E. M. Reid) Mai (1987). Damit ist ein mehrmaliger mitteleuropäischer Nachweis der Art im Pliozän gegeben.

Vorkommen: Ab mittlerem Miozän in ganz Europa. Pliozän bisher nur noch Bulgarien ( $\mathrm{Pa}$ lamarev 1970). Im Oligozän-Miozän auch Westsibirien und Jakutien (Dorofeev 1963, Dorofeev \& Tjulina 1962).

\section{Onagraceae}

\section{Ludwigia chandlerae Knobloch}

Taf. 3, Fig. 25

1963 Ludwigia palustris (L.) Ell. fossilis Mai, Majewski \& Unger, Geologie 12 (7): 786, t. IV, f. 14-15 -- Rippersroda (Oberpliozän).

1988 Ludwigia chandlerae Knobloch, Tertiary Res. 9 (1-4): 109-110. pl. 2, figs. $1-10-$ Strekov b. Komárno (Pont).

Material: Oberzella MfN 2003/098, 4 Expl.

Beschreibung: Samen länglich-schief-eiförmig, 0,3-0,4 mm breit, ohne subapikales Anhängsel. Mit schiefem, spitzem oder stumpfem chalazalem Pol. Raphe als erhabene Leiste über die ganze Länge des Samens verlaufend. Testa lederartig, deutlich strukturiert, mit quer-punktater Zellstruktur. Zellen in Längsrichtung angeordnet.

Bemerkungen: Knobloch (1988) fasst alle mit den Samen von Ludwigia palustris (L.) Elliott verglichenen fossilen Reste unter $L$. chandlerae Knobloch (1988) zusammen. Die heute einzige Art mit submediterran-atlantischem Areal und Teilarealen in Westasien, Nord- und Südafrika sowie Nordamerika (Vogelverbreitung) besitzt sehr charakteristische Samen, die sich im fossilien Zustand gut erkennen lassen. Bemerkenswert sind das Fehlen oder die starke Verkümmerung eines chalazalen, korkigen Gewebes und die deutliche, längsreihige Anordnung der Oberflächenstruktur. $\mathrm{Zu}$ diesem Formenkreis gehört ein Teil des Materials, das russische Autoren (Dorofeev, Weliczkiewicz) unter "Hypericum" coriaceum Nikitin (1948, nomen nudum) abbilden. Da ein Typus für diese Art bisher nicht fixiert ist, muss der Gebrauch dieses Artnamens bei Ludwigia unterbleiben.

Vorkommen: Mittleres bis Höheres Miozän und Pliozän (Knobloch 1988; Mai 2001; Mai \& Wähnert 2000); Gozdnica-Serie und Ruszów in Schlesien (Sadowska \& Szynkiewicz 1998). In Osteuropa bis ins Eem-Interglazial (Weliczkiewicz 1973).

\section{Trapaceae}

\section{Trapa heerii Fritsch}

Taf. 8, Fig. 14

1885 Trapa heerii v. Fritsch, Jb. preuß. geol. Landesanst. f. 1884: $429-436$; t. 26 , f. $29-41$ - Rippersroda (Oberpliozän).

Materia1: Oberzella MfN 2002/041, 1 Expl.

Beschreibung: Die vorliegende Frucht hat eine Länge von $8 \mathrm{~mm}$, eine Breite (mit Hörnern) von $11 \mathrm{~mm}$, ohne Hörner $8 \mathrm{~mm}$. Weiter vgl. Mai \& Walther 1988, p. 168.

Vor k o m men : Pliozän von Brunssum und Krościenko (Kirchheimer 1957); Thüringen (Mai \& Walther 1988).

\section{Aceraceae}

\section{Acer berganum Mai \& Walther}

Taf. 9, Figs 1-2

1988 Acer berganum Mai \& Walther, Quartärpaläontologie 7: 172, Taf XXXII, Fig. 2 - Berga (Oberpliozän). 


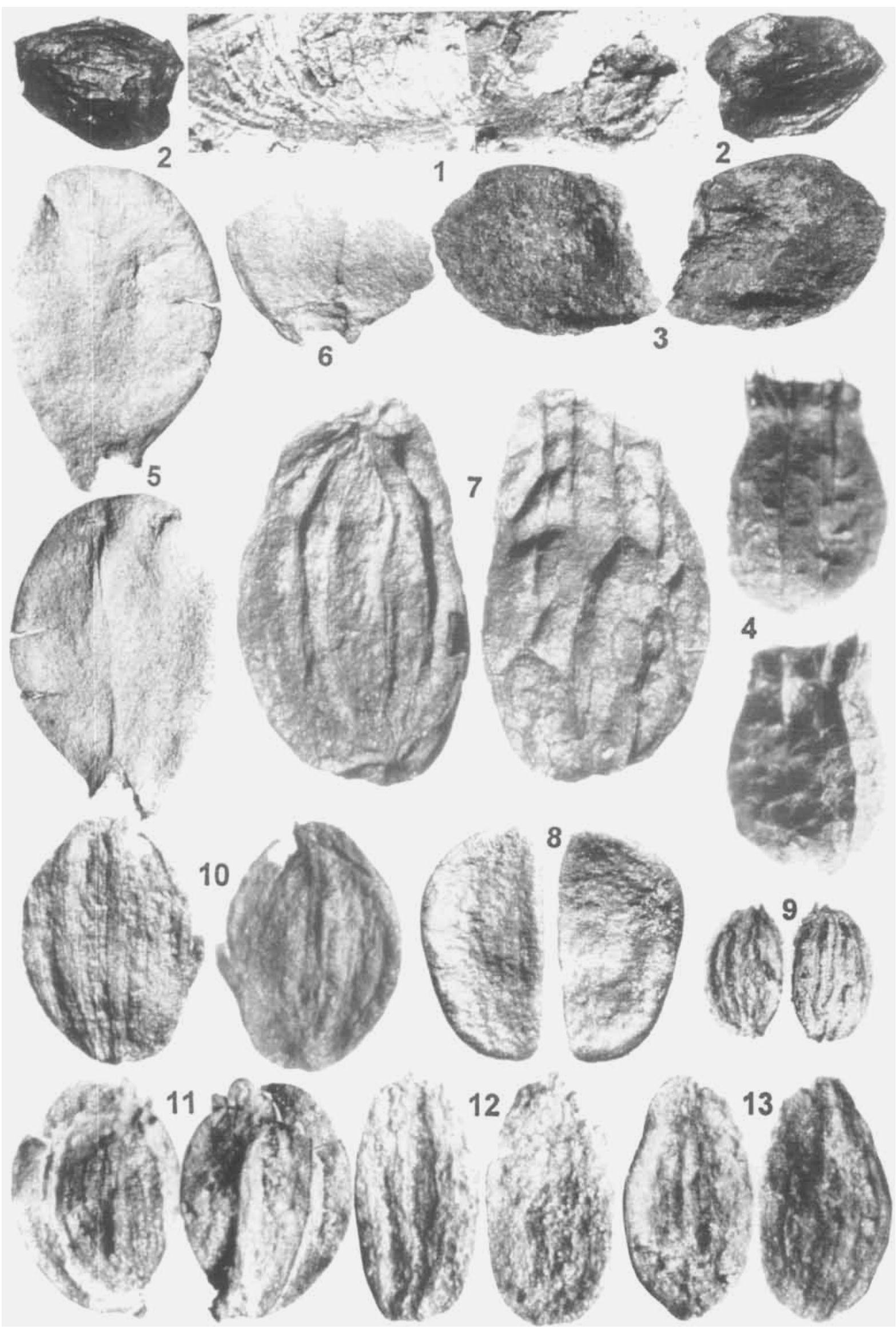


Material: Oberzella MfN 2002/058 (Ob 022, 028).

Beschreibung: Endokarpien schief-eiförmig, etwas aufgeblasen, 6-7 $\mathrm{mm}$ hoch, 3-4 $\mathrm{mm}$ lang, mit nahezu gerader Ventralseite, nur an der Dorsalseite gekielt, über die Oberfläche im oberen Drittel ein bis zwei dünne, sich gabelnde Rippen laufend, Griffelansatz kurz, Ventralpore groß. Wände mäßig dick, hornig-faserig, flachgedrückt. Fruchtflügel bis $22 \mathrm{~mm}$ lang und $7 \mathrm{~mm}$ breit, an der Basis mäßig verschmälert, in der Mitte breit, mit gebogenem Rücken und deutlichen, gegabelten Nerven. Divergenz spitzwinkelig.

Bemerkungen: Eine Art der Sect. Acer. Die Endokarpien sind denen von $A$. heldreichii Orph. (Balkanhalbinsel) sehr ähnlich. Auch die nunmehr gefundenen Fruchtflügel entsprechen denen der Sect. Acer.

Vork ommen: Nur im Pliozän von Thüringen (Mai \& Walther 1988) und Nochten-Ost/Lausitz (Mai \& Wähnert 2000).

\section{Sabiaceae}

\section{Meliosma cf. miessleri Mai}

\section{Taf. 3, Figs 8-9}

1964 Meliosma cf. miessleri Mai, Pal. Abh., B 2 (1): 109-110, XIV, f. 19-24 - Hartau (Untermiozän).

Material: Barchfeld MfN 2003/152, 2 Expl.

Beschreibung: Steinkerne kreisrund bis schiefnierenförmig, unilocular, zusammengedrückt, dünnwandig. Oberfläche schwach nervig. Funikulusgrube ohne deutlichen Plazentapfropf, nach innen mit marginalem Leitbündelkanal. Dehiszenz zweiklappig. Länge 3,5-3,8 mm. Wände aus radialen Sklereiden.

Bemerkungen: Die beiden aus Barchfeld vorliegenden Dehiszenzklappen gehören sicherlich zu einer Meliosma-Art, nicht jedoch zu der im Pliozän bekannten $M$. wetteraviensis (Ludwig) Mai aus der Sect. Kingsboroughia. Der innere, schiefe marginale Leitbündelkanal und die Struktur der Endokarpwand erinnert sehr an die Steinkerne von Meliosma sect. Meliosma. Aus dieser Sektion kommen zwei Arten für einen Vergleich in Frage: M. miessleri Mai (1964) aus dem Miozän und $M$. canavesana Martinetto (2001) aus dem Pliozän Oberitaliens. Beide Arten zeigen aber eine deutlicher ausgeprägte Retikulation der Oberfläche des Endokarps, die letztgenannte sogar mit hohen Rippen. Wir neigen deshalb mehr zu einer Annäherung an $M$. miessleri Mai (1964). Die Art wurde mit den ostasiatischen Arten $M$. pendens Rehd. \& Wils. und M. myriantha Sieb. \& Zucc. verglichen. Sicher ist ihre Zuordnung in die Untergattung Meliosma, in der nach Van Beusekom (1971: 401) keine rezente Art als unmittelbare Vergleichsart namhaft gemacht werden kann.

Vork ommen: Im Oligozän von Nordböhmen (Bůžek, Holý \& Kvaček 1976) und Nordwestsachsen (Mai \& Walther 1991); etwas häufiger im Untermiozän in Mitteleuropa (Mai 2000a). Im Pliozän Neufund.

\section{Cornaceae}

\section{Swida bessarabica Negru}

Taf. 1, Figs 22--23

1972 Swida bessarabica Negru, Rannjesarmatsk. flora severovostoka Moldavii: 144-146, Taf. XXVIII, Figs 1-12; Textfig. 37 - Bursuk (Mittelmiozän).

Material: Kaltensundheim MfN Ka 9747, (3 Expl.).

Beschreibung: Endokarpien fast rund, breiteiförmig bis elliptisch, ursprünglich kugelig, bei der Fossilisation zusammengedrückt. Basis leicht verschmälert bis zugerundet, mit kurz verdickter und stumpfer Anheftungsstelle. Apex breit zugerundet, leicht horizontal abgestutzt, mit 2 Fächern. Dehiszenzfurche, die das Endokarp im größten Durchmesser umläuft, schmal und niedrig, apikal breiter, mit Mühe und Not wahrnehmbar. Leitbündel zu viert bis fünft auf jeder Seite, meridional verlaufend, zwischen 4 bis 5 kurzen, stumpfen Rippen, die gerade oder schwach gekrümmt verlaufen, bisweilen aber Oberfläche an Spitze und Basis glatt. Wände des Endokarps dick, im Querbruch matt glän-

Tafel 9. Flora von Oberzella. 1-2. Acer berganum Mai \& Walther - MfN 2002/058. Flügelfrucht (Ob 022); $\times$ 4. 2. Endokarp von beiden Seiten (Ob 028); × 6,5. 3. Acer campestrianum Dorofeev - MfN 2002/057. Endokarp von beiden Seiten; $\times 6,5.4$. Proserpinaca reticulata C. \& E. M. Reid - MfN 2003/087. Frucht von zwei Seiten; $\times 20$. 5-6. Frangula alnus Miller fossilis MNN 2003/091. 5. Pyrene von zwei Seiten; $\times$ 12. 6. Bruchstück einer Pyrene mit basaler Zange; $\times$ 12. 7. Ilex aquifolium L. fossilis - MfN 2003/059. Steinkern von beiden Seiten; $\times 12$. 8. Aralia szaferi Mai \& Walther - MfN 2003/094. Steinkern von beiden Seiten; $\times$ 15. 9. Apium nodiflorum (L.) Lagasca fossilis - MfN 2003/053. Teilfrucht von zwei Seiten; $\times 25.10$. Sium latifolium L. fossilis - MfN 2003/045. Teilfrucht von beiden Seiten; $\times 25$. 11. Cicuta virosa L. fossilis - MfN $2003 / 049$. Teilfrucht von beiden Seiten; $\times 25,12-13$. Oenanthe aquatica (L.) Poiret fossilis - MfN 2003/077. Teilfrüchte jeweils von beiden Seiten; $\times 25$. 
zend. Durchmesser der Endokarpien 3,2-2,8 $-3,0-2,5 \mathrm{~mm}$.

Bemerkungen: Diese Endokarpien mittlerer Größe verglich Negru (1972) vor allem mit der heutigen Swida australis (C. A. Mey.) Pojarkova (Pontisch von der Balkanhalbinsel bis Kleinasien, in Bergwäldern verbreitet). Von tertiären Arten stehen Swida tertiaria Dorofeev (1963) und die relativ unbekannte Swida salinarum Zablocki (1930) nahe, deren Typus nach Łańcucka-Środoniowa \& Zastawniak 1997 (S. 18) verloren gegangen ist. Beide zeigen mit 3,0-4,9 mm Durchmesser größere Abmessungen.

Vorkommen: Mittelmiozän von Moldavien (Negru 1972). Süd- und Südwestpolen (Szafer 1961; Łańcucka-Środoniowa \& Zastawniak 1997). Nun auch Pliozän.

\section{Apiaceae}

\section{Sium latifolium Linné fossilis}

Taf. 9. Fig. 10

1977 Sium cf. latifolium L. - Dorofeev. Fauna i flora Simbugino: 75-76, t. XVII, f. 13. 14 - Simbugino/Baschk. (Oberpliozän).

Material: Oberzella MfN 2003/045 (Ob 045).

Beschreibung: Teilfrüchtchen länglich-oval, leicht gekrümmt auf der Ventralseite. Dorsalseite gewölbt, mit 5 Rippen auf der ganzen Breite, diese ziemlich dick, in der Mitte flach, aufeinanderfolgend in der Höhe. Ventralseite mit verbreiterten, flachen seitlichen Rippen, in der Vertiefung der Mitte mit einer einzelnen, dünnen Rippe. Basis verschmälert, etwas abgesetzt und abgeschnitten. Apex verschmälert, mit Resten des Griffelpolsters. Teilfrüchte 2,1-2,2 mm lang und nur 0,8-0,9 $\mathrm{mm}$ breit.

Bemerkungen: Die fossilen Teilfrüchte sind denen der rezenten $S$. latifolium L. sehr ähnlich, aber kleiner und dünner. Die Art ist gegenwärtig in Röhrichtgesellschaften im submeridionalen und borealen Eurasien von der Atlantikküste bis in den Fernen Osten verbreitet und häufig, auch im nördlichen Mediterrangebiet.

Vorkommen: Oberpliozän von Baschkirien (Dorofeev 1977), Belorussland (Weliczkiewicz 1990). Im Pleistozän der Wolganiederung, am Don und Ob-Irtysch-Gebiet in Sibirien (Kac, Kac \& Kipiani 1965); Warthe-Interstadial der Gr. Marga bei Senftenberg (Firbas \& Grahmann 1928).

\section{Caprifoliaceae}

\section{Diervilla tertiaria V. P. Nikitin}

Taf. 10, Figs 6-8

1976 Diervilla tertiaria V.P. Nikitin, Mioc. Mamontovoj Gory: 189, t. LXXIV, f. 1-7 - Mamontovaja Gora/Sibirien (Miozän).

Material: Oberzella MfN 2003/031 (Ob 031).

Beschreibung: Samen etwa $0,6-1,0 \mathrm{~mm}$ im Längs-Durchmesser, abgeflacht-oval, mit allen Übergängen zwischen einer nahezu rundlichen bis zur gestreckt-ovalen Form, nicht sehr aufgebläht über die Mitte, am Rande gerundet, selten kantig. Hilum schräg abgestutzt, neben einer lochförmigen oder auf einem schrägen Spitzchen endenden Mikropyle. Chalazales Ende gerundet. Oberfläche mit regelmäßig angeordneten, sehr kleinen, polygonalen Grübchen mit bis zu 0,01 mm Durchmesser; Testa dünn, glänzend.

Bemerkungen: Die fossilen Samen lassen sich mit jenen von Diervilla lonicera Mill. und $D$. sessilifolia Buckl. vergleichen, nicht aber mit $D$. rivularis Gatt. Sie sind aber kleiner als die rezenten Samen und besitzen zartere Oberflächenstruktur. Sie entsprechen den sibirischen Fossilfunden.

Vorkommen: Bisher nur Miozän in Sibirien (V. P. Nikitin 1976) und Obermiozän der Gozdnica-Serie in Schlesien (Mai 2001). Neufund im Pliozän Thüringens.

Tafel 10. Flora von Oberzella. Naumburgia subrhyrsiflora (Nikitin) Nikitin - MfN 2003/064. Samen von beiden Seiten; $\times 25$. 2-3. Euphorbia platyphyllos L. fossilis - MfN 2003/027. 2. Dehiszierter Samen von außen und innen; $\times 25$. 3. Stark angebrochener Samen; $\times 25$. 4-5. Weigela szaferi Łańcucka-Srodoniowa - MfN 2003/030. 4. Samen mit Flügelrest; $\times 40.5$. Samen nach Verlust des Flügels; $\times$ 40, 6-8. Diervilla tertiaria V. P. Nikitin -- MfN 2003/031. 6. Samen von beiden Seiten; $\times$ 40. 7. Weiterer länglicher Samen von beiden Seiten: $\times 100$ 40. 8. Bruchstück eines Samens, $\times 40$. 9. Solanum dulcamara L. fossilis - MfN 2003/073. Samen in Seitenansicht: $\times$ 30. 10-11. Bidens tripartita L. fossilis - MfN 2003/063. Zwei Bruchstücke einer Achaene: $\times$ 15. 12. Lactuca protomuralis Mai \& Walther - MfN 2003/062. Achaene von beiden Seiten ohne Pappus; $\times$ 15. 13-19. Leontodon rhoenensis nov. spec. - MfN 2003/067. 13. Achaene von beiden Seiten ohne Pappus; $\times 15$. Holotypus. 14. Weitere Achaene; $\times 15$. 15. Apikalteil vom Holotypus mit Ansatznarbe des Pappus; $\times 60$. 16. Apikalteil mit Ansatznarbe des Pappus von Fig, 14; × 60. 17-19. Details der Oberflächenstruktur der Achaene von Fig. 13-14; $\times 60$. 


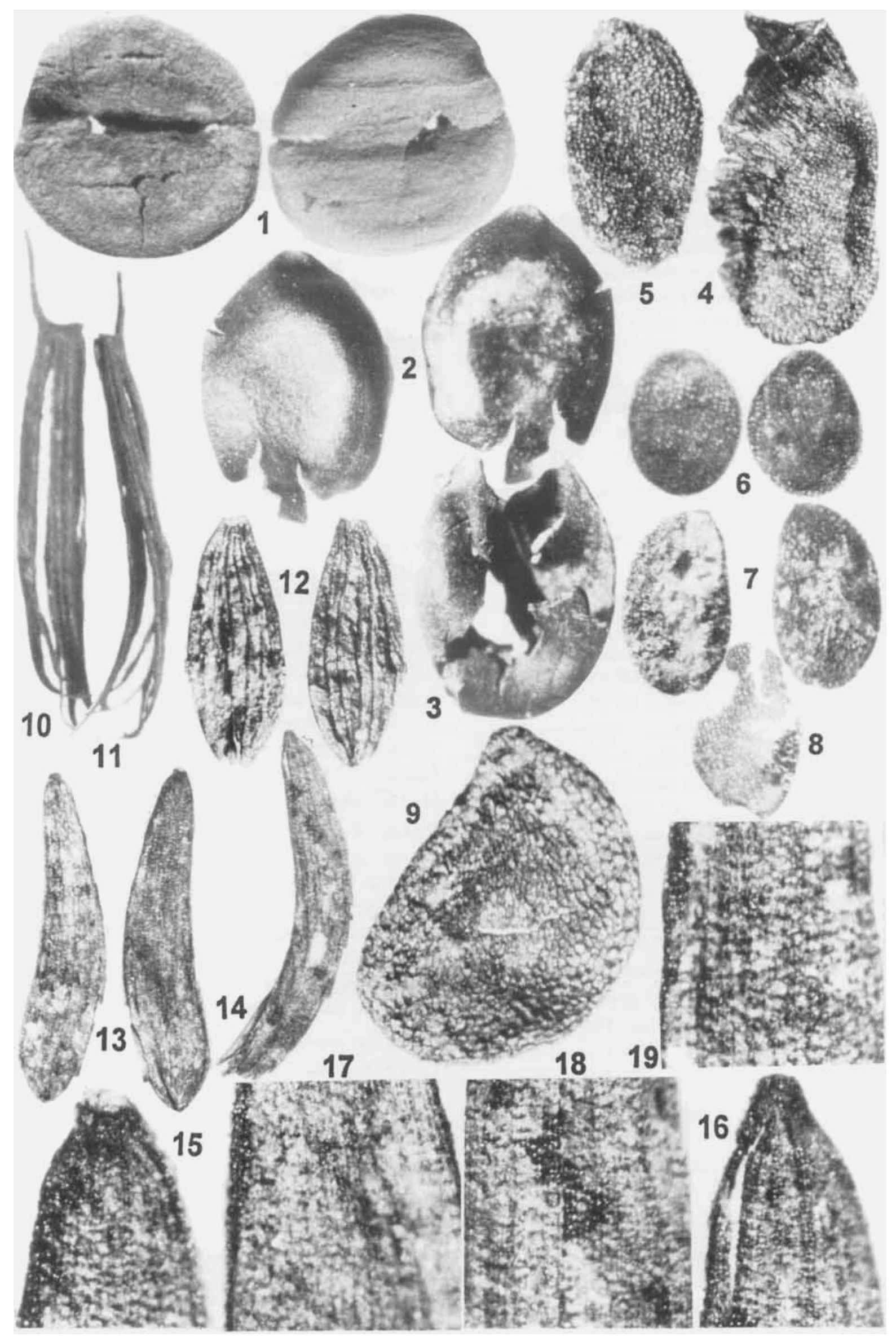




\section{Lamiaceae}

\section{Collinsonia europaea Mai}

Taf. 3, Figs 20-22

1991 Collinsonia europaea Mai in Mai \& Walther, Abh. Staatl. Mus. Mineral. Geologie, Dresden 38: 125, Taf. 15, Fig. 17 - Hartau 1/69 (Untermiozän).

Material: Oberzella MfN 2003/044 (Ob 044).

Beschreibung: Nüsschen geschwollen-rundlich, fast kugelförmig, ohne Kante, 1,6-2,2 mm im Durchmesser, mit basaler, breitgezogener Kontaktstelle. Oberfläche mit zartem, sehr weitmaschigem Netz von Leitbündeln, das leicht abradiert; zur Basis hin Leitbündel gestreckt und unvernetzt; fein punktat, matt glänzend.

Bemerkungen: Verglichen wurden die fossilen Nüsschen mit denen von $C$. canadensis $L$. (Kanada), deren nahe Verwandtschaft unverkennbar ist. Andere Gattungen der Saturejeae oder Salvieae zeigen abweichende Merkmale.

Vorkommen: Oberoligozän bis Untermiozän in Nordwestsachsen und der Lausitz (Mai \& Walther 1991). Erstfund im Pliozän.

\section{Glechoma hederacea Linné fossilis}

Taf. 3, Figs 18-19

1940 Glechoma hederacea L. fossilis Nikitin, Mater. Geol. Zapad. Sibiri 12: 54 - Ob/W-Sibirien (Pleistozän).

Material: Oberzella MfN 2003/041 (Ob 041).

Beschreibung: Nüsschen verkehrt-eiförmig, gerundet schwach dreikantig. Ventralseite etwas konkav erhoben. Dorsalseite abgeflacht, kleiner, deutlich abgesetzt an der Basis. Hilum klein. Oberfläche glatt, schwarz, nicht glänzend, areolat. Länge 1,5-1,7 mm; Breite 1,0 mm.

Bemerkungen: Die Art ist gegenwärtig weit verbreitet in Europa, Nord- und Mittelasien, Japan und ist eine charakteristische krautige Liane an Flußufern, in Gebüschen und auf Wiesen.

Vorkommen: Pliozän in Schlesien (Mai \& Wähnert 2000). Pleistozän von England, Polen, der Wolganiederung und am $\mathrm{Ob} /$ Westsibirien.

\section{Lycopus europaeus Linné fossilis}

\section{Taf. 3, Figs 12, 24}

1892 Lycopus europaeus Linné fossilis C. Reid, Quart. J. geol. Soc. London 48: 358 - Pakefield (Cromer- Interglazial).

Material: Barchfeld MfN 2003/121; Kaltensundheim MfN Ka 9723, 9731, 9747; Oberzella MfN 2003/037 (Ob 037).

Beschreibung: Mai \& Walther 1988, p. 202.

Bemerkungen: Bei der Bestimmung der sehr formvariablen Nüsschen aus dem Pliozän ist $L y$ - copus pliocenicus Dorofeev (1986b) nicht auszuschließen. Diese Art aus dem Oberpliozän von Dvorec am Dnjepr steht u. a. L. exaltatus L. näher als L. europaeus L. Wir hatten festgestellt, daß eine Trennung dieser beiden Arten bei abradiertem Randsaum ohnehin sehr erschwert ist (Mai \& Walther 1988: 202).

Vorkommen: Miozän von Westsibirien, Osteuropa (Nikitin 1948, Dorofeev 1963); in Mitteleuropa ab Mittelmiozän (Mai 2001). In den meisten pliozänen und interglazialen Floren Europas, auch in einigen Interstadialen (Mai \& Walther 1988).

\section{Mentha pliocenica Dorofeev}

\section{Taf. 3, Figs 13-14}

1986b Mentha pliocenica Dorofeev, Problemy Paleobot:: 69, Abb. 7/1-9 - Dvorec (Oberpliozän).

Material: Barchfeld MfN 2003/120.

Beschreibung: Nüsschen rundlich-elliptisch, etwas verbreitert in der unteren Hälfte, 0,6-0,8 mm lang, wenig zusammengedrückt, oben rundlich oder kaum verengt. Basale Ansatzstelle auf einer keilförmigen, pyramidalen Verengung mit drei ungleichen Seiten. Dorsalseite gewölbt oder flach. Ventralseite schwach zweikantig-gewölbt. Perikarp dick, zweischichtig. Äußere Schicht aus vieleckigen und etwas gestreckten Zellen, locker, glänzend, mit einer graubraunen Oberfläche, die durch Abrasion teilweise rauh erscheint, ohne Grübchen auf den unversehrten Abschnitten. Innere Schicht viel dünner, mit glatter, fast schwarzer Oberfläche, aus kleinen, isodiametrischen Zellen.

Bemerkungen: Diese pliozäne Art steht den beiden heutigen Arten $M$. aquatica L. und $M$. arvensis L. nahe (Dorofeev 1986b). Möglicherweise gehören zu der Art auch die Nüsschen aus Tegelen und Rippersroda, die von C. \& E. M. Reid (1907a), Zagwijn (1963) und Mai, Majewski \& Unger (1963) unter $M$. aquatica L. fossilis beschrieben oder abgebildet wurden.

Vorkommen: Oberes Pliozän von Belorussland (Dorofeev 1986b, Weliczkiewicz 1990) und möglicherweise auch Tegelen (C. \& E. M. Reid 1907a) und Rippersroda (Mai \& Walther 1988).

\section{Teucrium pripiatense (Dorofeev) Weliczkiewicz \& Zastawniak}

Taf. 3, Figs $15-17$

1967b Ajuga pripiatense Dorofeev, Dokl.Akad.Nauk Beloruss. 11 (8): 722 , PI. 1 , fig. 25 - Zhitkovichy (Unterpliozän).

1988 Teucrium chamaedrys L. fossilis Mai \& Walther, Quartärpaläontol. 7: 206, t. XXXIX, f. 21,22 - Berga (Oberpliozän) 
2003 Teucrium pripiatense Weliczkiewicz \& Zastawniak, Mskr.: 76, Pl. 11, figs 23,24 - Cholmech/Gomel (Oberpliozän).

Material: Barchfeld MfN 2003/122.

Beschreibung: Nüsschen elliptisch oder rundlich-eiförmig, fast symmetrisch; 1,4-2 $\mathrm{mm}$ lang und 1,2-1,8 $\mathrm{mm}$ breit. Ventralseite konkav, mit einer kreisrunden Vertiefung und Anheftungsstelle, welche fast $1 / 2$ bis $3 / 4$ der Ventralseite im unteren Teil einnimmt. Ränder der Vertiefung nach innen gebogen. Operculum konvex. Oberfläche der Dorsalseite netzig, mit hinreichend dicken Adern und unterschiedlich großen, polygonalen, seichten Gruben.

Bemerkungen: Die ursprünglich als Ajuga L. beschriebenen Nüsschen wurden von Weliczkiewicz \& Zastawniak (2003) als Reste von Teucrium pripiatense (Dorofeev) Weliczk. \& Zastawniak bezeichnet. Sie waren aus Berga als Teucrium chamaedrys L. fossilis beschrieben worden. Unter den heutigen Teucrium-Arten hat die südeurasiatische $T$. chamaedrys $\mathrm{L}$. die ähnlichsten Nüsschen. Aber diese sind größer, ihr Operculum weniger konvex und die Gruben der Oberfläche undeutlicher. Noch mehr unterscheiden sich durch elongate Form und Größe die Nüsschen von $T$. polium $\mathrm{L}$. und $T$. botrys $\mathrm{L}$.

Vorkommen: Unterpliozän in Belorussland (Dorofeev 1967b); Oberpliozän von Thüringen (Mai \& Walther 1988); Belorussland (Weliczkiewicz \& Zastawniak 2003) und Dongebiet (Teucrium spec. 2 Nikitin 1957).

\section{Lobeliaceae}

\section{Lobelia pliocenica (Dorofeev) Mai}

\section{Taf. 3, Fig. 26}

1960b Typha pliocenica Dorofeev, Plioc. fl. Baškirsk. Predural'ja: 20, t. 1, f. 8-14-Verchne Taševo/Baschkirien (Pliozän).

2000b Lobelia pliocenica Mai, Feddes Repert. 111: 484-485, Taf. I, Figs 1, 2 - Rippersroda (Oberpliozän).

Material: Oberzella MfN 2002/062 (Ob 015).

Beschreibung: Samen in der Mitte und an der Basis geschwollen, etwas gekrümmt, nicht 3mal länger als breit. Mikropylarhöckerchen tief eingesenkt. Raphefurche deutlich in Längsrichtung. Maschenschicht aus ovalen bis hexagonalen Zellen, großzellig, durch dünne, parallele Zwischenwände mit Innenskulptur versehen. Samen $0,8-0,3 \mathrm{~mm}$.

Bemerkungen: Bisher als „Typha“ pliocenica Dorofeev (1960b) oder "Gentiana pneumonanthe L. foss.“ falsch interpretiert (Mai, Majewski \&
Unger 1963). Es besteht weitgehende Übereinstimmung des Samenbaues mit den Samen von Lobelia dortmanna L. Diese Art der überschwemmten Ufer von oligotrophen Seen und Sümpfen ist heute euramerisch verbreitet. Sie tritt im pazifischen Nordamerika von Oregon bis British Columbia, im atlantischen Nordamerika von New Jersey und Wisconsin bis Minnesota und Neufundland auf. In Europa werden Nordeuropa und Teile des nördlichen Mitteleuropa von Irland bis Weißrussland besiedelt. Die Arealbindung ist eindeutig atlantisch-subatlantisch. Andere Arten aus Nordamerika oder Ostasien konnten bisher nicht zum Vergleich beschafft werden.

Vorkommen: Vom Untermiozän in Weißrussland bis Obermiozän in Westsibirien. Pliozän von Mitteleuropa bis Baschkirien. Im Altpleistozän in Weißrussland und Litauen (Mai 2000b).

\section{Asteraceae}

\section{Bidens tripartita Linné fossilis}

Taf. 10, Figs 10-11

1896 Bidens tripartita L. fossilis C. Reid, Rep. Brit. Association: 400 - Hoxne (Mittelpleistozän).

Material: Oberzella MfN 2003/063 (Ob 063).

Beschreibung: Achaenen 3,2-4,5 - 1,2-1,8 $\mathrm{mm}$, keilförmig, abgeflacht-viereckig, an der abgesetzten Spitze über den Rand verdickt, mit 4 pfriemlichen Stacheln, die an der Verlängerung der Rippen liegen; jeder Stachel und auch die spitzen Rippen tragen nach unten gerichtete Zähnchen. Wände wenig dick, aber fest, über die Rippen verstärkt. Oberfläche leicht und unklar stricheliert, von brauner Farbe.

Bemerkungen: Bidens-Achaenen lassen sich im allgemeinen gut bestimmen. Nur die beiden Arten $B$. cernua L. und B. tripartita L. machen eine Ausnahme. Nach unseren Vergleichen haben wir uns bei der Bestimmung des pliozänen Materials für B. tripartita L. entschieden. Diese Art ist in Eurasien heute eine wichtige Kennart der Bidentetea-Klasse, deren annuelle Gesellschaften nasse, zeitweise überschwemmte, nährstoffreiche See- und Teichufer, Gräben und Nassstellen in Wiesen besiedeln.

Vorkommen: Tegelen; Oberstes Pliozän vom Wylerberg/Cleve (Fliegel \& Stoller 1910) und Dvorec/Belorussland (Weliczkiewicz 1975). In zahlreichen Interglazialen von England bis Baschkirien. 


\section{Leontodon rhoenensis nov spec.}

\section{Taf. 10, Figs 13-19}

Holotypus: Taf. 10, Fig. 13 - Oberzella (Tonlinse 3. Oberpliozän) - MfN Berlin 2003/067, coll. Gümbel \& Mai.

Material: Oberzella MfN 2003/067 (Ob 067). mehrere Exemplare.

Diagnosis: Achaenes linear, flattened, straight or somewhat curved, at the base truncate, at the apex narrowed to beakshaped prolonged (without any remains of the pappus); thin longitudinally ribbed, around and between the ribs transversely wrinkled, sometimes with dentate sculpture. Length 3-3,5 mm; breadth 0,5-0,6 $\mathrm{mm}$.

Derivatio nominis: After the Rhön-Mountains, lat. Rhoena.

Beschreibung: Früchtchen (Achaenen) linealisch, etwas abgeflacht, gerade bis schwach gebogen, basal abrupt abgestutzt, apikal zusammengezogen bis schnabelartig verlängert (fossil ohne Reste des Pappus). Über die Oberfläche dünnlängsrippig und quer sehr fein gerunzelt, mit teilweise zähnchenartiger Skulptur. Länge 3-3,5 $\mathrm{mm}$; Breite 0,5-0,6 mm.

Bemerkungen: Eine Art der Gattung Leontodon Linné, deren Achaenen mit keiner der heutigen europäischen Arten übereinstimmen und die deshalb als neue, fossile Art zu beschreiben sind. Bemerkenswert ist die feine Skulptur der Oberfläche, einschließlich der dünnen Längsberippung. Wenn die Früchtchen sehr unterschiedlich in Gestalt und Größe sind, käme für eine nähere Verwandtschaft die Sect. Thrincia Roth. in Frage. Fossil sind in Europa Arten nur aus dem Pleistozän beschrieben: Leontodon autumnalis L. fossilis C. \& E. M. Reid (1907b); Środon (1968); L. hispidus L. fossilis Klimaszewski \& Szafer (1945); L. pseudotaraxaci Schur fossilis šrodon (1968) und L. saxatilis Lamk. fossilis C. Reid (1899). Keine dieser abgebildeten Arten entspricht unseren Fossilresten.

Vorkommen: Neufund im Pliozän von Thüringen.

Alle im weiteren Text erwähnten und in der systematischen Beschreibung nicht aufgeführten Funde wurden in drei Tabellen (S. 178-179 und 181-182: Barchfeld (Ba) Kaltensundheim (Ka) und Oberzella $(\mathrm{Ob})$ ) zusammengestellt.

\section{Diskussion der neuen Pflanzenfunde}

Planzenreste aus dem jüngsten Tertiär (Obermiozän bis Pliozän) waren in der Rhön bis zur Mitte des vorigen Jahrhunderts unbekannt. Aus Buche- nau und Hünfeld in der Kuppigen Rhön wurden durch Leschik 1952a, b und 1954 erste Mikrofloren und einige pflanzliche Makroreste (Früchte und Samen) beschrieben. Es folgten dann die fossilen Floren von Oberzella (Mikroflora Krutzsch \& Majewski 1965; Krutzsch 1988; Makroreste Mai \& Walther 1988), von Kaltensundheim (Mikroflora Kahlke \& Ukraintseva 1986; Krutzsch 1988, Makroflora Mai \& Walther 1988) und von Wollbach bei Bad Neustadt/Oberfranken (Makroflora Kelber 1980, 1988). Ihre paläobiologische und biostratigraphische Auswertung gestaltete sich infolge ihrer relativen Artenarmut sehr schwierig, gemessen an den Floren des gleichen Zeitabschnittes in benachbarten Ablagerungsräumen (Krutzsch 1988, Kelber 1988). Nur durch die Querverbindungen zu den vielen Fundstellen mit tierischen Fossilien der sog. "Arvernensis-Zeit" wurde auch eine Zuordnung der fossilen Floren möglich, die sich, mit Ausnahme der Flora von Wollbach, auf das Oberpliozän bezog.

Nach Azzaroli (1970) und Tobien (1970) charakterisieren die Großsäugetiere Anancus arvernensis, Mammut borsoni und Tapirus arvernensis den langen Zeitabschnitt von etwa Mitte Pliozän bis Ende Oberes Villafranchium (Csarnotium, Ruscinium), nach Mein (1975) die Säugetierzonen MN 15 bis MN 17. Das ist ein Zeitraum, der nach paläomagnetischen Daten von etwa 3,4 my. bis 1,65 my. reicht. Wir wissen inzwischen, dass diese lange Zeit paläofloristisch nach der Makroflorengliederung in Mittel- und Westeuropa durch mindestens 4 Florenkomplexe (Mai \& Walther 1988; Mai 1995) repräsentiert wird; nach der Mikrofloren(Pollen-)-gliederung ist er in 6 Abschnitte (Krutzsch 1988) zu unterteilen. Die neu gefundenen Makrofloren von Barchfeld (32 Arten), Kaltensundheim (66 Arten) und Oberzella (102 Arten) lassen sich nicht genau, zumindest aber annähernd in diese Gliederungsschemen einpassen. Dabei bedienen wir uns der bewährten „Methode der pflanzengeographischen Verwandtschaft" (Szafer 1947), die im Pliozän bisher besonders gute Resultate ergeben hat (Mai 1995: 252). Die Arten lassen folgende pflanzengeographische Verwandtschaft erkennen:

1. Holarktische (circumpolare und kosmopolitische) Elemente:

Carex nigra (Ka, Ob), Carex pseudocyperus $(\mathrm{Ob})$, Carex riparia $(\mathrm{Ka}, \mathrm{Ob})$, Chenopodium aff. album (Ba), Comarum palustre (Ka), Hippuris vulgaris $(\mathrm{Ka})$, Lemna gibba $(\mathrm{Ka})$, Lemna trisulca 
(Ka), Mentha pliocenica (Ba), Myrica goretskyi (Ka), Myriophyllum spicatum u. praespicatum (Ka), Naumburgia subthyrsiflora (Ob), Pinus spec. (Ob), Polygonum pliocenicum (Ka, Ob), Polygonum wolfii $(\mathrm{Ob})$, Populus spec. $(\mathrm{Ob})$, Potamogeton filiformoides (Ka), Potamogeton neptunii (Ka), Potamogeton panormitanoides (Ka), Potamogeton tanaiticus (Ka), Potentilla supina (Ba), Ranunculus aquatilis (Ka, $\mathrm{Ob})$, Ranunculus gailensis $(\mathrm{Ba}, \mathrm{Ka}, \mathrm{Ob})$, Ranunculus sceleratus (Ba), Rubus spec. (Ka, Ob), Rubus idaeus (Ka), Rumex acetosella $(\mathrm{Ka})$, Salix spec. (Ka, Ob), Urtica dioica $(\mathrm{Ka}, \mathrm{Ob})$, Viola palustris $(\mathrm{Ka})$.

Der hohe Anteil solcher weitverbreiteter Elemente ist sehr typisch für Floren des oberen Pliozäns und anschließenden Altpleistozäns im zentralen Europa. Er beträgt für Barchfeld $12,8 \%$, für Kaltensundheim $30 \%$ und für Oberzella $13 \%$.

\section{Europäische Elemente:}

Acer berganum (Ob), Baldellia ranunculoides $(\mathrm{Ka}, \mathrm{Ob})$, Carex ornithopoda $(\mathrm{Ob})$, Carpinus betulus (Ba), Corylus avellana (Ka, Ob), Euphorbia platyphyllos $(\mathrm{Ob})$, Hypericum tertiaerum $(\mathrm{Ka}$, $\mathrm{Ob})$, Lobelia pliocenica (Ob), Potamogeton palaeorutilus (Ka, $\mathrm{Ob})$, Potentilla heptaphylla $(\mathrm{Ba})$, Rumex hydrolapathum (Ka, $\mathrm{Ob})$, Stratiotes aloides $(\mathrm{Ob})$, Swida bessarabica (Ka), Thesium nikitinii $(\mathrm{Ka})$, Typha aspera $(\mathrm{Ba}, \mathrm{Ob})$.

Die Anteile dieser heimischen Elemente betragen in Barchfeld $9,8 \%$, in Kaltensundheim $12 \%$ und in Oberzella $11 \%$ an der gesamten Flora.

\section{Eurasiatische Elemente:}

Acer campestrianum (Ob), Alisma spec. ex gr. plantago $(\mathrm{Ob})$, Alnus tanaitica $(\mathrm{Ob})$, Argusia cf. complicata (Ka), Apium nodiflorum (Ob), Bidens tripartita (Ob), Caldesia cylindrica (Ba, Ob), Carex acutiformis (Ka), Carex caespitosa (Ka), Carex elongatoides (Ka, $\mathrm{Ob})$, Carex flavaeformis (Ka), Carex hostianoides (Ob), Ceratophyllum pannonicum (Ob), Cicuta virosa (Ob), Cirsium palustre (Ka), Euphorbia stricta (Ka), Frangula alnus $(\mathrm{Ob})$, Glechoma hederacea $(\mathrm{Ob})$, Ilex aquifolium (Ka, $\mathrm{Ob})$, Lactuca protomuralis $(\mathrm{Ob})$, Leontodon rhoenensis $(\mathrm{Ob})$, Ludwigia chandlerae $(\mathrm{Ob})$, Lycopus antiquus (Ka), Lycopus europaeus (Ba, Ka, Ob), Mentha longifolia (Ob), Nuphar canaliculata $(\mathrm{Ob})$, Oenanthe aquatica $(\mathrm{Ob})$, Origanum vulgare $(\mathrm{Ob})$, Peucedanum moebii $(\mathrm{Ob})$, Physalis alkekengii (Ka), Picea abies (Ka, Ob), Potamogeton aculeatus $(\mathrm{Ob})$, Potamogeton borysthenicus (Ob), Potamogeton polymorphus (Ka,
$\mathrm{Ob})$, Potentilla erecta (Ka), Prunella vulgaris (Ka), Prunus spinosa (Ka), Pyrus microsperma $(\mathrm{Ob})$, Ranunculus reidii (Ob), Sagittaria sagittifolia (Ob), Salvinia miocenica (Ob), Schoenoplectus lacustris (Ka), Scirpus sylvaticus (Ka, $\mathrm{Ob})$, Silene cf. conica (Ka), Sium latifolium (Ob), Solanum dulcamara $(\mathrm{Ob})$, Sparganium neglectum (Ba, Ka, Ob), Stellaria holostea (Ka), Teucrium pripiatense $(\mathrm{Ba})$, Thalictrum simplex $(\mathrm{Ka})$, Vitis cf. sylvestris $(\mathrm{Ba}, \mathrm{Ob})$.

Die sehr große Zahl dieser Elemente ist typisch für Floren des jüngsten Tertiärs und verteilt sich wie folgt: Barchfeld 19,2\%, Kaltensundheim $30 \%$ und Oberzella $32,5 \%$. Alle Arten der ersten drei Gruppen werden im allgemeinen als heimische (native) Elemente bezeichnet und charakterisieren in einem hohen Maße die fossilen Floren, je jünger sie werden:

Prozente die nativen Elemente: Barchfeld $52 \%$, Kaltensundheim $72 \%$, Oberzella $67,5 \%$.

4. Westasiatische (Hyrkano-kolchische) Elemente:

Ampelopsis macrosperma (Ob), Ceratophyllum protanaiticum $(\mathrm{Ob})$, Hypericum androsaemum $(\mathrm{Ob})$, Pterocarya limburgensis (Ob), Ranunculus trachycarpoides $(\mathrm{Ob})$, Zelkova ungeri $(\mathrm{Ob})$.

Nur in Oberzella sind Arten dieser Elemente vorhanden und erreichen $6 \%$.

\section{Ostasiatische Elemente:}

Acanthopanax uralensis (Ka), Acer striatum (Ka), Acorus palaeocalamus (Ob), Actinidia faveolata $(\mathrm{Ba}, \mathrm{Ka}, \mathrm{Ob})$, Alnus lusatica $(\mathrm{Ob})$, Betula cholmechensis $(\mathrm{Ka}, \mathrm{Ob})$, Betula digitata $(\mathrm{Ob})$, Carex carpophora (Ba), Carpinus miocenica (Ka), Cercidiphyllum helveticum $(\mathrm{Ob})$, Corylopsis urselensis $(\mathrm{Ob})$, Eleocharis praemaximowiczii (Ka, Ob), Ficus tambovica (Ob), Humulus scabrellus $(\mathrm{Ob})$, Hypericum foveolatum $(\mathrm{Ba}, \mathrm{Ka})$, Liriodendron geminata (Ob), Magnolia cor (Ba, $\mathrm{Ob})$, Magnolia ultima (Ob), Morus ucrainica (Ba), Phellodondron elegans (Ka), Picea rotunde-squamosa $(\mathrm{Ba})$, Potamogeton felixii $(\mathrm{Ka}), \mathrm{Po}-$ tentilla pliocenica $(\mathrm{Ka})$, Prunus tenerirugosa (Ob), Pyracantha angusticarpa (Ob), Sambucus pulchella $(\mathrm{Ba}, \mathrm{Ob})$, Thalictrum minimum $(\mathrm{Ba})$, Thalictrum pliocenicum $(\mathrm{Ob})$, Trapa heerii $(\mathrm{Ob})$, Trichosanthes fragilis (Ob), Tsuga sect. Tsuga (Ob), Typha pseudoovata (Ka), Weigela szaferi $(\mathrm{Ob})$.

Der Anteil der ostasiatischen Florenelemente ist in allen drei Floren noch recht hoch: Barchfeld $23 \%$, Kaltensundheim $18 \%$ und Oberzella $19 \%$. 


\section{Nordamerikanische Elemente:}

Aralia szaferi $(\mathrm{Ob})$, Boehmeria lithuanica $(\mathrm{Ka})$, Carex elongatoides (Ka, Ob), Carex flagellata $(\mathrm{Ob})$, Carex hostianoides (Ob), Carex klarae (Ba), Carpinus miocenica $(\mathrm{Ka})$, Collinsonia europaea $(\mathrm{Ob})$, Decodon globosus (Ba, Ob), Diervilla tertiaria $(\mathrm{Ob})$, Dulichium arundinaceum $(\mathrm{Ob})$, Fagus deucalionis $(\mathrm{Ba})$, Itea europaea $(\mathrm{Ob}), \mathrm{Li}$ riodendron geminata $(\mathrm{Ob})$, Lobelia pliocenica $(\mathrm{Ob})$, Pilea bashkirica (Ba), Pilea cantalensis $(\mathrm{Ob})$, Proserpinaca reticulata (Ob), Prunus schlechtendalii $(\mathrm{Ob})$, Ranunculus tanaiticus (Ka), Sambucus pulchella (Ba, Ob), Scirpus (Schoenoplectus) isolepioides (Ob), Taxodium dubium $(\mathrm{Ba}, \mathrm{Ka})$, Viola bergaensis (Ka), Viola neogenica (Ba, Ob).

Auch der Anteil nordamerikanischer Elemente ist in den jungtertiären Floren beachtlich. Er beträgt in Barchfeld $22,7 \%$, in Kaltensundheim nur $8 \%$, in Oberzella $15,5 \%$ und ist damit überall niedriger als der ostasiatische Anteil.

7. Subtropische und ausgestorbene Elemente:

Acorellus distachyoformis (Ka), Cyperus fuscus $(\mathrm{Ka})$, Epipremnites reniculus (Ob), Meliosma cf. miessleri (Ba), Microdiptera menzelii ( $\mathrm{Ba}, \mathrm{Ob})$, Selaginella borysthenica (Ba), Symplocos casparyi $(\mathrm{Ob})$, Trema lusatica $(\mathrm{Ba})$.

Diese Florenelemente sind trotz ihres sehr geringen Anteiles (Barchfeld 12\%, Kaltensundheim $2 \%$, Oberzella $3 \%$ ) beim artlichen Vergleich sehr bedeutsam für die biostratigraphische Einstufung einer fossilen Flora im ausgehenden Tertiär. Im einzelnen schwanken die pflanzengeographischen Elemente in sehr unterschiedlichen Prozentsätzen (Abb. 3). Die unter 4.-7. genannten Elemente werden allgemein als "exotische Elemente" bezeichnet und sind sehr wichtig für eine biostratigraphische Zuordnung. Es sind folgende Prozentanteile ermittelt worden: Barchfeld 59,2\% - Kaltensundheim $28 \%$ - Oberzella 37,5\%.

Im Vergleich mit den benachbarten Vorkommen:

Gerstungen 51,7\% - Rippersroda 29,8\% Berga 52,6\%.

Danach sieht es so aus, dass Barchfeld, Gerstungen und Berga auf der einen Seite und Kaltensundheim sowie Rippersroda auf der anderen Seite etwa altersgleich sein müssten. Oberzella stände dazwischen. Ganz so einfach sind die Verhältnisse jedoch nicht.

Sehr wichtig für eine zeitliche Einordnung fossiler Floren ist die stratigraphische Reichweite der sie zusammensetzenden Arten, also deren historische Elemente. Für die in Rede stehenden drei Lokalfloren sind wichtig:

1. Miozäne Elemente, d.h. Arten, deren Typus aus dem Miozän stammt oder die im Miozän schon beachtliche Bedeutung hatten:

Acorellus distachyoformis (Ka), Actinidia faveolata (Ba, $\mathrm{Ka}, \mathrm{Ob})$, Alnus lusatica (Ob), Ampelopsis macrosperma $(\mathrm{Ob})$, Carex elongatoides (Ka, $\mathrm{Ob})$, Carex flavaeformis (Ka), Carex hostianoides $(\mathrm{Ob})$, Carex klarae (Ba), Carpinus miocenica (Ka), Ceratophyllum pannonicum (Ob), Cercidiphyllum helveticum $(\mathrm{Ob})$, Collinsonia europaea (Ob), Decodon globosus (Ba, Ob), Diervilla tertiaria (Ob), Epipremnites reniculus (Ob), Fagus deucalionis $(\mathrm{Ba})$, Ficus tambovica (Ob), Hypericum tertiaerum (Ka, Ob), Itea europaea $(\mathrm{Ob})$, Lycopus antiquus (Ka), Liriodendron geminata $(\mathrm{Ob})$, Magnolia ultima (Ob), Meliosma cf. miessleri (Ba), Microdiptera menzelii (Ba, Ob), $\mathrm{Nu}$ phar canaliculata $(\mathrm{Ob})$, Picea rotunde-squamosa (Ba, Ka), Pilea bashkirica (Ba), Prunus schlechtendalii (Ob), Pyracantha angusticarpa (Ob), Pyrus microsperma (Ob), Sparganium neglectum (Ba, Ka, Ob), Symplocos casparyi (Ob), Swida bessarabica $(\mathrm{Ka})$, Taxodium dubium $(\mathrm{Ba}, \mathrm{Ka})$, Thalictrum minimum (Ba), Trema lusatica (Ba), Zelkova ungeri $(\mathrm{Ob})$.

Gemessen an der Gesamtzahl der Arten zeigt Barchfeld den größten Anteil solcher mitteltertiärer Arten, gefolgt von Oberzella, schwach ausgeprägt in Kaltensundheim.

Ein anderes Kennzeichen von jungtertiären Floren ist ihr Anteil von Florenelementen, welche erst im Pliozän einsetzen und dann im Pleistozän häufiger werden. Das sind meist fossile Reste heutiger Arten:

Acer campestrianum (Ob), Argusia complicata $(\mathrm{Ka})$, Baldellia ranunculoides $(\mathrm{Ka}, \mathrm{Ob})$, Carex acutiformis $(\mathrm{Ka})$, Carex caespitosa $(\mathrm{Ka})$, Carex nigra $(\mathrm{Ka}, \mathrm{Ob})$, Carex ornithopoda $(\mathrm{Ob})$, Carex pseudocyperus $(\mathrm{Ob})$, Carex riparia $(\mathrm{Ka}, \mathrm{Ob}), C i$ cuta virosa $(\mathrm{Ob})$, Cirsium palustre $(\mathrm{Ka})$, Comarum palustre (Ka), Cyperus fuscus (Ka), Euphorbia platyphyllos (Ob), Euphorbia stricta (Ka), Frangula alnus $(\mathrm{Ob})$, Glechoma hederacea $(\mathrm{Ob})$, Hippuris vulgaris $(\mathrm{Ka})$, Lemna gibba $(\mathrm{Ka})$, Lemna trisulca (Ka), Mentha longifolia (Ob), Myriophyllum spicatum $(\mathrm{Ka})$, Oenanthe aquatica $(\mathrm{Ob})$, Origanum vulgare $(\mathrm{Ob})$, Physalis alkekengi $(\mathrm{Ka})$, Picea abies (Ka, Ob), Potamogeton neptunii (Ka), Potamogeton panormitanoides (Ka), Potamogeton palaeorutilus (Ka, Ob), Potentilla erecta (Ka), Potentilla heptaphylla (Ba), Prunella vulgaris (Ka), Rumex acetosella (Ka), Rumex hydrola- 
pathum (Ka, Ob), Sagittaria sagittifolia $(\mathrm{Ob})$, Schoenoplectus lacustris (Ka), Sium latifolium $(\mathrm{Ob})$, Stellaria holostea (Ka), Stratiotes aloides (Ob), Teucrium pripiatense (Ba), Thalictrum simplex $(\mathrm{Ka})$, Thesium nikitinii $(\mathrm{Ka})$, Typha pseudoovata $(\mathrm{Ka})$, Viola palustris $(\mathrm{Ka})$, Weigela szafe$r i(\mathrm{Ob})$.

Von diesen jungen Florenelementen zeigt Kaltensundheim die überwiegende Mehrzahl, gefolgt von Oberzella, während die Anzahl in Barchfeld unbedeutend ist. Wäre das ein Kriterium für ein jüngeres Alter, müsste Barchfeld die ältere, Kaltensundheim die jüngste Flora der drei Fundstellen sein. Das widerspricht den Ergebnissen unserer Untersuchungen wie im folgenden dargestellt:

Um unsere biostratigraphischen Überlegungen $\mathrm{zu}$ präzisieren, legen wir 2 Versionen (Abb. 3, I und II) einer Auswertung der pflanzengeographischen Elemente unter Bezugnahme auf paläomagnetische Daten (Wiegank 1981, 1982) vor. Wichtige Fixpunkte in diesen Skalen sind:

Kaltensundheim -- Erdfall im Oberpliozän, zeitlich eingeordnet durch die oberpliozäne Waldfauna des unteren Villafranchiums mit Mammut (Zygolophodon) borsoni (Aussterbedatum etwa 2,56 Mio. J.). Paläomagnetische Daten: GaußEpoche, etwa 2,80-2,43 Mio. J. (Wiegank 1981).

Rippersroda-Muschelkalkdoline und faunenführende Zersatzkiese, zeitlich eingeordnet durch oberstpliozäne Fauna mit Anancus arvernensis, Leptobos sp., Euctenoceros ernesti und Mimomys pliocaenicus (Dietrich 1953). Paläomagnetische Daten: Matuyama-Epoche/Olduvai-Grenze bis 1,88 Mio. J. (Wiegank 1982).

Vermutlich jünger als die Erdfall-Füllung von Kaltensundheim, aber noch oberpliozänen $\mathrm{Al}$ ters, dürften die im Vorland der Rhön weit verbreiteten fluviatilen „Arvernensis-Schotter“ sein, die sowohl Reste von Anancus arvernensis als auch Mammut (Zygolophodon) borsoni geliefert haben (z. B. Sülzfeld, Jüchsen und Ostheim). Auf der Basis widersprüchlicher geologischer Argumente ist das Alter der Mastodontenschotter von Sülzfeld strittig. Wiegank (1981) ordnet sie in die Gauß-Epoche bei 2,55-2,65 Mio. J. ein. Diese Alterstellung ist für die fossilen Floren der Dolinen von Oberzella, Barchfeld und Gerstungen, in Rechnung zu ziehen.

Die Version I unserer Korrelationstabelle basiert im Wesentlichen auf den Überlegungen von Krutzsch (1988) über die Florenabfolge im Pliozän von Südthüringen nach mikrobotanischen Untersuchungen aus.
Die Flora von Gerstungen (palynologisch bisher zu arm, um eine spezielle zeitliche Einschätzung zu treffen) soll einem Maximum im tiefsten Oberpliozän entsprechen oder bereits „Brunssum" sein. Es folgt eine Überlieferungslücke, dann das sog. „Berga-Maximum“ (Abschnitt 5). - Da Berga und Oberzella jedoch die gleichen Prozentanteile bei den pflanzengeographischen Elementen besitzen und die Hauptmenge der Arten identisch ist, können wir diese Ansicht hier nicht teilen. - Kaltensundheim soll nach Krutzsch (1988) wegen der ,kühlgemäßigten Minimum-Flora" (Abschnitt 4) in das Minimum zwischen Berga und Reuver s. str. gehören. Die Flora von Oberzella (Krutzsch \& Majewski 1965) repräsentiert den Abschnitt 3 und ist dem „Reuver s. str.“ zeitgleich. Nach einer zeitlichen Lücke folgt die Mikroflora von Rippersroda (Mai, Majewski \& Unger 1960), die den Abschnitt 1 und 2 ausfüllt und in die Zeit von etwa 2,4 bis 2,3 Mill. J. fällt.

Die Version II der Korrelationstabelle zeigt, daß die Floren- und Faunenreste von Kaltensundheim eine biostratigraphische Alterseinstufung ermöglichen, die älter als 2,56 Mill. J. (Aussterbedatum $M$. borsoni) sein muss. Nach Mai \& Walther (1988) ist mit der Makroflora von Kaltensundheim die „erste echte oberpliozäne Verarmungs- und Abkühlungsphase an der Basis des Oberpliozäns" erfasst und wird mit dem Florenkomplex von Ceyssac (Franz. Zentralmassiv) verglichen (ca. 2,7-2,6 Mill. J.).

Diese Abkühlung ist durch den hohen Prozentsatz circumpolarer und europäisch-eurasiatischer Elemente bei dem geringsten Anteil subtropischer und ausgestorbener Elemente klar erkennbar. Das wird auch von den Palynologen anerkannt. Die Mikroflora von Kaltensundheim ist nach Krutzsch (1988) eine „kühl gemäßigte Minimum-Flora von DBF-Charakter" mit vielen sogenannten quartären Kräuterelementen und repräsentiert die Basis des Villafranchiums. Die von Ukraintseva (Kahlke \& Ukraintseva 1986) untersuchte Mikroflora wird als ,plio-pleistozäne Übergangsflora“ interpretiert.

Die Fundstellen Barchfeld und Gerstungen sind im Zusammenhang mit den „ArvernensisSchottern" zu sehen. Weil sich beide Florenfundstellen durch eine beachtliche Anzahl ,älterer" (miozäner) Florenelemente auszeichnen (z. B. Meliosma cf. miessleri, Trema lusatica $=\mathrm{Ba}$; Cunninghamia miocenica, Hypericum miocenicum, Ranunculus marginalis, Stachyurus merkaensis = $\mathrm{Ge}$ ), werden diese Floren von uns an die Basis des „Florenkomplexes Reuver“ (Mai 1995) ge- 
stellt. Das widerspricht der Deutung von Krutzsch (1988), der die Basis der „ArvernensisSchotter" mit dem sog. Wetterau-Maximum parallelisiert. Einen zwingenden Beweis gibt es für beide Anschauungen jedoch nicht.

Sehr zutreffend ist nach unseren neuen floristischen Befunden indessen eine altersmäßige Gleichstellung der Floren von Berga und Oberzella. Das zeigt sich auch im gleichsinnigen Verlauf der Kurven der phytogeographischen Elemente bei Version I und II. Der Exotenanteil von $52,6 \%$ (Berga) und $43,5 \%$ (Oberzella) liegt genau im Schwankungsbereich des Florenkomplexes Reuver (Mai 1995).

Es folgt mit einer zeitlichen Lücke der Florenkomplex Rippersroda, gekennzeichnet durch eine Flora mit viel weniger Exoten $(29,8 \%)$ und einem deutlich ärmeren Bestand an Gattungen ostasiatischer, westasiatischer oder nordamerikanischer Verwandtschaft. Durch eine ,arvernensis-Fauna" ist die Fundstelle in die Mein-Zone $17 \mathrm{zu}$ stellen. Sie wurde mit 2,12-1,88 Mill. J. paläomagnetisch in die Matuyama-Epoche datiert (Wiegank 1982).

Auch nach diesen neuen Auswertungen lassen sich im Zeitabschnitt von etwa 2,8 bis 2,1 Mio. J. im Vorland der Rhön und in Südthüringen nur die Zeugen von drei Florenkomplexen unterscheiden:

- Perrier-Rippersroda: Rippersroda bei Arnstadt (Mai, Majewski \& Unger 1960)

- Reuver-Berga: Oberzella (diese Arbeit; Krutzsch \& Majewski 1965)

- Ceyssac: Kaltensundheim (Mai \& Walther 1988; Krutzsch 1988)

Die paläobiologische Rekonstruktion für die einzelnen oberpliozänen Florenfundpunkte in der Vorderrhön ist zu einem großen Teil bereits von Mai \& Walther 1988 gegeben worden:

In der aus der Doline von Kaltensundheim geborgenen und von uns ergänzten Makroflora überwiegen Wasser- und Sumpfpflanzengesellschaften mit heutigen Arten oder z. T. längerlebigen tertiären Arten. Es sind sowohl die Ried- als auch die Unterwassergesellschaften gut repräsentiert, wie das bei Faulschlammablagerungen, die subaquatische Rutschungen zeigen, zu erwarten ist. Beispiele von Eutrophie-Anzeigern aus dem Fossilmaterial sind unter anderem Carex riparia, Cyperus fuscus, Lemna gibba, Lemna trisulca, Myriophyllum spicatum, Ranunculus gailensis, Schoenoplectus lacustris und Sparganium neglectum. Als solcher Indikator, und nicht als Kriterium für brackische Beeinflussung, wird auch das seltene Vorkommen von Acorellus distachyoformis gesehen. Submersengesellschaften zeichnen sich durch einen Reichtum von PotamogetonArten aus. $\mathrm{Zu}$ den bisherigen vier Arten kommen durch unsere Neubearbeitung noch 3 Arten hinzu, welche bisher nur aus oberpliozänen Ablagerungen bekannt waren. Waldgesellschaften sind durch Reste von Taxodium dubium, Betula cholmechensis, Carpinus miocenica, Picea rotundesquamosa, Picea abies, Prunus spinosa, Corylus avellana, Acanthopanax uralensis, Actinidia faveolata und Ilex aquifolium repräsentiert, denen wir noch Myrica goretskyi und Swida bessarabica hinzufügen konnten, so dass der Sumpfwaldcharakter der Gesellschaften deutlicher wird. Für einige Sumpf- und Wasserpflanzen musste dabei die Determination geändert werden:

Elatine pseudoalsinastrum $=$ Hypericum foveolatum, Eleocharis microstylosa $=$ Eleocharis praemaximowiczii, Ranunculus hederaceus $=$ Ranunculus aquatilis, Ranunculus sceleratoides $=$ Ranunculus gailensis und Typha hercynica $=$ Typha pseudoovata.

Die Schlufflinse vom Dönnersenberg bei Barchfeld lässt durch ihren Gehalt an Treibholz eine Entstehung in einem langsam fließenden Gewässer vermuten. In der Tat ist die Taphozönose durch Ried- und Großseggen-Sumpfpflanzen wie Carex carpophora, Lycopus europaeus, Mentha pliocenica und Teucrium pripiatense sowie Pflanzen von Schlammfluren wie Chenopodium spec. und Ranunculus sceleratus geprägt. Gehölze wie Carpinus betulus, Fagus cf. deucalionis, Morus ucrainica, Picea rotunde-squamosa, Sambucus pulchella und Taxodium dubium treten quantitativ nicht so stark hervor. Miozäne Relikte - Meliosma cf. miessleri, Trema lusatica und Lianen - Actinidia faveolata, Vitis cf. sylvestris - geben eine Tendenz der Waldformation zum Mixed Mesophytic Forest an. Insgesamt liegt aber diese Flora mit 32 Arten an der Untergrenze einer Auswertbarkeit.

Völlig anders gestaltet sich die Situation bei der Füllung der Doline von Oberzella. Aus beiden Tonlinsen ist hier eine einheitlich zusammengesetzte Flora gewonnen worden, die reiche oberpliozäne Sommerlaubwald- sowie Sumpfund Wasserpflanzen-Gesellschaften widerspiegelt. Nach dem Überwiegen von Alnus lusatica ist mit einem dominanten Erlenbruchwald in den Randbereichen der Doline zu rechnen, der auch Pterocarya limburgensis, Alnus tanaitica, Frangula alnus, Decodon globosus und Microdiptera menzelii als relativ häufige Arten enthält. Oligodominante Mischwälder sind vom Typ der spät- 
tertiären Mixed Mesophytic Forests. Sie zeigen Arten wie Acer berganum, Acer campestrianum, Actinidia faveolata, Ampelopsis macrosperma, Aralia szaferi, Betula cholmechensis, Betula digitata, Cercidiphyllum helveticum, Corylopsis urselensis, Diervilla tertiaria, Ficus tambovica, Humulus scabrellus, Ilex aquifolium, Itea europaea, Liriodendron geminata, Magnolia cor, Magnolia ultima, Prunus schlechtendalii, Prunus tenerirugosa, Pyracantha angusticarpa, Pyrus microsperma, Sambucus pulchella, Symplocos lignitarum, Trichosanthes fragilis, Vitis cf. sylvestris, Weigela szaferi und Zelkova ungeri. Bei den Koniferen treten Picea abies, Pinus spec. und Tsuga sect. Tsuga auf. Einen Stillwasserstandort belegt eine Schwimmpflanzen-Gesellschaft mit Massenvorkommen von Salvinia miocenica, dazu auch $\mathrm{Nu}$ phar canaliculata, Ranunculus aquatilis, Stratiotes aloides und Trapa heerii. Vordergründig sind auch Laichkraut-Hornblatt-Unterwassergesellschaften aus mindestens 4 Potamogeton-Arten und 2 Ceratophyllum-Arten. Typisch für die Stillwasser der Dolinen scheint auch Lobelia pliocenica zu sein. Es folgen Röhrichtpflanzen wie Baldellia ranunculoides, Eleocharis praemaximowiczii, Lycopus europaeus, Scirpus isolepioides, Oenanthe aquatica, Alisma cf. plantago. Sehr untergeordnet sind Riede, die mit Carex elongatoides, $C$. flagellata, $C$. pseudocyperus, C. rostrata, Scirpus sylvaticus, $\mathrm{Du}$ lichium arundinaceum, Typha aspera und anderen in der Häufigkeit anschließen. Eine Reihe von Arten, die bisher nur aus dem Miozän und tieferen Pliozän bekannt waren oder aus der osteuropäischen Florenregion beschrieben wurden, sind in Oberzella erstmalig für das Pliozän Thüringens nachgewiesen worden. Als stratigraphisch wichtig sind Arten wie Acorus palaeocalamus, Alnus tanaitica, Collinsonia europaea, Diervilla tertiaria, Eleocharis praemaximowiczii, Ficus tambovica, Itea europaea, Potamogeton aculeatus, $P$. borysthenicus, Pyrus microsperma, Thalictrum pliocenicum, die unseres Wissens nach bisher nirgendwo in Mitteleuropa die Plio/Pleistozän-Grenze überschritten haben. Diese exotischen Arten und die Aufschotterung im Liegenden der Fundschichten der Flora sind unsere stärksten Argumente für die Einstufung des Vorkommens in das „Oberpliozän“ (etwa dem „Reuverien“ der Niederlande entsprechend).

\section{Danksagung}

Diese Arbeit über die pliozänen Floren ist im Rahmen einer ehrenamtlichen Tätigkeit am Museum für
Naturkunde der Humboldt-Universität zu Berlin entstanden. Sie wurde im Paläontologischen Institut wohlwollend unterstützt und gefördert. Bei der Lösung geologischer Fragen erhielten wir Unterstützung von Dr. G. Böhme und Dr. J. Ellenberg. Für die Erledigung der umfangreichen technischen Arbeiten sei Frau C. Radke und Frau D. Raspe sehr herzlich gedankt.

\section{Literatur}

Azzaroli, A. 1970. Villafranchian correlations based on large Mammals. - Giornale di Geologia, Annales Museum. Geologia Bologna, ser. 2a , 35 (1967), I: 111-131.

Baas, J. 1932. Eine frühdiluviale Flora im Mainzer Becken. Botanische Zeitschrift 25 (6/7): 289-371.

Berger, W. 1953. Studium zur Systematik und Geschichte der Gattung Carpinus. Beschreibung einiger neuer Arten aus dem Altpliozän des Wiener Beckens. - Botaniska Notiser 106 (1953) 1: 1-47.

Blanckenhorn, M. 1902. Oberpliozän mit Mastodon arvernensis auf Blatt Ostheim v. d. Rhön. - Jahrbuch preußischen geologischen Landesanstalt f. 1901, 22: 364-371.

Böhme, G. 1963. Über den Skelettfund eines Pliocerviden aus dem Pliozän von Kaltensundheim/Rhön. - Paläontologische Abhandlungen 1 (4): 353-372.

- 1992. Pliozäne Erdfallbildung in der östlichen Vorderrhön und ihre Bedeutung für die Morphogenese des Gebietes. Zeitschrift für geologische Wissenschaften 20 (5/6): 447-454.

- 2002. Amphibienreste aus dem Oberpliozän von Kaltensundheim/Rhön (Thüringen). - Mitteilungen aus dem Museum für Naturkunde Berlin, Geowiss. Reihe 5 (2002) 231-238.

Bücking, H. 1916. Geologischer Führer durch die Rhön Sammlung der Geologischen Führer XXI, Berlin 1916.

Bülow, W. v \& Mai, D. H. 1992. Die südlichen Trebser Schotter aus dem Oberpliozän Südwest-Mecklenburgs. - Eiszeitalter u. Gegenwart 42: 25-39.

Bůžek, Č. \& Holý, F. \& Kvaček. Z. 1976. Tertiary flora from the Volcanogenic Series at Markvartice and Veseličko near Ceska Kamenice (Ceské středohoři Mts.). - Sborník geologickych věd, paleontologie, rad P 18: 69-132.

Bủžek, Č., Kvaček, Z. \& Holŷ, F. 1985. Late Pliocene palaeoenvironment and correlation of the Vildštejn floristic complex within central Europe. - Rozpravy čs. Akad. Věd, Řada matem.-přírodn. 95 (7): 3-72.

Chandler, M. E. J. 1923. The Geological History of the Genus Stratiotes: an Account of the Evolutionary Changes which have occured within the Genus during Tertiary and Quaternary Time. - Quart. J. Geol. Soc. London 79: $117-137$.

Czeczott, H., Skirgiełlo, A. \& Zalewska, Z. 1961. Flora kopalna Turowa koło Bogatyni II. - Prace Ziemi, Warszawa 4: $1-117$.

Denk, Th. 2002. Revision of Fagus (Oakfamily) from the Tertiary of Europe and South-Western Asia. $-6^{\text {th }}$ European Paleobotany-Palynology Conference, Abstracts Athens: $75-76$.

Dietrich, W. O. 1953. Neue Funde des etruskischen Nashorn in Deutschland und die Frage der Villafranchium-Faunen. - Geologie 2 (6): 417-430.

Dorofeev, P. I. 1951. Méotični roslini z okolic' Odesi.- Botaničeskij Zurnal Ukrainskij Akademii Nauk 8 (3): 31-40.

- 1960a. O tretičnoj flora Belorussii. - Botaničeskij Žurnal 45 (10): $1418-1435$.

- 1960b. O pliocenovoj flore Baškirskogo Predural’ja. Voprosy geol. vostočn. Okrainy Russk. Platformy i Južnogo Urala 5: 15-24.

- 1962a. O pliocenovoj flore Baškirii. - Botaničeskij Žurnal 47 (6): 787-801. 
- 1963. Tretičnye flory Zapadnoj Sibiri. - Izdatel'stvo Akademii Nauk SSSR, 345 pp., Moskva-Leningrad.

- 1966. Pliocenovaja flora Matanova Sada na Donu. - Izdatel'stvo „Nauka“, 87 pp., Moskva-Leningrad.

- 1967a. O pliocenovoj flore Belorussii. - In Nižnij Plejstocen lednikov. rajonov Russk. ravniny - Izdatel'stvo „Nauka“", pp. 92-110, Moskva.

- 1967b. O neogenovoj flore pos. Žitkoviči na juge Belorussii. - Doklady Akademii Nauk BSSR 11 (8): 719-723.

- 1971. O pliocenovoj flore d. Cholmeč na Dnepre. - Doklady Akademii Nauk SSSR 200 (4): 917-920.

- 1973. Plody i semena Aira iz Neogena Belorussii. - Doklady Akademii Nauk BSSR 17 (7): 656-659.

- 1974. Cabombaceae, Nymphaeaceae, Ceratophyllaceae, etc. - In Takhtajan, A. L. (Red.): Iskopaemye cvetkovye rastenija SSSR, tom 1 - Izdatel'stvo „Nauka“, pp. 52-88, Leningrad.

- 1977. Simbuginskaja flora. - In Fauna i flora Simbugino. - Izdatel'stvo „Nauka“, 235 pp.; Moskva.

- 1982a. K sistematike tretičnych Typha. - Paleokarpologičeskie issledovanija Kajnozoja. Izdatel'stvo Nauka i technika: 5-26, Minsk.

- 1982b. Ulmaceae, Moraceae, Cannabaceae, Urticaceae, Fagaceae, Betulaceae - semena i plody. - In Takhtajan, A. L. (Red.): Iskopaemye cvetkovye rastenija SSSR, tom. 2 - Izdatel'stvo „Nauka“, pp. 7-176, Leningrad.

- 1986a. Iskopaemye Potamogeton. Posobie dlja opredelenija iskopaemych plodov. - 134 pp., Izdatel'stvo "Nauka“, Leningrad.

- 1986b. O pliocenovoj flore der. Dvorec na Dnepre. Problemy Paleobotaniki (Red. A.L. Takhtajan): 44-71. Izdatel'stvo "Nauka", Leningrad.

- 1988. Miocenovye flory Tambovskoj oblasti. - Izdatel'stvo „Nauka“, 198 pp., Leningrad.

- 1994. Leitneriales. Leitneriaceae: Leitneria Chapm. und Myricales: Myrica L., Comptonia LHerit. Vidy, ustanovlennye po plodam. - In Budancev, L. Ju.: Iskopaemye cvetkovye rastenija Rossii i sopredel'nych gosudarstv., tom. 3: Leitneriaceae - Juglandaceae: pp. 8-12, 13-57, Sankt-Petersburg.

Dorofeev, P. I. \& Tjulina, L. N. 1962. Materialy k iskopaemoj flore Mamontovoj Gory na Aldane. - Problemy botaniki 6: $46-54$

Dorofeev, P. I. \& Weliczkiewicz, F. Ju. 1971. O pozdnepliocenovoj flore der. Dvorec na Dnepre. - Doklady Akademii Nauk SSSR 200 (5): 1173-1176.

Ellenberg, J. 1968. Beziehungen zwischen Auslaugung und quartärer Sedimentation im thüringischen Werra-Kaligebiet. - Zeitschrift der deutschen geologischen Geschichte (Jg. 1965) 117: 670-679.

- 1982. Die Subrosion im Werra-Kaligebiet der DDR, quartärgeologische, geomorphologische und tektonische Aspekte. - Zeitschrift für geologische Wissenschaften 10 (1): 61-71.

Engelhardt, H. \& Kinkelin, F. 1908. Oberpliozäne Flora des Untermaintales. - Abhandlungen Senckenbergischen naturforschenden Gesellschaft 29 (3): 151-281, Frankfurt a. M.

Eyde, R. H. 1972. Note on the Geologic Histories of Flowering Plants. - Brittonia 24: 111-116, New York

Firbas, F. \& Grahmann, R. 1928. Über jungdiluviale und alluviale Torflager in der Grube Marga bei Senftenberg (Niederlausitz). - Sächsische Akademie der Wissenschaften, Abhandlungen Mathematisch-physikalische Klasse $\mathbf{4 0}$ (1928) 4: 1-63.

Fliegel, G. \& Stoller, J. 1910. Jungtertiäre und altdiluviale pflanzenführende Ablagerungen im Niederrheingebiet. Jahrbuch preußischen geologischen Landesanstalt $\mathbf{3 1}$ (1910): 227-257.

Fritsch, K. v. 1885. Das Pliozän im Thalgebiete der zahmen Gera in Thüringen. - Jahrbuch preußischen geologischen Landesanstalt f. 1884: $389-437$.

- 1972. Neue Untersuchungen im Pliozän der Hagenauer Umgebung (nördliches Elsass). - Mainzer naturwissenschaftliches Archiv 11: 191-221.
Geyler, Th. \& Kinkelin, F. 1887. Oberpliozänflora aus den Baugruben des Klärbeckens bei Niederrad und der Schleuse bei Höchst a. M. - Abhandlungen der Senckenbergischen naturforschenden Gesellschaft Frankfurt (Main) 15: 1-47.

Gregor, H.-J. 1975. Die mittelmiozäne Mastixiodeen - Flora aus dem Braunkohlen-Tagebau Oder II bei Wackersdorf (Oberpfalz). - Diss., 250 S., München.

- 1984. Chenopodium wetzleri nov. spec. - Erstnachweis der Gattung Chenopodium Linné in der Oberen Süßwasser-Molasse Bayerns. - In Molasseforschung, Günzburg 84 (1984): 22-24. (August Wetzler Gedenkbd.).

Gregor, H.-J. \& Bogner, J. 1984. Fossile Araceen Mitteleuropas und ihre rezenten Vergleichsformen. - Documenta naturae 19: $1-12$.

Gümbel, F. \& Mai, D. H. 2002. Neue Pflanzenfunde aus dem Tertiär der Rhön. - Teil 1: Miozäne Fundstellen. - Mitteilungen aus dem Museum für Naturkunde in Berlin, Geowissenschaftliche Reihe 5 ( 2002): 345-384.

Hartz, N. 1909. Bidrag til Danmarks tertiaere og diluviale Flora. - Danmarks geologiske Unders øgelse, II R. 20 (1909): 1-292.

Hirsch, L. 1937. Tertiärgeologische Untersuchungen in der Rhön. - Dissertation Universität Giessen, 166 S., Würzburg (Triltsch).

Il'jinskaja, I. A. 1953. Monographie der Gattung Pterocarya Kunth. - Trudy Botaničeskij Institut Akademija Nauk, SSSR, ser. 1, 10: 7-123. (russ.).

Kac, N. Ja., Kac, S. V. \& Kipiani, M. G. 1965. Atlas i opredelitel plodov i semjan vstrečajuščichsja $\mathrm{v}$ četvertičnych otloženijach SSSR (Atlas and keys of fruits and seeds occuring in the Quarternary deposits of the USSR). Izdatel'stvo „Nauka“, 367 pp., Moskva (russ.).

Kästner, H. 1974. Jungtertiärer Vulkanismus. - In Hoppe, W. \& Seidel, G.: Geologie von Thüringen. Gotha/Leipzig: 782-789.

Kahlke, H.-D. \& Ukraintseva, V. V. 1986. Late Pliocene Flora, Vegetation and Fauna from the South of Thüringen (Suhl District). - Botaničeskij Žurnal 71: 16-22.

Kelber, K.-P. 1980. Blatt- und Fruchtreste aus dem Jungtertiär von Wollbach, Unterfranken. - Courier ForschungsInstitut Senckenberg 42: 40-42.

1988. Exkursionspunkt: Sandgrube Wollbach bei Bad Neustadt - Die Taphoflora von Wollbach. - Führer zur Exkurssion C, Rhön u. Vorländer, DEUQUA, 24. Tg. Hannover: 20-24.

Kilpper, K. 1959. Eine Pliozänflora aus den KieseloolithSchichten von Frimmersdorf. - Fortschritte in der Geologie Rheinland und Westfalen 4: 55-68.

Kirchheimer, F. 1949. Zur Kenntnis der Pliocaenflora von Soufflenheim im Elsaß. - Berichte Oberhessischen Gesellschaft Natur- u. Heilkunde, Neue Folge, naturwissenschaftliche Abteilung 24: 206--230.

- 1950. Die Symplocaceen der erdgeschichtlichen Vergangenheit. - Palaeontographica, B, 90: 1-52.

- 1957. Die Laubgewächse der Braunkohlenzeit. - Verl. VEB W. Knapp, 783 S., Halle.

Klimaszewski, M. \& Szafer, W. 1945. Pleistocen w Łękach Dolnych koło Tarnowo. - Starunia 19: 1-34.

Knobloch, E. 1976. Samen und Früchte aus dem Pannon von Kunovice Mähren. - Věstník Ústředního ústavu geologickěho, Praha 51: 221-230.

- 1988. New records of fruits and seeds from the Upper Miocene and Lower Pliocene of Moravia and Slovakia. Tertiary Res. 9 (1-4): 107-116.

Knobloch, E. \& Mai, D. H. 1975. Sparganium neglectum Beeby foss. im europäischen Jungtertiär und Quartär. - Casopis pro mineralogii a geologii, Praha 20: $141-147$.

Kownas, St. 1955. Trzeciorzędowa flora z Dobrzynia nad Wisła. - Acta Geologica Polonica 5: 439-516, Warszawa.

Krutzsch, W. 1988. Kritische Bemerkungen zur Palynologie und zur klimastratigraphischen Gliederung des Pliozäns 
bis tieferen Altpleistozäns in Süd-, Südwest-, Nordwestund pro parte Mitteleuropa sowie die Lage der Plio-Pleistozän-Grenze in diesem Gebiet. - Quartärpaläontologie 7: $7-51$.

Krutzsch, W. \& Majewski, J. 1965. Die mikrobotanische Datierung des Tertiärvorkommen von Oberzella (Bl. Vacha/ Südthüringen). - Mitteilungen des Zentralen Geologischen Instituts, H. 1: $65-70$.

Łańcucka-Środoniowa, M. \& Zastawniak, E. 1997. The middle Miocene flora of Weliczka-revision of Jan Zablockis collection. - Acta Palaeobotanica 37 (1): $17-49$.

Leschik, G. 1952a. Zur Frage der Pliozän-Pleistozän-Grenze. - Zeitschrift der deutschen geologischen Gesellschaft 103: $68-74$.

- 1952b. Mikrobotanisch-stratigraphische Untersuchungen der jungpliozänen Braunkohle von Buchenau (Kr. Hünfeld). - Palaeontographica, B, 92 (1-2): 1-51.

- 1954. Die oberpliozäne Flora von Hünfeld (Hessen). Senckenbergiana Lethaea 35 (3/4): 247-262.

Ludwig, R. 1857. Fossile Pflanzen aus der jüngsten Wetterauer Braunkohle. - Palaeontographica 5 (3-4): 81-109, Kassel.

- 1861. Fossile Pflanzen aus dem tertiären Spateisenstein von Montabaur. - Palaeontographica 8 (6) (1861) $160-180$.

Mädler, K. 1939. Die pliozäne Flora von Frankfurt am Main. - Abhandlungen der Senckenbergischen naturforschenden Gesellschaft 446: 1-202.

Mai, D. H. 1964. Die Mastixioideen-Floren im Tertiär der Oberlausitz. - Paläontologische Abhandlungen Berlin, Abt. B, 2 (1): 1-192.

- 1973. Die Revision der Originale von R. Ludwig 1857, ein Beitrag zur Flora des unteren Villafranchien. - Acta Palaeobotanica 14: 89-117.

- 1975. Beiträge zur Bestimmung und Nomenklatur fossiler Magnolien. - Feddes Repertorium Berlin 86 (9-10) $559-578$.

- 1983. Die fossile Pflanzenwelt des interglazialen Travertins von Bilzingsleben (Kreis Artern, Thüringen). - In Bilzingsleben II. Deutsch. Verl. Wiss. Berlin S. 45-129. (Veröff. Landesmus. Vorgesch. Halle 36).

- 1984. Karpologische Untersuchungen der Steinkerne fossiler und rezenter Amygdalaceae (Rosales). - Feddes Repertorium Berlin 95 (5-6): 301-330.

- 1985. Beiträge zur Geschichte einiger holziger Saxifragales-Gattungen. - Gleditschia Berlin 13: 75-88.

- 1987. Neue Arten nach Früchten und Samen aus dem Tertiär von Nordwestsachsen und der Lausitz. - Feddes Repertorium 98 (1-2): 105-126, Berlin.

- 1989. Die fossile Flora des Blättertons von Wischgrund und anderer gleichartiger Fundsteilen der Klettwitzer Hochfläche. Natur und Landschaft, Cottbus 11: 3-44.

- 1995. Tertiäre Vegetationsgeschichte Europas. - Verl. G. Fischer, Jena, Stuttgart, New York, $691 \mathrm{~S}$.

- 1999a. Die untermiozänen Floren aus der Spremberger Folge und dem 2. Flözhorizont in der Lausitz. Teil I: Farnpflanzen, Koniferen und Monokotyledonen. - Palaeontographica, B, $250(1-3): 1-76$.

- 1999b. Die untermiozänen Floren aus der Spremberger Folge und dem 2. Flözhorizont in der Lausitz. Teil II: Polycarpicae und Apetale. - Palaeontographica, B, 251 $(1-3): 1-70$.

- 2000a. Die untermiozänen Floren aus der Spremberger Folge und dem 2. Flözhorizont in der Lausitz. Teil III: Dialypetale und Sympetale. - Palaeontographica, B, 253 (1-3): $1-106$.

- 2000b. Lobelia pliocenica (Dorofeev) comb. nova - ein neues atlantisches Florenelement im Jungtertiär und Altquartär Europas. - Feddes Repertorium Berlin 111 $(7-8): 481-492$

- 2000c. Die mittelmiozänen und obermiozänen Floren aus der Meuroer und Raunoer Folge in der Lausitz. Teil I:
Farnpflanzen, Koniferen und Monokotyledonen. - Palaeontographica, B, $256(1-3)$ : 1-68.

- 2001. Die mittelmiozänen und obermiozänen Floren aus der Meuroer und Raunoer Folge in der Lausitz. Teil II: Dicotyledonen. - Palaeontographica, B, 257 (1-6): 35-174.

Mai, D. H., Majewski, J. \& Unger, K. P. 1963. Pliozän und Altpleistozän von Rippersroda in Thüringen. - Geologe 12 (6); $765-815$

Mai, D. H. \& Palamarev, E. 1997. Neue paläofloristiche Funde aus kontinentalen und brackischen Tertiärformationen in Bulgarien. - Feddes Repertorium Berlin 108 (7-8): $481-506$.

Mai, D. H. \& Walther, H. 1978. Die Floren der Haselbacher Serie im Weißelster-Becken. - Abhandlungen Staatliches Museum Mineralogie und Geologie Dresden 28: 1-101.

- 1988. Die pliozänen Floren von Thüringen, Deutsche Demokratische Republik. - Quartärpaläontologie 7: 55-297.

- 1991. Die oligozänen und untermiozänen Floren NWSachsens und des Bitterfelder Raumes. - Abhandlungen Staatliches Museum Mineralogie und Geologie Dresden 38: $1-230$.

Mai, D. H. \& Wähnert, V. 2000. On the problems of the Pliocene floras in Lusatia and Lower Silesia. - Acta Palaeobotanica 40 (2): 165-205.

Martinetto, E. 2001. Studies on some exotic elements of the Pliocene floras of Italy. - Palaeontographica, B, 259: $149-166$.

Martini, E., Rothe, P., Kelber, K.-P. \& Schiller, W. 1994. Sedimentäres Tertiär der Rhön (Exkursion I am 9. April 1994) - Jahresberichte und Mitteilungen oberrheinischen geologischen Verein, N.F. 76: 219-244, Stuttgart.

Mein, P. 1975. Resultats du Groupe de Travail des Vertébrés. - Report on Activity of the R.C.M.N.S. Working Groups (1971-1975), (I.U.G.S., Commission on Stratigraphy; Subcommission on Neogene Stratigraphy): 77-81.

Müller-Stoll, W. 1938. Die jüngsttertiäre Flora des Eisensteins von Dernbach (Westerwald). - Botanisches Zentralblatt, Beihefte, B 48: 376-434.

Negru, A. G. 1969. O sistematičeskom položenij miocenovych ostatkov Carpinus v Moldavii. - Botaničeskij Žurnal 54: $760-765$.

- 1972. Rannjesarmatskaja flora severovostoka Moldavii. Izdatel'stvo ,Schtiinca“c, 169 pp., Kishinev.

- 1979. Rannepontičeskaja flora južnoj časti DnestrovskoPrutskogo Meždureč’ja. - 110 pp., Izdatel'stvo „Schtiinca". Kishinev.

- 1986. Mèotičeskaja flora Severno - Zapadnogo Pričernomor'ja. - Izdatel'stvo „Schtiinca“, 157 pp., Kishinev.

Nikitin, P. A. 1929. The systematic position of the fossil genus Diclidocarya E. M. Reid. - Journal of Botany London. 67: $33-38$,

- 1940. Četvertičnye semennye flory beregov r. Obi. - In Materialy po geologii Zap. Sibiri. - Tomsk 12 (1940) 54: 1-54.

- 1948. Pliocenovye flory $\mathrm{S}$ reki Obi $\mathrm{v}$ rajone Tomska. Doklady Akademii Nauk SSSR 61 (6): 1103-1106, Moskva-Leningrad.

- 1957. Pliocenoye i četvertičnye flory Voroneshskoj oblasti. (Pliozäne und pleistozäne Floren im Gebiet von Woronesh). - Izdatel'stvo Akademii Nauk SSSR, 205 pp., Moskva-Leningrad.

Nikitin, V. P. 1976. Miocen Mamontovoj Gory. IX. Sistematičeskaja čast'. - Trudi Inst. Geol. Geofis., Akad. Nauk SSSR, Sibir. otd., 233: 171-194.

Nilsson, O. \& Hjelmqvist, H. 1967. Studies on the Nutlet Structure of South Scandinavian Species of Carex. - Botaniska Notiser 120 (4): 460-485.

Palamarev, E. 1970. Fosilni flori ot tri v' gliscni basejna v jugozapadna B'lgarija (Fossile Floren aus drei Braunkohlenbecken in Südwestbulgarien). - Izvestija na Botaničeskija Institut bulgarska Akademija Naukíte 20: 35-79, Sofia. 
- 1982. Neogenskata karpoflora na Melniskija basejn (Die neogene Carpoflora aus dem Melnik-Becken), - Paleontologija Stratigrafija i Lithologija 16: 3--44. Sofia.

Quenstedt. F. A. 1867. Handbuch der Petrefaktenkunde. Verl. H. Laupp. 2. Aufl., 982 S.. Tübingen.

Raniecka-Bobrowska, J. 1959. Trzeciorzedowa flora nasienna z Konina. - Instytut Geologiczny Biuletyn Warszawa 130: $159-252$

Reid, C. 1892. The pleistocene deposits of the Sussex Coast, and their equivalents in other districts. - Quartaly Journal of the geological Society 48: 344-364.

- 1896. The relation of the Palaeolithic Man to the Glacial Epoch (Hoxne). - Report of the British Association of Geologists 1896: 400.

- 1899. The Origin of the British Flora. - (Dulau \& Co.) London.

Reid, C. \& Reid. E.M. (1907a). The flora of Tegelen-surMeuse, near Venloo, in the province Limburg. -- Verslaten Konigliche Akademie van Wetenschappen sect. 2. 13 (6): $1-26$

- 1907b. On the Pre-Glacial Flora of Britain. - Journal of the Linnean Society (Bot.) 38: 206-233.

- 1910. A further investigation of the Pliocene flora of Tegelen. - Verslaten Konigliche Akademie van Wetenschappen, Natuurkd. Afdeling. 19 (1910): 192-199.

- 1915. The Pliocene Floras of the Dutch-Prussian border. - Mededeelingen van de Rijksopsporing van Delfstoffen 6: $1-178$, The Hague.

Reid, E. M. 1920. Recherches sur quelque graines pliocènes du Pont-de-Gail (Cantal). - Bulletin Société géologique France, Séries IV, 20: 48-87.

- 1921. On two preglacial Floras from Castle Eden and a comparative Review of Pliocene floras. - Quartaly Journal of the geological Society 76 (2): 104-161.

- 1923. Nouvelles recherches sur les graines du Pliocène inférieur du Pont-du-Gail (Cantal). - Bulletin Société géologique France, Séries IV. 23: 308-355.

- 1927. A new species of Diclidocarya Reid from the Senftenberg Brown-coal. - Journal Botany London 65: 1-4.

Rothmaler, W. 1976. Exkursionsflora für die Gebiete der DDR und der BRD - Kritischer Band. - Verl. Volk und Wissen, Bd. 4: 1-811, Berlin.

Rutte, E. 1987. Rhein, Main, Donau. Wie - wann - warum sie wurden. Eine geologische Geschichte. - Sigmaringen.

Rutte. E. \& Wilczewski, N. 1995. Tertiär - In Mainfranken und Rhön. Sammlung Geologischer Führer 74: 3., überarb. Aufl.: 61-76, Berlin-Stuttgart; Verl Gebr. Borntraeger.

Sadowska. A. \& Szynkiewicz, A. (eds) 1998. Tertiary-Quaternary (Pleistocene) floras of Belchatów (Middle Poland) and several localities in south-western Poland. - Guide to Excursion 2; The $5^{\text {th }}$ European Palaeobotanical and Palynological Conference Cracow (1998): 79 pp.

Schaarschmidt, F. 1958. Fund eines Mastodon in der Rhön. Neue Museumskunde 1: 290-292.

Schultz, G. 1962. Zur Geologie der Braunkohlen bei Zülpich (Niederrheinische Bucht). - Neues Jahrbuch für Geologie und Paläontologie, Abhhandlungen 116 (1): 89-118.

Środon, A. 1968. O roślinności interstadialu Paudorf w Karpatach Zachodnich. - Acta Palaeobotanica 9 (1): 3-27.

Szafer, W. 1947. Flora plioceńska z Krościenka n Dunajcem (The pliocene Flora of Krościenko in Poland) I-II. Rozprawy polska Akademia Umiejętności Wydziału matematyczno-przyrodniczego $72(1-2)$ : 1-375. Kraków.
- 1954. Plioceńska flora okolic Czorsztyna i jej stosunek do Plejstocenu. - Prace Instytut Geologiczny Warszawa 11: $1-238$.

- 1961. Mioceńska flora ze Starych Gliwic na Ślassku. Prace Instytut Geologiczny Warszawa 33: 1-205.

Tobien, H. 1970. Biostratigraphy of the mammalian faunas at the pliocene-pleistocene boundary in middle and western Europe. - Palaeogeography, Palaeoclimatology, Palaeoecology 8: 77-93.

Unger, F. 1841-1847. Chloris protogaea. Beiträge zur Flora der Vorwelt. - (Verl. Wilhelm Engelmann), H. 1-10: 150 S., Leipzig.

Van Beusekom, C. F. 1971. Revision of Meliosma (Sabiaceae), Section Lorenzanea excepted, living and fossil, Geography and Phylogeny. - Blumea 19: 355-529.

Van Der Burgh, J. 1978. The Pliocene flora of Fortuna-Garsdorf I. Fruits and seeds of Angiosperms. - Review Palaeobotany Palynology 26 (1-4): 173-211.

- 1987. Miocene floras in the Lower Rhenish Basin and their ecological interpretation. - Review Palaeobotany. Palynology 52: 299-366.

Weber, H. 1952. Pliozän und Auslaugung im Gebiet der oberen Werra. - Geologica 8, 136 S., Berlin.

- 1955. Einführung in die Geologie Thüringens. - 201 pp., Dtsch. Verl. d. Wissenschaften, Berlin.

Weliczkiewicz, F. Ju. 1973. Antropogenovye flory Belorussii i smežnych oblastej. - Izdatel'stvo Nauka i technika, pp. 234, Minsk

- 1975. Novye dannye o flore d. Dvorec na Dnepre. - Stratigrafija i Paleogeografija Antropogena. - Izdatel'stvo Nauka i technika, Minsk pp. 110-133.

- 1979. Istorija pleistocenovoj flory srednej polosy Vostočno-Evropejskoj ravniny. - In Sovetskaja paleokarpologija (itogi i perspektivy). - Nauka, Moskva: 76-121.

- 1982. Plejstocenovye flory lednikovych oblastej VostochoEvropejskoj ravininy. - Izdatel'stvo Nauka i technika, Minsk, $239 \mathrm{pp}$.

- 1990. Pozdnepliocenovaja flora Dvoreca na Dnepre. - Izdatel'stvo Nauka i technika, pp. 100, Minsk.

Weliczkiewicz, F. Ju. \& Lesiak, M. A. 1999. Potamogeton species of the Kholmech flora in Belarus. - Acta Palaeobotanica 30 (1): 15-27.

Weliczkiewicz, F. Ju. \& Zastawniak, E. 2003. The Pliocene flora of Kholmech, south-eastern Belarus and its correlation with other Pliocene floras of Europe. - Acta Palaeobotanica 42 (2): 137-259.

Wiegank, F. 1981. Paläomagnetische Untersuchungen zur Klärung der stratigraphischen Position und des absoluten Alters plio-pleistozäner Ablagerungen im Südwesten der DDR. - Quartärpaläontologie 4: 179-187.

- 1982. Ergebnisse magnetostratigraphischer Untersuchungen im höheren Känozoikum der DDR. - Zeitschrift für geologische Wissenschaften 10 (6): 737-744

Zabłocki, J. 1928, 1930. Tertiäre Flora des Salzlagers von Wieliczka I-II. - Acta Society Botanica Polonica 5 (2): 174-208 und 7 (2): 139-156.

Zagwijn. W. H. 1959. Zur stratigraphischen und pollenanalytischen Gliederung der pliozänen Ablagerungen im Roertal-Graben und Venloer Graben der Niederlande. Fortschritte der Geologie Rheinland u. Westfalen, Krefeld 4: $5-26$.

- 1963. Pollen-analytic investigations in the Tiglian of the Netherlands. - Mededelingen van de geologische Stichting. N.S. Utrecht 16: $49-71$ 